\title{
Climatic Roots of Loss Aversion
}

\author{
Oded Galor and Viacheslav Savitskiy*
}

December 20, 2017

\begin{abstract}
This research explores the origins of loss aversion and the variation in its prevalence across regions, nations and ethnic group. It advances the hypothesis and establishes empirically that the evolution of loss aversion in the course of human history can be traced to the adaptation of individuals to the asymmetric effects of climatic shocks on reproductive success during the Malthusian epoch. Exploiting variations in the degree of loss aversion among second generation migrants in Europe and the US, as well as across precolonial ethnic groups, the research establishes that consistent with the predictions of the theory, individuals and ethnic groups that are originated in regions in which climatic conditions tended to be spatially correlated, and thus shocks were aggregate in nature, are characterized by greater intensity of loss aversion, while descendants of regions marked by climatic volatility have greater propensity towards loss-neutrality.
\end{abstract}

Keywords: Loss Aversion, Cultural evolution, evolution of preferences, natural selection, Malthusian epoch

JEL Classification: D81, D91, Z10

\footnotetext{
*Galor: Department of Economics, Brown University, NBER, CEPR, IZA, and CES-Ifo. Email: Oded_Galor@brown.edu; Savitskiy: Department of Economics, Brown University. Email: Viacheslav_Savitskiy@brown.edu
} 


\section{Introduction}

The intriguing phenomenon of loss aversion has been central for the understanding of human behavior in the past few decades. The predisposition of individuals to view asymmetrically losses and gains has been documented in a wide range of experimental and empirical evidence (Tversky and Kahneman, 1991; Kahneman et al., 1991; Benartzi and Thaler, 1995) and its remarkable implications has been established in the economic, political and social arenas. ${ }^{1}$ Nevertheless, despite the importance of this phenomenon for the understanding of human and social behavior, and conceivably comparative economic development across globe, the origins of loss aversion and the variation in its intensity across regions and societies have remained largely obscured.

This research explores the origins of loss aversion and the variation in the prevalence of this important trait across regions, nations, and ethnic groups. It advances the hypothesis and establishes empirically that the evolution of loss aversion in the course of human history can be traced to the adaptation of individuals to the asymmetric effects that climatic shocks had on reproductive success during the Malthusian epoch; an era in which adverse climatic conditions could have brought individuals to extinction.

The study develops an evolutionary theory that captures the fundamental asymmetry that the Malthusian environment has generated with respect to the attitude of individuals towards gains and loses in productivity, and thus with respect to the evolution of loss aversion. In light of existing evidence that resources per capita during the Malthusian era where in the proximity of the subsistence consumption constraint, lineages of individuals who were subjected to significant adverse transitory productivity shocks during this period had become extinct, while lineages of individuals who had experience transitory favorable climatic conditions had a larger reproductive success only temporarily (Ashraf and Galor, 2011; Vollrath, 2011; Dalgaard and Strulik, 2015).

In view of the constraining effects of the subsistence consumption constraint during the Malthusian epoch, individuals who were characterized by loss aversion would have chosen safe agricultural practices that would assure their subsistence consumption while minimizing the risk of catastrophic realizations that would inevitably make their dynasties extinct. In contrast, individuals who had not assigned asymmetric weight to gains and loses may had favored riskier agricultural practices that were associated

\footnotetext{
${ }^{1}$ For instance, Jervis (1992), Levy (1996), Barberis and Huang (2001), Genesove and Mayer (2001), Shalev (2002), Fisher and Montalto (2011).
} 
with higher expected return as well as higher expected extinction.

In a Malthusian environment in which climatic shocks are aggregate in nature, individuals who were engaged in risky agricultural practices would have likely been affected by a catastrophic climatic realization that could have brought them to extinction. Hence, in an environment characterized by aggregate productivity shocks the trait of loss aversion, and the associated choice of the safer production mode, would have been favored by the forces of natural selection and would have dominated the population in the long run. However, in a Malthusian environment characterized by greater climatic volatility, holding the aggregate nature of the shock constant, although the trait of loss aversion would have still maximize the survival probability of each individual, some loss-neutral dynasties would have experienced a sequence of unlikely realizations of optimal climatic conditions, and thus would have generated a significantly higher reproductive success and would have ultimately dominated the population in the long run.

The theory generates two fundamental testable predictions about the climatic origins of the observed predisposition toward loss-aversion. It suggests that individuals, as well as societies, that are originated in regions of the world in which climatic shocks tended to be spatially correlated, and thus aggregate in nature, would be characterized by greater intensity of loss aversion. In contrast, descendants of regions of the world that were characterized by greater climatic volatility will tend to exhibit a higher degree of loss-neutrality.

Exploiting variations in the degree of loss aversion among second generation migrants in Europe and the US, as well as across precolonial ethnic groups, the research establishes that consistent with the predictions of the theory, individuals and ethnic groups that are originated in regions in which climatic conditions tended to be spatially correlated, and thus shocks were aggregate in nature, are characterized by greater intensity of loss aversion, while descendants of regions characterized by greater climatic volatility have higher propensity towards loss-neutrality.

The empirical analysis is conducted at different layers that are designed to establish the robustness of the findings in distinct samples and units of analysis, exploiting variation across individuals and ethnic groups, based on the European Social Survey (ESS), General Social Survey (GSS), World Value Survey (WVS), the Ethnographic Atlas (EA), and the Standard Cross Cultural Sample (SCCS). In particular, the analysis exploits: (i) variation in loss-aversion across second-generation migrants in the US as well as Europe, accounting for time-invariant host country fixed effects, potentially confounding 
geographical characteristics of the migrants' countries of origin, as well as migrants' individual characteristics such as, age, gender, income and eduction; (ii) variation in loss-aversion across individuals within each country, accounting for a wide range of potentially confounding geographical characteristics, regional fixed effects, as well as individual characteristics, such as age, gender, income and eduction; (iii) variation in loss-aversion across precolonial ethnic groups, accounting for potentially confounding regional fixed effects, geographical characteristics as well as ethnographic characteristics such as the intensity of agriculture, settlement structure, the use of the plow.

In light of the predictions of the theory, the prevalence of loss aversion is linked to intertemporal climatic volatility as well as special correlation in climatic conditions. A-priori one could have captured these climatic characteristics using either temperature or precipitation. However, as established in the empirical section, while productivity in the Malthusian era is significantly correlated with various characteristics of temperature, it is orthogonal to the corresponding measures of precipitation. Thus the proposed hypothesis is examined based on the impact of measures of intertemporal temperature volatility, as well as spatial correlation in temperature on the intensity of loss aversion. ${ }^{2}$ In particular, following the methodology of Durante (2009), these measures are constructed based on the monthly database over the period 1900-2000, using the $0.5^{\circ} \times 0.5^{\circ}$ resolution of the Climatic Research Unit $(\mathrm{CRU}) .^{3}$

Variations in the prevalence and the distribution of loss-aversion across individuals is captured by a variety of newly introduced measures of the intensity of loss aversion. Exploiting the ESS, GSS and the WVS, the degree of loss aversion is captured by individual's ranking of potential job characteristics. In particular, preference for job security over other characteristics such as salary and promotion opportunities are used as a proxy for loss-aversion. Importantly, since conceivably a layoff is typically only a transitory phenomenon, preferences for job security over higher salary does not simply represents the trade-off between potential gains and loss of income, and thus risk aversion, but rather the reluctance of individuals to lose something that is in their possession, and thus loss aversion.

Differences in the prevalence and the distribution of loss-aversion across ethnic groups are captured

\footnotetext{
${ }^{2}$ Loss aversion is indeed affected by the various measures of temperature rather than by the corresponding measures of precipitation.

${ }^{3}$ Potential concerns about changes in climate over the course of human history that is relevant for the evolution of loss aversion, appears are largely misplaced. As established in the empirical section, climatic volatility climatic volatility and temperature spatial correlation over the past 100 year period are highly correlated with the corresponding climatic characteristics in the past 2000 years.
} 
by two ethnographic characteristics reported by the EA and the SCCS. In particular, loss aversion is captured by parental preferences for sleeping in closed proximity to their infants; an overly cautious behavior driven by the fear of losing a child during his sleep, despite the low probability that is associated with this event. Alternatively, loss aversion is captured by the prevailing types of games played by members of an ethnic group. In particular, loss-aversion among members of the ethnic group, is captured by the prevalence of games that are predominantly strategy-based, rather than those governed by chance.

The first part of the empirical analysis explores the effect of intertemporal temperature volatility and temperature spatial correlation on the preferences of second-generation migrants in Europe and the US for job security versus salary and other characteristics, as reported by the ESS and the GSS. In line with the predictions of the theory, the analysis establishes: (i) a statistically and economically significant adverse effect of temperature volatility in the parental country of origin on the degree of loss aversion among second-generation migrants, and (ii) a statistically and economically significant positive effect of temperature spatial correlation in the parental country of origin on the degree of loss aversion among second-generation migrants. Moreover, consistent with the proposed theory that underlines the role of intergenerational transmission in the evolution of loss aversion, the estimated effects of temperature volatility and spatial correlation in the parental country of origin (rather than those in country of residence) on loss aversion, capture the culturally-embodied, intergenerationallytransmitted effect, rather than the direct effect of geography. Furthermore, the findings are robust to the inclusion of country-of-birth fixed-effects, and for accounting for the potentially confounding effects of a wide range of geographical characteristics at the parental county of origin, the years elapsed since the parental country transitioned to agriculture, and a range of individual characteristics, such as age, gender, education and income.

The results are further robust to a large number of placebo and robustness tests. In particular, the analysis suggests that intertemporal temperature volatility and temperature spatial correlation have no effect on the valuation of job characteristics that are orthogonal to the loss aversion (e.g., salary vs. promotion). Moreover, these climatic conditions do not have an effect of other cultural traits of second generation migrants such as, long term orientation, obedience, altruism, and attitudes towards equality, and gender roles.

The second part of the empirical analysis focuses on the effect of temperature intertemporal volatil- 
ity and spatial correlation on the variation in loss-aversion across individuals within each country, as reported by the WVS. These results further support the proposed theory. They establish a statistically and economically significant negative association between temperature volatility and degree of loss aversion among individuals, and a statistically and economically significant positive association between temperature spatial correlation and loss aversion, as captured by their preferences of job security versus other characteristics. The findings are robust to the inclusion of country-of-birth fixed-effects, and for accounting for the potentially confounding effects of a wide range of geographical characteristics, as well as individual characteristics, such as age, gender, education and income. Importantly, the results are unaffected qualitatively if one adjust the climatic variables for the ancestral composition of the contemporary population, reinforcing the hypothesized intergenerationally-transmitted and culturally-embodied nature of the effect.

Finally, the empirical analysis explores the effect idiosyncratic and aggregate components of climatic shocks on the degree of loss aversion across precolonial ethnic groups. In particular, it establishes a statistically and economically significant negative association between temperature volatility and loss aversion and a statistically and economically significant positive association between temperature spatial correlation and loss aversion, as reported by the EA. Moreover, placebo tests, establishes that the this climatic conditions are not associated with a wide range of other ethnographic characteristics, such as, sex taboos, political integration, inherited property rights, gender roles in agriculture, attitude towards premarital sex and belief in the evil eye. Thus, in line with the proposed theory, this evidence suggests that the hypothesized evolutionary process had matured already in the precolonial period.

The research represent that first attempt to shed light on the geographical origins of loss aversion and the distribution of this trait across the globe. Moreover, it contributes to the understanding of the evolution of preferences (e.g., Bisin and Verdier, 2001; Galor and Moav, 2002), and the biogeographical

roots of preferences (e.g., Alesina et al., 2013; Galor and Özak, 2016; Giuliano and Nunn, 2017) and comparative economic development (e.g., Diamond, 1997; Ashraf and Galor, 2011, 2013; Spolaore and Wacziarg, 2013; Mayshar et al., 2016).

\section{An Evolutionary Theory of Loss Aversion}

This section advances an evolutionary theory that captures the critical role of climatic forces in the evolution of loss aversion in the course of human history. The theory suggests the contemporary 
distribution of the intensity of loss aversion across individuals can be traced to the adaptation of their ancestral populations to the climatic forces that affected their productivity during Malthusian era.

The model captures the fundamental asymmetry that the Malthusian environment has generated with respect to the attitude of individuals towards gains and loses in productivity, and thus with respect to the evolution of loss aversion. In light of existing evidence that resources per capita during the Malthusian era where in the proximity of the subsistence consumption constraint, lineages of individuals who were subjected to significant adverse transitory productivity shocks during this period had become extinct, while lineages of individuals who had experience favorable climatic realization had a larger reproductive success only temporarily (Ashraf and Galor, 2011). Hence, in view of constraining effects of the subsistence consumption constraint during the Malthusian epoch, individuals who were characterized by loss aversion would have chosen safe agricultural practices that would assure their subsistence consumption while minimizing the risk for catastrophic realizations that would inevitably make their dynasties extinct. In contrast, individuals who had not assign asymmetric weight to gains and loses may had favored riskier agricultural practices that were associated with higher expected return and higher risk of extinction.

In a Malthusian environment characterized by aggregate productivity shocks, individuals who were engaged in a risky agricultural practices would have eventually affected by catastrophic climatic realization that would have become extinct. Hence, in an environment characterized by aggregate productivity shocks the trait of loss aversion, and the associated choice of the safer production mode, would have been favored by the forces of natural selection and would have dominated the population in the long run. However, in a Malthusian environment characterized by idiosyncratic shocks, although the trait of loss aversion would have still maximize the survival probability of each individual, some dynasties of individuals, who had not assigned asymmetric weight to gains and loses, would have experienced a long and (and very unlikely) realization of optimal climatic conditions. Hence, these few loss-neutral dynasties would have generated a significantly higher reproductive success and would have ultimately dominated the population in the long run.

\subsection{The Basic Structure of the Model}

Consider an overlapping-generations economy in a Malthusian stage of development. In every time period the economy is populated by a continuum of two-period lived individuals who are identical 
in all respects except for their degree of loss aversion. Loss Aversion is transmitted within each dynasty with alteration. Individuals have access to two production modes. A safe mode that generates subsistence consumption and a risky one that is associated with a higher consumption in a favorable climatic state and consumption below subsistence (leading to extinction) in an adverse climatic state. Individuals allocate their disposable income between consumption and fertility, while facing a subsistence consumption constraint. Thus, in line with the one of the main characteristics of the Malthusian epoch, richer individuals have higher reproductive success and the effect of loss aversion on the choice of the production mode affect the composition of loss aversion in society.

\subsection{Production}

In every time period two production modes are feasible in the economy: a safe mode and a risky mode. The safe mode of production is associated with hunting, gathering or the cultivation of crops that are largely insensitive to climatic conditions (e.g., roots and tubers), while the risky mode of production is associated with the cultivation of crops that generate higher expected yield but are more sensitive to climatic conditions (e.g., cereal).

The yield generated by individual $i$ of generation $t$ using the the safe mode of production, $y_{i t}^{s}$, is independent of the climatic conditions and is constant across individuals and generations.

$$
y_{i t}^{s}=\bar{y},
$$

where the yield under safe mode of production, $\bar{y}$, exceeds the subsistence consumption constraint (i.e., $\bar{y}>\tilde{c})$. In particular, in line with the dominating characteristics of the Malthusian epoch, this yield permits each individual to satisfy the subsistence consumption constraint and their fertility rates are at the replacement level. Hence, in the absence of technological progress, if all individual would choose the safe mode of production, the economy will be in a Malthusian steady-state where consumption is constant at the subsistence level and population is constant as well.

In contrast, the yield generated by individual $i$ of generation $t$ using the the risky mode of production, $y_{i t}^{r}$, depend of the climatic conditions, $\tau_{i t}$, experienced in the geographical location of individual $i$.

$$
y_{i t}^{r}=y\left(\tau_{i t}\right)
$$


where as depicted in Figure 1, $y\left(\tau_{i t}\right)$ is a symmetric, Strictly concave, hump-shaped function which attains its maximum at $\tau^{*}{ }^{4}$ The optimal climatic conditions, $\tau^{*}$, can be viewed as the ones to which crops have adapted in the long-run and hence deviations from $\tau^{*}$ result in a lower yield.

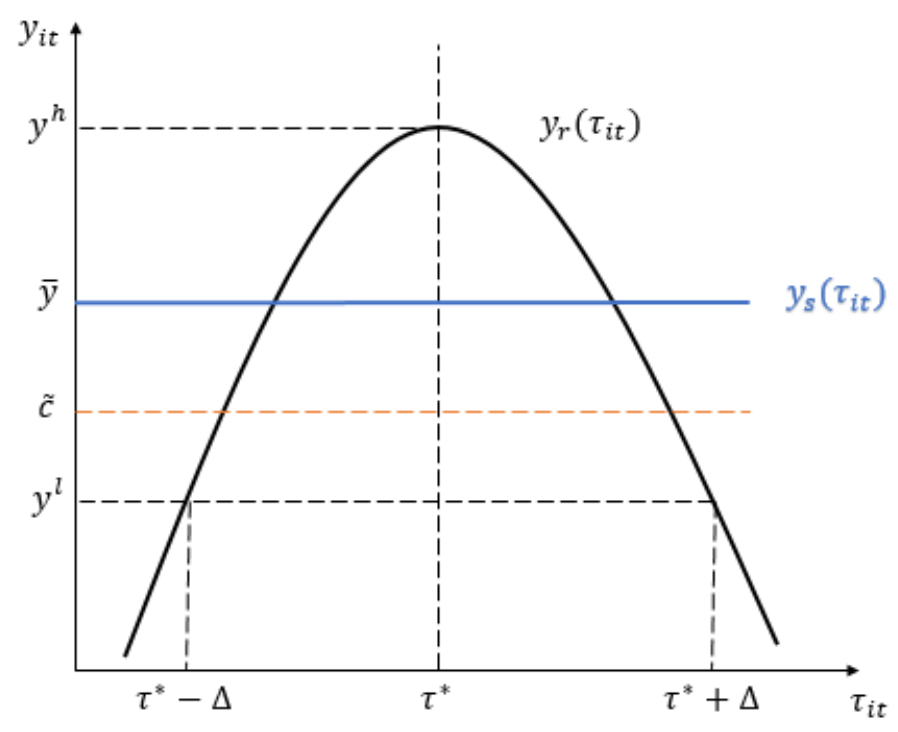

Figure 1: Crop yield as a function of temperature

In particular, an individual $i$ in period $t$ will experience with probability $p$ the optimal climatic conditions, $\tau^{*}$, whereas with probability $(1-p)$ the individual will experience either a positive or negative deviation of magnitude $\Delta$ from the optimal climatic conditions (e.g., sub-optimally low or high temperature). Hence,

$$
\tau_{i t}=\left\{\begin{array}{llc}
\tau^{*}-\Delta & \text { with probability } & \frac{1-p}{2} \\
\tau^{*} & \text { with probability } & p \\
\tau^{*}+\Delta & \text { with probability } & \frac{1-p}{2}
\end{array}\right.
$$

The yield generated by individual $i$ of generation $t$ using the the risky mode of production, $y_{i t}^{r}$, is therefore

$$
y_{i t}^{r}=y\left(\tau_{i t}\right)= \begin{cases}y^{h} \equiv y\left(\tau^{*}\right)>\bar{y} \quad \text { with probability } \quad p \\ y^{l} \equiv y\left(\tau^{*} \pm \Delta\right)<\tilde{c} & \text { with probability } 1-p\end{cases}
$$
$\tau^{*}$

${ }^{4}$ The qualitative results would not be affected if $y\left(\tau_{i t}\right)$ will be a hump shaped function that is not symmetric around 
Hence, an adverse climatic realization would not permit individual $i$ who is engaged in the risky production mode to satisfy the subsistence consumption constraint, i.e., $y^{l}<\tilde{c}$. In contrast, a favorable climatic realization would generate a yield that is higher than the one obtained under the safe mode of production and would assure consumption above subsistence, i.e., $y^{h}>\bar{y}>\tilde{c}$. Moreover, while the high yield realization under the risky mode of production is independent of the of magnitude of the deviation from the optimal climatic conditions, $\Delta$, the low yield realization is negatively affected by $\Delta$, (i.e., $\partial y^{l} / \partial \Delta<0$.)

Climatic volatility is spatially correlated across individuals within a generation (while being independent over time). In particular, a fraction $\mu \in[0,1]$ of individuals experience an identical (aggregate) realization of the climatic shock based on the distribution specified in (3), whereas a faction $1-\mu$ experience idiosyncratic realizations based on the same distribution. ${ }^{5}$

\section{$2.3 \quad$ Individuals}

In every period $t$, a continuum $I$ of two-period lived individuals is born. Individuals are ex-ante identical in all respects except for their degree of loss aversion with respect to consumption. The extant of loss aversion is heterogeneous within each generation and is transmitted intergenerationally, from parent to child, without alteration. The initial distribution of loss aversion across types is uniform over the existing range of the loss aversion parameter.

In the first period of their life - childhood - individuals are passive economic agents and they consume part of their parental resource. In the second period of their life - adulthood - individuals are active economic agents. Based on their degree of loss aversion, they choose their desirable mode of production, they produced, and optimally allocate the resulted yield between consumption and child rearing.

In light of the association between the degree of loss aversion and the choice of the production mode, the nature of the climatic shocks (i.e, their degree of spatial correlation) determines individuals' yield and hence their reproductive success and consequently contributes to the evolution of loss aversion in the population.

\footnotetext{
${ }^{5}$ This specification assures that the idiosyncratic and the aggregate dimensions of climatic volatility are orthogonal to one another. This formulation permit the examination of (i) a change in cross-individual correlation of shocks (i.e., $\mu$ ), while maintaining the distribution of the shocks, from point of view of individual $i$, and (ii) a change in the climatic volatility parameter (i.e., $\Delta$ ), while holding the spatial correlation constant.
} 


\subsubsection{Preferences, Constraints, and Optimization}

Individuals derive utility from consumption and fertility. The preferences of an adult individual $i$ in period $t$ are represented by a utility function that reflect the asymmetric utility that individuals attribute to gain and losses in consumption, with respect to a reference consumption level, $\tilde{c}$. The level of utility generated by a an adult $i$ in period $t, u_{i t}$, is

$$
u_{i t}=u_{i}\left(c_{i t}, n_{i t}\right)= \begin{cases}(1-\gamma)\left[\ln \left(c_{i t}\right)-\ln \tilde{c}\right]+\gamma \ln \left(n_{i t}+\epsilon\right) & \text { if } c_{i t} \geq \tilde{c} \\ \frac{1}{\theta_{i}}(1-\gamma)\left[\ln \left(c_{i t}\right)-\ln \tilde{c}\right]+\gamma \ln \left(n_{i t}+\epsilon\right) & \text { if } c_{i t}<\tilde{c}\end{cases}
$$

where (i) the subsistence consumption constraint, $\tilde{c}$, is the natural reference point of consumption for each individual $i$; (ii) $\epsilon>0$ is a positive parameter that is designed to assure that the individual level of utility will be bounded from below; ${ }^{6}$ (iii) $1 / \theta_{i} \in[1, \infty$ ) is the coefficient of loss aversion of individual $i$, where in period 0

$$
\theta_{i} \sim U(0,1)
$$

Consumption above subsistence, $\tilde{c}$, is considered by the individual to reflect a gain with respect to the natural reference consumption level, whereas consumption below subsistence, $\tilde{c}$, is considered by the individual to reflect a loss with respect to this natural reference consumption level. Hence, the parameter $\theta_{i} \in(0 ; 1]$ is inversely related to the degree of the individual's loss aversion with respect to subsistence consumption. In particular, $\theta_{i}=1$ corresponds to the conventional 'loss-neutral' behavior, while $0<\theta_{i}<1$ reflects loss aversion.

An adult $i$ in period $t$ is subject two two constraints: A budget constraint and a subsistence consumption constraint. Once the choice of the production mode is made and uncertainty is realized, an adult $i$ in period $t$ allocates the resulting income, $y_{i t}$, between consumption and fertility.

$$
c_{i t}+\rho n_{i t} \leq y_{i t},
$$

where $\rho>0$ is the cost of raising a child in terms of the final output. Moreover, the individual faces the

\footnotetext{
${ }^{6}$ This restriction assures that some individuals will be willing to choose the risky mode of production despite that fact that an adverse climatic realization may make their dynasty extinct.
} 
subsistence consumption constraint, below which individual can survive but is unable to reproduce. ${ }^{7}$

$$
n_{i t}=0 \text { if } c_{i t}<\tilde{c} \text {. }
$$

Hence, an adult $i$ in period $t$ allocates the income $y_{i t}$, between consumption, $c_{i t}$, and fertility, $n_{i t}$, so as to maximize the utility function $u_{i}\left(c_{i t}, n_{i t}\right)$.

$$
\begin{aligned}
\left(c_{i t}, n_{i t}\right)= & \operatorname{argmax} u_{i}\left(c_{i t}, n_{i t}\right) \\
\text { s.t. } & c_{i t}+\rho n_{i t}=y_{i t} ; \\
& n_{i t} \geq 0 ; \quad c_{i t} \geq 0 ; \\
& n_{i t}=0 \text { if } \quad c_{i t}<\tilde{c} .
\end{aligned}
$$

Given the properties of the utility function, a solution to the maximization problem exists and is unique, and given the income realization, it is time independent. In particular, if $y_{i t} \in[0 ; \tilde{c}]$, individuals will be able to be engaged in reproduction (i.e., $n_{i t}=0$ ) and will therefore consume their entire yield, $y_{i t}$. However, if $y_{i t} \in\left[\tilde{c}, y^{h}\right]$ then assuming that $y^{h} \leq[\tilde{c} /(1 / \gamma)]-\rho \epsilon$, the subsistence consumption constraints binds and individuals will consume the subsistence consumption, $\tilde{c}$, and hence given their budget constraint will devote the reaming income to raise $\left(y_{i t}-\tilde{c}\right) / \rho$ children. ${ }^{8}$

$$
\begin{gathered}
c_{i t}=c_{i}\left(y_{i t}\right)=\left\{\begin{array}{lll}
y_{i t} & \text { if } & y_{i t} \in[0 ; \tilde{c}] \\
\tilde{c} & \text { if } & y_{i t} \in\left[\tilde{c}, y^{h}\right] ;
\end{array}\right. \\
n_{i t}=n_{i}\left(y_{i t}\right)=\left\{\begin{array}{lll}
0 & \text { if } & y_{i t} \in[0 ; \tilde{c}] \\
\left(y_{i t}-\tilde{c}\right) / \rho & \text { if } & y_{i t} \in\left[\tilde{c}, y^{h}\right] .
\end{array}\right.
\end{gathered}
$$

In particular, as follows from (9), individuals who are engaged in the safe mode of production and generate an $\bar{y}>\tilde{c}$ would find it optimal to consume the subsistence level of consumption, and as postulated earlier, would have precisely one child. Namely, the safe yield $\bar{y}$ is assumed to be such that $\bar{y}=\tilde{c}+\rho$, permitting fertility at the replacement level (i.e., $n(\bar{y})=(\bar{y}-\tilde{c}) / \rho=1)$.

Accordingly, the fertility rate of individuals who are engaged in the risky mode of production and

\footnotetext{
${ }^{7}$ Alternatively, one can assume that if consumption is below subsistence, individuals do not survive and thus do not reproduce. As long as utility from consumption below subsistence is above $-\infty$ the qualitative analysis would remain intact.

${ }^{8}$ As established empirically, this is a plausible assumption in the context of the Malthusian epoch.
} 
obtain a favorable climatic realization that result in a level of income of $y^{h}>\bar{y}$ will be therefore above replacement (i.e., $\left.n\left(y^{h}\right)=\left(y^{h}-\tilde{c}\right) / \rho>1\right)$.

Consumption and the fertility are therefore a function of the individual's income (i.e., $c_{i t}=c\left(y_{i t}\right)$ and $\left.n_{i t}=n\left(y_{i t}\right)\right)$, and hence conditional on the income realization, the consumption and the fertility functions are identical across individuals and time.

The indirect utility function of an adult $i$ in period $t, V_{i t}$, is therefore

$$
v_{i t}=u_{i}\left(c\left(y_{i t}\right), n\left(y_{i t}\right)\right) \equiv v_{i}\left(y_{i t}\right)
$$

\subsubsection{Choice of Production Mode}

Individuals chose their desirable mode of production prior to the realization of the climatic conditions. Their choice is designed to maximize their expected utility, conditional on the expected probability distribution of the climatic shocks, and it may differ across individuals based on their degree of loss aversion.

As follows from (4),(5),(9), and (10), The expected utility $u_{i t}^{r}$, generated by adult $i$ in period $t$ who choses the risky production mode, is

$$
\begin{aligned}
u_{i t}^{r} & \equiv \mathbb{E}\left[v_{i}\left(y_{i t}^{r}\right)\right] \\
& =p\left[\gamma \ln \left(\frac{y^{h}-\tilde{c}}{\rho}+\epsilon\right)\right]+(1-p)\left[\frac{1}{\theta_{i}}(1-\gamma)\left[\ln y^{l}-\ln \tilde{c}\right]+\gamma \ln \epsilon\right] \\
& \equiv u^{r}\left(\theta_{i}\right),
\end{aligned}
$$

where since $\ln y^{l}<\ln \tilde{c}$,

$$
\lim _{\theta \rightarrow 0} u^{r}\left(\theta_{i}\right)=-\infty \quad \text { and } \quad \frac{d u^{r}\left(\theta_{i}\right)}{d \theta_{i}}>0 \quad \forall \theta_{i} \in(0 ; 1)
$$

Analogously, as follows from (5),(9), and (10), the utility, $u_{i t}^{s}$, generated by adult $i$ in period $t$ who choses the safe production mode is

$$
u_{i t}^{s}=\gamma \ln (1+\epsilon) \equiv u^{s} .
$$

Hence, the utility generated by individuals who choses the safe production mode is constant across types and time. 
Assuming that the risky production mode is sufficient attractive so as to assure that at least lossneutral individuals prefers this mode of production (i.e., $\left.u^{r}(1)>u^{s}\right)^{9}$, then it follows from (14) and (15) and the Intermediate Value Theorem that there exists a unique and time invariant level of the parameter of risk aversion, $\hat{\theta} \in(0 ; 1)$, such that $u^{r}(\hat{\theta})=u^{s}$.

$$
\hat{\theta}=\frac{(1-p)(1-\gamma)\left(\ln \tilde{c}-\ln y^{l}\right)}{\gamma\left[p \ln \left(\frac{y^{h}-\tilde{c}}{\rho}+\epsilon\right)+(1-p) \ln \epsilon-\ln (1+\epsilon)\right]} \equiv \hat{\theta}(\Delta)
$$

noting that as follows from (4) $y^{l}=y\left(\tau^{*} \pm \Delta\right)$. In particular, since $\partial \hat{\theta} / \partial y^{l}<0$, and thus as follows from (4), since $\partial y_{l} / \partial \Delta>0$, the cut-off level $\hat{\theta}$ is positively affected by the magnitude of the shocks, $\Delta$, i.e., $\hat{\theta}^{\prime}(\Delta)>0$.

As follows from (13), (14), (15), and (16),

$$
u^{r}\left(\theta_{i}\right) \begin{cases}<u^{s} & \forall \theta_{i} \in(0, \hat{\theta}) \\ >u^{s} & \forall \theta_{i} \in(\hat{\theta}, 1] .\end{cases}
$$

Namely, the most loss averse individuals in society (i.e., $i \in I^{A} \equiv\left\{i \in I \mid \theta_{i} \in(0 ; \hat{\theta}]\right)$ would choose the safe mode of production, whereas the least averse individuals in society individual (i.e., $i \in I^{B} \equiv\{i \in$ $\left.I \mid \theta_{i} \in(\hat{\theta} ; 1]\right\}$ would chose the risky production mode.

The yield of an adult $i$ of generation $t$ is therefore

$$
y_{i t}=\left\{\begin{array}{llll}
y^{l} \quad \text { with probability } & (1-p) & \text { if } & \theta_{i} \geq \hat{\theta} \\
y^{h} \quad \text { with probability } \quad p & \text { if } \quad \theta_{i} \geq \hat{\theta} \\
y_{i t}^{s}=\bar{y} \quad \text { if } \quad \theta_{i} \leq \hat{\theta}, & & &
\end{array}\right.
$$

and the level of fertility is:

$$
n_{i t}=\left\{\begin{array}{llll}
0 & \text { if } & \theta_{i}>\hat{\theta} \text { and } y_{i t}=y^{l} \\
\frac{y_{i t}-\tilde{c}}{\rho}>1 & \text { if } & \theta_{i}>\hat{\theta} \text { and } y_{i t}=y^{h} \\
1 & \text { if } & \theta_{i} \leq \hat{\theta} .
\end{array}\right.
$$

Moreover, since climatic volatility is spatially correlated across individuals within a generation

$$
{ }^{9} \text { Namely, } p\left[\gamma \ln \left(\frac{y^{h}-\tilde{c}}{\rho}+\epsilon\right)\right]+(1-p)\left[(1-\gamma)\left[\ln y^{l}-\ln \tilde{c}\right]+\gamma \ln \epsilon\right]>\gamma \ln (1+\epsilon) \text {. }
$$


(while being independent over time). In particular, since a fraction $\mu \in[0,1]$ of individuals experience an identical (aggregate) realization of the climatic shock based on the distribution specified in (3), whereas a faction $1-\mu$ experience idiosyncratic realizations based on the same distribution, the distribution of fertility across individuals who are engaged in the risky production mode (i.e, individuals whose $\left.\theta_{i}>\hat{\theta}\right)$ is

$$
n_{i t}=\left\{\begin{array}{llc}
\tilde{n}_{i t} & \text { with probability } & 1-\mu \\
\tilde{n}_{t} & \text { with probability } \quad \mu,
\end{array}\right.
$$

where the fertility rate of individuals who experience an idiosyncratic realization of the climatic shock, $\tilde{n}_{i t}$, as well as those who expereience an aggregate realization, $\tilde{n}_{t}$, are identically distributed, i.e.,

$$
\left\{\tilde{n}_{i t}, \tilde{n}_{t}\right\}=\left\{\begin{array}{lcc}
0 & \text { with probability } & 1-p \\
\frac{y^{h}-\tilde{c}}{\rho} & \text { with probability } & p .
\end{array}\right.
$$

\subsection{The Evolution of the Composition of Loss Aversion}

The evolution of the composition of loss aversion is governed by the effect of loss aversion on the differential reproductive success across individual. Since loss aversion is assumed to be transmitted intergenerationaly within each dynasty $i$ without any alteration, if a greater propensity towards loss aversion is associated with higher income, and thus higher reproductive success, then loss aversion will become more prevalent in the population in the long-run.

As established in (16), the threshold level of the parameter of loss aversion, $\hat{\theta}$, below which individuals are engaged in the safe production mode is constant and is time invariant. Moreover, as established in (31), individuals whose $\theta_{i} \leq \hat{\theta}$ (i.e., members of group $A$ ) have identical fertility rate (i.e., $n_{i t}=1$ if $\theta_{i} \leq \hat{\theta}$ ), while the fertility rates of individuals whose $\theta_{i}>\hat{\theta}$, (i.e., members of group $B$ ) is identically distributed based upon the expression in I (20) and (21). Hence, the distribution of loss aversion within each of the two groups has no effect on the aggregate fertility within each of the groups.

Nevertheless, differential fertility rates across the two groups affect the relative sizes of the two groups, their representation of in the population, and thus the evolution of distribution of loss aversion in the population as a whole. 
The total population in the economy in period $t . N_{t}$ is decomposed into members of group $A, N_{t}^{A}$, and member of group $B, N_{t}^{A}$, i.e.,

$$
N_{t}^{A}+N_{t}^{B}=N_{t}
$$

Hence, since that the initial distribution of types $i$ is uniformly distributed over the entire feasible domain of $\theta_{i}$, (i.e., since $\left.\theta_{i} \sim U(0,1]\right)$, it follows that

$$
\begin{aligned}
& N_{0}^{A}=\hat{\theta} N_{0} \\
& N_{0}^{B}=(1-\hat{\theta}) N_{0} .
\end{aligned}
$$

Moreover, since this distribution remains intact over time due to the stationarity of $\hat{\theta}$, the evolution of the size population of group $A$ from period $t-1$ to period $t$, is governed by the difference equation

$$
N_{t}^{A}=\left[\int_{i \in\left\{i \mid \theta_{i} \leq \hat{\theta}\right\}} n_{i t} d i\right] N_{t-1}^{A} .
$$

Hence, as follows from (19), $n_{i t}=1$, and the size of the population of group $A$ in period $t$, noting (23), is constant over time.

$$
N_{t}^{A}=\left[\prod_{s=1}^{t} \int_{i \in\left\{i \mid \theta_{i} \leq \hat{\theta}\right\}} n_{i s} d i\right] N_{0}^{A}=\hat{\theta} N_{0} \equiv N^{A}(\hat{\theta}(\Delta)) .
$$

where as follows from (25) and (16), $d N_{t}^{A} / d \Delta>0$.

Similarly, the evolution of the size of the population of group $B$ from period $t-1$ to period $t$, is goverend by the difference equation

$$
N_{t}^{B}=\left[\int_{i \in\left\{i \mid \theta_{i}>\hat{\theta}\right\}} n_{i t} d i\right] N_{t-1}^{B} .
$$

Hence, in view of the spatial distribution of $n_{i t} \forall i \in\left\{i \mid \theta_{i}>\hat{\theta}\right\}$, as specified in (20) and (21), the population of group $B$ in period $t$, noting (23), is

$$
\begin{aligned}
N_{t}^{B} & =\prod_{s=1}^{t}\left[\int_{i \in\left\{i \mid \theta_{i}>\hat{\theta}\right\}} n_{i s} d i\right] N_{0}^{B}=\prod_{s=1}^{t}\left[(1-\mu) \int_{i \in\left\{i \mid \theta_{i}>\hat{\theta}\right\}} \tilde{n}_{i s} d i+\mu \tilde{n}_{s}\right] N_{0}^{B} \\
& =\prod_{s=1}^{t}\left[(1-\mu) p \frac{y^{h}-\tilde{c}}{\rho}+\mu \tilde{n}_{s}\right](1-\hat{\theta}) N_{0} \equiv N_{t}^{B}(\hat{\theta}(\Delta), \mu),
\end{aligned}
$$


where $\partial N_{t}^{B} / \partial \Delta<0\left(\right.$ since $\partial N_{t}^{B} / \partial \hat{\theta}<0$ and $\left.\hat{\theta}^{\prime}(\Delta)>0\right)$.

The share of the less loss averse individuals in the population who choose the risky mode of production (i.e., the share of group $B$ in the population) in period $t, \beta_{t}$, is

$$
\beta_{t} \equiv \frac{N_{t}^{B}}{N_{t}^{A}+N_{t}^{B}} \equiv \beta_{t}(\hat{\theta}(\Delta), \mu)
$$

where as follows $(25)$ and $(27), \partial \beta_{t} / \partial \Delta<0$.

Given the uniform distribution of loss aversion in the population in time 0, and since this distribution remains intact over time due to the stationarity of $\hat{\theta}$, the average level of loss aversion in the population in period $t, \bar{\theta}_{t}$, is

$$
\begin{aligned}
\bar{\theta}_{t} & =\beta_{t} \mathbb{E}(\theta \mid \theta \in(\hat{\theta} ; 1])+\left(1-\beta_{t}\right) \mathbb{E}(\theta \mid \theta \in(0 ; \hat{\theta}]) \\
& =\beta_{t} \frac{1+\hat{\theta}}{2}+\left(1-\beta_{t}\right) \frac{\hat{\theta}}{2}=\frac{\beta_{t}+\hat{\theta}}{2} \equiv \bar{\theta}_{t}(\hat{\theta}(\Delta), \mu),
\end{aligned}
$$

where as follows from (28), $\partial \bar{\theta}_{t} / \partial \Delta$ is ambiguous.

The asymptotic share of the less loss averse individuals in the population who choose the risky mode of production (i.e., $\lim _{t \rightarrow \infty} \beta_{t}$, ) is determined by the relative long run reproductive success and therefore by the asymptotic rate of population growth, $n^{j}$, of each of group. Since $N_{t}^{j}=\left(n^{j}\right)^{t} N_{0}^{j}$, if population growth is constant at a rate $n^{j}$,

$$
\bar{n}^{j}=\lim _{t \rightarrow \infty} \frac{1}{t} \log N_{t}^{j} ; \quad j=A, B,
$$

Hence, as follows from (25), the asymptotic rate of population growth of the more loss averse group, $A$, is

$$
\bar{n}^{A}=0 \text {. }
$$

reflecting the fact that population of this group is constant overtime.

Similarly, the asymptotic rate of population growth of the less loss averse group, $B$, as follows from $(27)$, is

$$
\bar{n}^{B}=\operatorname{plim}_{t \rightarrow \infty} \frac{1}{t} \sum_{s=1}^{t} \log \left[(1-\mu) p \frac{y^{h}-\tilde{c}}{\rho}+\mu \tilde{n}_{s}\right]+\lim _{t \rightarrow \infty} \frac{1}{t} \log \left((1-\hat{\theta}) N_{0}\right) .
$$


Hence, since as $t$ approaches infinity the Law of Large Numbers applies,

$$
\begin{aligned}
\bar{n}^{B} & =\mathbb{E} \log \left[(1-\mu) p \frac{y^{h}-\tilde{c}}{\rho}+\mu \tilde{n}_{s}\right]= \\
& =p \log \left[(1-\mu) p \frac{y^{h}-\tilde{c}}{\rho}+\mu \frac{y^{h}-\tilde{c}}{\rho}\right]+(1-p) \log \left[(1-\mu) p \frac{y^{h}-\tilde{c}}{\rho}\right]= \\
& =p \log [\mu+(1-\mu) p]+(1-p) \log [(1-\mu) p]+\log \left(\frac{y^{h}-\tilde{c}}{\rho}\right) \equiv \bar{n}^{B}(\mu),
\end{aligned}
$$

where

$$
\bar{n}^{B}(1)=-\infty \quad \text { and } \quad \frac{d \bar{n}^{B}(\mu)}{d \mu}<0
$$

Since $\bar{n}^{B}(0)>\bar{n}^{A}=0$, as follows from the assumption that the mean return in the risky mode of production is higher that in the safe mode of production (i.e., $u^{r}(1)>u^{s}$ ), it follows from (34) and from the Intermediate Value Theorem, that there exists a unique $\hat{\mu} \in(0 ; 1)$ such that

$$
\begin{array}{ll}
\bar{n}^{B}(\mu)>\bar{n}^{A}=0 \quad \text { for } \quad \mu<\hat{\mu} ; \\
\bar{n}^{B}(\hat{\mu})=\bar{n}^{A}=0 ; \\
\bar{n}^{B}(\mu)<\bar{n}^{A}=0 \quad \text { for } \quad \mu>\hat{\mu} .
\end{array}
$$

Hence, the asymptotic share, $\bar{\beta}$, of individuals who choose the risky mode of production is

$$
\bar{\beta}=\beta(\hat{\theta}, \mu)= \begin{cases}0 & \text { if } \mu>\hat{\mu} \\ 1-\hat{\theta} & \text { if } \mu=\hat{\mu} \\ 1 & \text { if } \mu<\hat{\mu}\end{cases}
$$

and the average level of loss aversion in the population in the long run, $\bar{\theta}$, as follows from (29), is

$$
\bar{\theta} \equiv \lim _{t \rightarrow \infty} \bar{\theta}_{t}=\frac{\beta(\hat{\theta}, \mu)+\hat{\theta}}{2}=\bar{\theta}(\hat{\theta}(\Delta), \mu)=\left\{\begin{array}{ccc}
\frac{\hat{\theta}}{2} & \text { if } \quad \mu>\hat{\mu} \\
\frac{1}{2} & \text { if } \quad \mu=\hat{\mu} \\
\frac{1+\hat{\theta}}{2} & \text { if } \quad \mu<\hat{\mu}
\end{array}\right.
$$


Hence, noting that $\hat{\theta}^{\prime}(\Delta)>0$, for $\mu \neq \hat{\mu}$

$$
\frac{\partial \bar{\theta}(\hat{\theta}(\Delta), \mu)}{\partial \Delta}>0
$$

\subsection{Testable Implications}

In order to derive the testable implication of the theoretical model, suppose that each geographical region, $r$, is populated by a continuum of groups of individuals. Suppose further that the spatial auto correlations in climatic shocks differ across these groups and their geographical locations and is characterized by a non-trivial distribution $\mu_{r}$ with cumulative distribution function $F_{\mu_{r}}(\mu)$. In particular, an increase in $\mu$ by $d \mu$ corresponds to the uniform shift of the entire distribution to the right, resulting in a new distribution $\mu_{r}^{\prime} \equiv \mu_{r}+d \mu$ with a cumulative distribution function $F_{\mu_{r}^{\prime}}(\mu)=F_{\mu_{r}}(\mu-d \mu)$.

The average $\bar{\theta}$ in the region $r$ is therefore

$$
\bar{\theta}_{r} \equiv \mathbb{E}_{\mu_{r}^{\prime}}(\bar{\theta}(\hat{\theta}, \mu))=\frac{\hat{\theta}}{2}\left(1-F_{\mu_{r}}(\hat{\mu}-d \mu)\right)+\frac{1+\hat{\theta}}{2} F_{\mu_{r}}(\hat{\mu}-d \mu)=\frac{F_{\mu_{r}}(\hat{\mu}-d \mu)+\hat{\theta}}{2}
$$

where as follows from the fact that $F_{\mu_{r}}(\mu)$ is non-decreasing, $\partial \bar{\theta}_{r} / \partial d \mu \leq 0$.

Hence, as follows from (38), (39), the testable predictions of the model are:

Proposition 2.1. If the economy is characterized by:

(i) a higher spatial correlation of climatic shocks, $\mu$, the average level of loss aversion that will be observed in the economy in the long run, $[1 / \bar{\theta}]$, will be higher.

(ii) a higher volatility of climatic shocks, $\Delta$, the average level of loss aversion that will be observed in the economy in the long run, $[1 / \bar{\theta}]$, will be lower.

Thus, the theory suggests that individuals and societies that are originated in regions of the world in which climatic shocks tended to be spatially correlated, and thus aggregate in nature, would be characterized by greater intensity of loss aversion, while descendants of regions that were characterized by idiosyncratic climatic shocks will tend to be more loss-neutral and to assign more symmetric weights to gains and loses. 


\section{Empirical Strategy and Data}

This section presents the empirical strategy developed to analyze the effect of the idiosyncratic and aggregate components of temperature shocks on contemporary variations in the rate of loss aversion. Moreover, it describes the global measures of temperature intertemporal volatility and spatial correlation that are designed to capture the idiosyncratic and aggregate components of temperature shocks, as well as a range of proxies for loss aversion, at the individual and ethnic group level.

\subsection{Identification Strategy}

The empirical analysis surmounts significant hurdles in the identification of the causal effect of climatic conditions of the evolution of loss aversion. In particular, the research adopts an empirical strategy that is designed to mitigate concerns about the potential role of reverse causality, as well as omitted variables, in the observed association between climatic characteristics and loss aversion.

First, the since unlike soil characteristics, climatic characteristics are largely orthogonal to individuals' preferences and thus choices, the focus on climatic (rather than soil) characteristics assures that the association between climatic characteristics and loss aversion is not driven by reversed causality in the identification. In particular, historical temperature patterns, for the most part, are determined by the regional geographical conditions and are orthogonal to human interventions.

Second, potential concerns about the role of omitted geographical, institutional, cultural, and human characteristics in the observed association between intertemporal climatic volatility and climatic spatial correlation and loss aversion are mitigated by accounting for a large set of confounding characteristics that might have determined loss aversion and are correlated with temperature volatility and temperature spatial correlation. In particular the analysis accounts for: potentially confounding effects of: geographical characteristics (e.g., absolute latitude, mean elevation, the level and diversity of the stability of land for agriculture, distance to coast or navigable river, percentage of land in the tropical, subtropical and temperate zones, level of precipitation, and landlocked societies), as well as the time elapsed since of the neolithic revolution; (ii) regional fixed effects, capturing unobserved timeinvariant heterogeneity at the regional level; (iii) host country fixed effects, and thus time-invariant country-of-birth specific factors, (e.g., geography, institutions, and culture); for second-generation migrants; (iv) individual characteristics (e.g., age, gender, number of siblings, religion, education level and income); (v) ethnographic characteristics (e.g., intensity of agriculture and animal husbandry, 
settlement structure and plow use) characteristics.

Third, the adoption of the epidemiological approach and the exploration of the determinants loss aversion among second-generation migrants, permits the analysis to overcome two major concerns: (i) it distinguishes between the effect of temperature volatility and spatial correlation in the parental country of origin (rather than those in country of residence) on loss aversion, capturing the culturallyembodied, intergenerationally-transmitted component of the effect of geography, rather than the direct effect of geography; (ii) it accounts for time invariant unobserved heterogeneity in the host country (e.g., geographical, cultural and institutional characteristics), and thus mitigating possible concerns about the confounding effect of host country-specific characteristics.

Finally, the analysis explores variation in the rate of loss aversion across ethnic groups, and thus captures the evolution of loss aversion in the precolonial era, establishes that some of the hypothesized evolutionary process was completed in the past.

\subsection{Dependent Variable: Proxies for Loss Aversion}

Adequately capturing variation in the rate of loss aversion in itself poses a significant challenge due to the absence of well-established convention over its proxies in the corresponding literature. To overcome this problem novel measures of loss aversion at an individual and ethnic group levels, are introduced.

Variations in the prevalence and the distribution of loss-aversion across individuals is captured by a variety of newly introduced measures of the intensity of loss aversion. Exploiting the ESS, GSS and the WVS, the degree of loss aversion is captured by individual's ranking of potential job characteristics. In particular, preference for job security over other characteristics such as salary and promotion opportunities are used as a proxy for loss-aversion. Importantly, since conceivably a layoff is typically only a transitory phenomenon, preferences for job security over higher salary does not simply represents the trade-off between potential gains and loss of income, and thus risk aversion, but rather the reluctance of individuals to lose something that is in their possession, and thus loss aversion. Alternatively, If one views a job as a 'gamble' with 'being employed' as a reference point, the state 'being fired' would then represent a down-side of this gamble. From this point of view, preference for job security over other characteristics or over salary would capture individual's rate of loss aversion, as it represents ones reluctance towards getting the down-side or 'loosing' the gamble.

The global distribution of the proxy for loss aversion based on the WVS is depicted in Figure 2, 
reflecting a lower degree of loss aversion in most countries in the upper part of Northern hemisphere as well as among the decedents of these regions in the US, Canada, Australia and New Zealand. In contrast, higher degree of loss aversion can be detected in Southern Europe and the decedents of these regions in Latin America, as well as in Africa and South Asia.

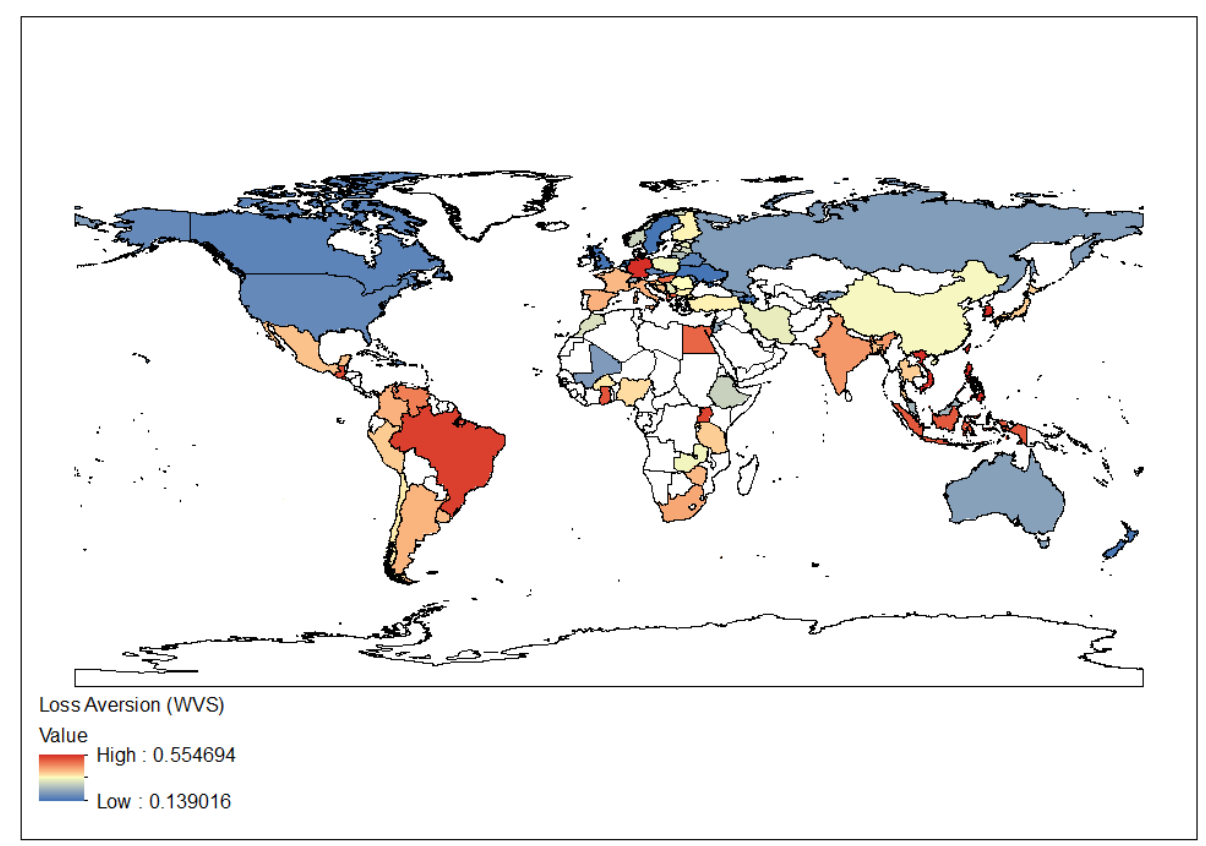

Figure 2: The Global Distribution of Loss Aversion as captured by the WVS

Proxies for the rate of loss aversion at an ethnic group level are constructed using several ethnographic characteristics, which supposedly capture revealed preference for cautiousness and are associated with loss averse behavior. Differences in the prevalence and the distribution of loss-aversion across ethnic groups are captured by two ethnographic characteristics reported by the EA and the SCCS. In particular, loss aversion is captured by parental preferences for sleeping in closed proximity to their infants; an overly cautious behavior driven by the fear of losing a child during his sleep, despite the low probability that is associated with this event. Alternatively, loss aversion is captured by the prevailing types of games played by members of an ethnic group. In particular, loss-aversion among members of the ethnic group, is captured by the prevalence of games that are predominantly strategy-based, rather than those governed by chance. The presence of a chance as the major element in games is 
associated with a lower rate of cautiousness and thus loss neutral population, while strategy based games would be more common among groups with more cautions and loss averse population.

\subsection{Independent Variable: Idiosyncratic and Aggregate Climatic Uncertainty}

This section describes the measures the will be used to capture the impact of the idiosyncratic and aggregate components of climatic shocks on loss aversion. In light of the predictions of the theory, the prevalence of loss aversion is linked to intertemporal climatic volatility as well as special correlation in climatic conditions. A-priori one could have captured these climatic characteristics using either temperature or precipitation. However, as established in Table A1, while productivity in the Malthusian era is significantly correlated with various characteristics of temperature, it is orthogonal to the corresponding measures of precipitation. Thus the proposed hypothesis is examined based on the impact of measures of intertemporal temperature volatility, as well as spatial correlation in temperature on the intensity of loss aversion.

As noted in the empirical strategy section, measures of intertemporal temperature volatility and temperature spatial correlation capture the distinction between the aggregate and the idiosyncratic nature of the shocks. Indeed, stronger temperature spatial correlation reflects a higher likelihood that neighboring regions would obtain similar realizations of temperature shock, capturing the aggregate nature of the shocks. Similarly, keeping the temperature spatial correlation constant, the level of temperature volatility corresponds to the variability of temperature shocks at a local level, capturing the idiosyncratic component of the shock.

Hence, following the methodology of Durante (2009), these measures are constructed based on the monthly temperatures over the period $1900-2000$, using the $0.5^{\circ} \times 0.5^{\circ}$ resolution of the Climatic Research Unit (CRU). ${ }^{10}$ In particular, intertemporal temperature volatility over the period 19002000 is the average volatility in each month over this 100 year period, where the monthly volatility is captured the variance in monthly temperature over this 100 year period. Similarly, temperature spatial correlation is the correlation between the sequences of 1200 monthly temperature in a given cell over the year 1900-2000, and the average of those sequences in its eight neighboring cells. Each of these measures is first calculated at the grid cell level and then aggregated at the country and ethnic

\footnotetext{
${ }^{10}$ Potential concerns about changes in climate over the course of human history that is relevant for the evolution of loss aversion, appears are largely misplaced. As reported in Table A10, climatic volatility and spatial correlation over the past 100 year period are highly correlated with the corresponding climatic characteristics in the past 1500 years.
} 
group levels.

The global distribution of these two climatic measures is depicted in Figures 3 and 4 . The figure suggests that higher intertemporal temperature volatility is observed in the upper part of the Northern hemisphere and a lower one closer to the equator. Indeed, in line with the proposed theory of a negative effect of climatic volatility on loss aversion, accounting for the post-1500 migration to the new world as well as to Australia and New Zealand, individuals originated from the most volatile regions of the world tend to be less loss averse (as depicted in Figure 2). Furthermore, consistent with the proposed theory of a positive effect of temperature spatial correlation on loss aversion, indeed higher intertemporal temperature volatility tends to be lower in the upper part of the northern hemisphere where loss aversion is lower, and lower in proximity to the equator where loss aversion is higher.

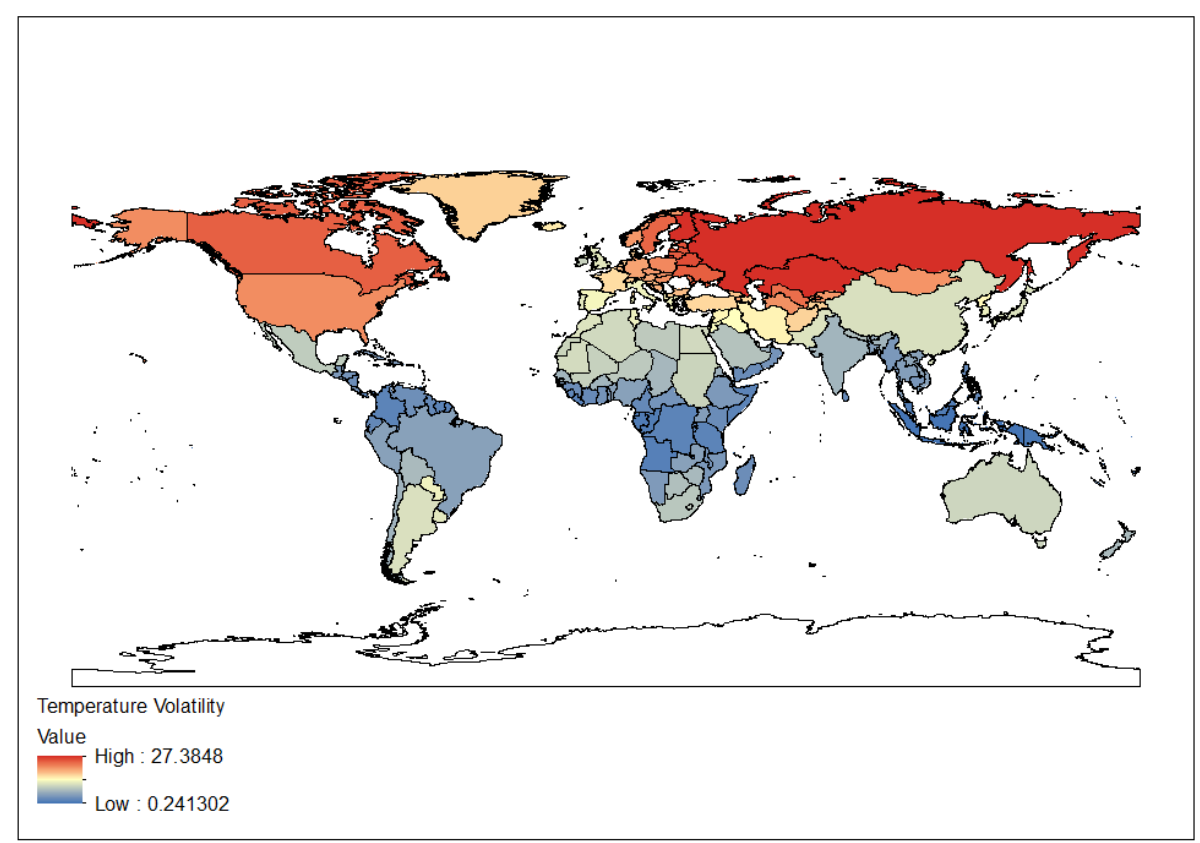

Figure 3: The Global Distribution of Intertemporal Temperature Volatility

As elaborated above, an alternative climatic dimension that could have been used to capture the idiosyncratic and the aggregate components of climatic shocks is precipitation. However, shocks to precipitation, unlike shocks to temperature appears orthogonal to productivity in the pre-industrial era and are therefore tangential to the evolution of loss aversion. In particular, as established in Table 


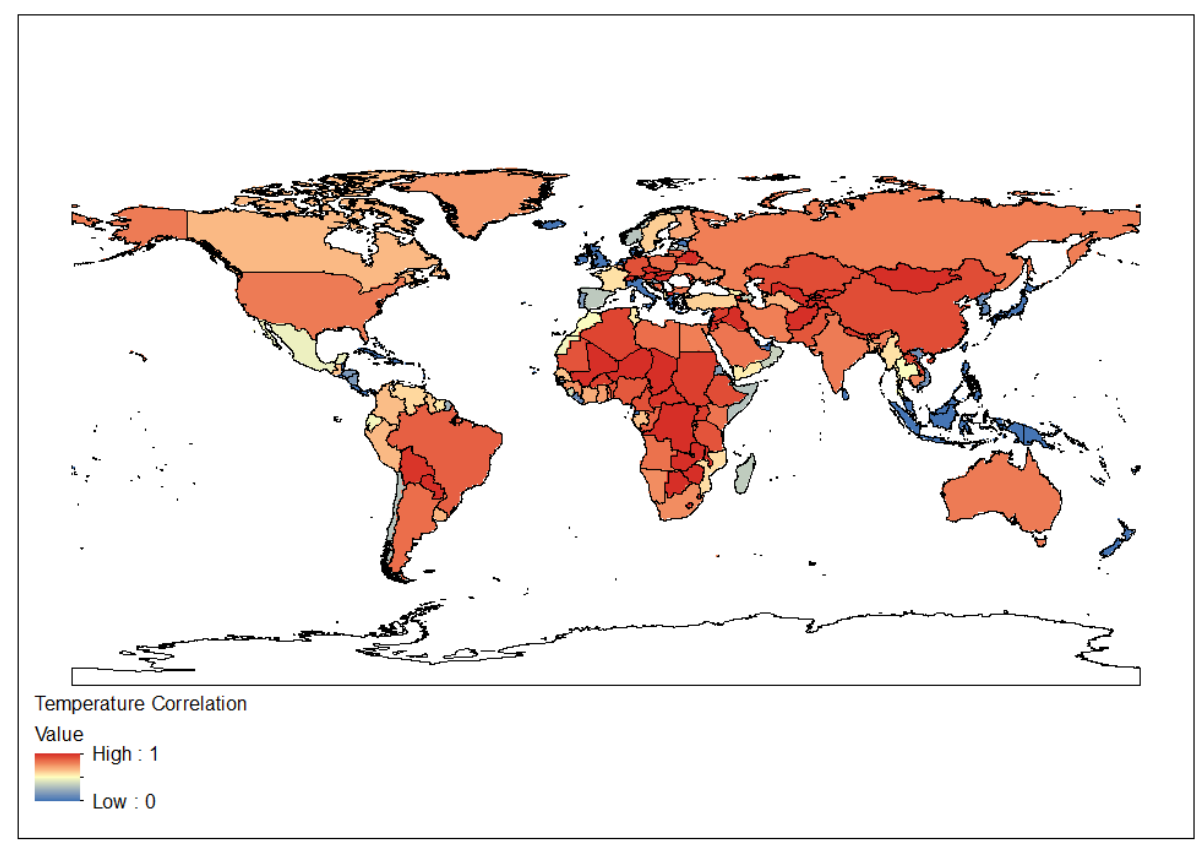

Figure 4: The Global Distribution of Temperature Spatial Correlation

1, a cross-country analysis suggests that neither the mean level of precipitation nor precipitation volatility have a statistically significant association with population density and urbanization level in the year 1500, and thus in light of the Malthusian paradigm (Ashraf and Galor, 2011), have no significant association with the level of technology and productivity in the year 1500. In contrast, the level of temperature volatility has a strong statistically and economically significant effect on both measures. Moreover, the qualitative results remains intact, if one accounts for the confounding effects of additional geographical characteristics (e.g., absolute latitude, mean elevation, percentage of arable land, mean land suitability, island and landlocked dummy, and distance to coast or river), the timing of the neolithic revolution, and regional fixed effects. These results may reflect that view that while the adverse effect of precipitation shocks can be potentially mitigated by irrigation and drainage systems, the the adverse effects of temperature shock are harder to be mitigated by human intervention. 
Table 1: Determinants of Population Density and Urbanization in the Year 1500

\begin{tabular}{|c|c|c|c|c|c|c|}
\hline & \multicolumn{5}{|c|}{ Population Density } & \multirow{2}{*}{$\frac{\text { Urbanization }}{(6)}$} \\
\hline & $(1)$ & $(2)$ & $(3)$ & $(4)$ & $(5)$ & \\
\hline Temperature (Volatility) & $\begin{array}{c}-0.543^{* * *} \\
(0.159)\end{array}$ & $\begin{array}{c}-0.538^{* * *} \\
(0.171)\end{array}$ & $\begin{array}{c}-0.691^{* * *} \\
(0.225)\end{array}$ & $\begin{array}{c}-1.012^{* * *} \\
(0.210)\end{array}$ & $\begin{array}{c}-0.908^{* * *} \\
(0.240)\end{array}$ & $\begin{array}{c}-0.854^{* *} \\
(0.401)\end{array}$ \\
\hline Precipitation (Volatility) & $\begin{array}{c}0.215 \\
(0.185)\end{array}$ & $\begin{array}{c}0.199 \\
(0.217)\end{array}$ & $\begin{array}{c}0.234 \\
(0.248)\end{array}$ & $\begin{array}{c}0.292 \\
(0.224)\end{array}$ & $\begin{array}{c}0.213 \\
(0.195)\end{array}$ & $\begin{array}{c}0.218 \\
(0.344)\end{array}$ \\
\hline Temperature (Mean) & $\begin{array}{c}-0.235^{*} \\
(0.138)\end{array}$ & $\begin{array}{c}-0.214 \\
(0.191)\end{array}$ & $\begin{array}{l}-0.324 \\
(0.212)\end{array}$ & $\begin{array}{c}-0.741^{* * *} \\
(0.220)\end{array}$ & $\begin{array}{c}-0.833^{* * *} \\
(0.226)\end{array}$ & $\begin{array}{c}0.228 \\
(0.448)\end{array}$ \\
\hline Precipitation (Mean) & $\begin{array}{l}-0.166 \\
(0.171)\end{array}$ & $\begin{array}{l}-0.150 \\
(0.178)\end{array}$ & $\begin{array}{l}-0.175 \\
(0.187)\end{array}$ & $\begin{array}{l}-0.254 \\
(0.155)\end{array}$ & $\begin{array}{l}-0.212 \\
(0.138)\end{array}$ & $\begin{array}{c}-0.157 \\
(0.375)\end{array}$ \\
\hline Percentage of Arable Land & $\begin{array}{c}0.439 * * * \\
(0.079)\end{array}$ & $\begin{array}{c}0.435^{* * *} \\
(0.109)\end{array}$ & $\begin{array}{c}0.433^{* * *} \\
(0.113)\end{array}$ & $\begin{array}{c}0.396 * * * \\
(0.102)\end{array}$ & $\begin{array}{c}0.277^{* * *} \\
(0.103)\end{array}$ & $\begin{array}{c}0.068 \\
(0.148)\end{array}$ \\
\hline Absolute Latitude & $\begin{array}{c}0.410^{* *} \\
(0.188)\end{array}$ & $\begin{array}{c}0.428^{* *} \\
(0.191)\end{array}$ & $\begin{array}{c}0.458^{*} \\
(0.263)\end{array}$ & $\begin{array}{c}0.211 \\
(0.242)\end{array}$ & $\begin{array}{c}0.129 \\
(0.220)\end{array}$ & $\begin{array}{c}0.531 \\
(0.461)\end{array}$ \\
\hline Elevation (Mean) & & $\begin{array}{c}0.013 \\
(0.077)\end{array}$ & $\begin{array}{l}-0.094 \\
(0.083)\end{array}$ & $\begin{array}{c}-0.312^{* * *} \\
(0.084)\end{array}$ & $\begin{array}{c}-0.364 * * * \\
(0.079)\end{array}$ & $\begin{array}{c}0.177 \\
(0.278)\end{array}$ \\
\hline Land Suitability (Mean) & & $\begin{array}{c}0.010 \\
(0.129)\end{array}$ & $\begin{array}{l}-0.016 \\
(0.133)\end{array}$ & $\begin{array}{l}-0.012 \\
(0.123)\end{array}$ & $\begin{array}{c}0.070 \\
(0.119)\end{array}$ & $\begin{array}{l}-0.018 \\
(0.200)\end{array}$ \\
\hline Neolithic Transition Timing & & & & $\begin{array}{c}0.406^{* * *} \\
(0.070)\end{array}$ & $\begin{array}{c}0.399^{* * *} \\
(0.108)\end{array}$ & $\begin{array}{l}-0.103 \\
(0.144)\end{array}$ \\
\hline Additional Geographical Controls & No & No & Yes & Yes & Yes & Yes \\
\hline Region FE & No & No & No & No & Yes & Yes \\
\hline Adjusted- $R^{2}$ & 0.32 & 0.31 & 0.32 & 0.42 & 0.44 & 0.21 \\
\hline Observations & 151 & 151 & 151 & 151 & 151 & 81 \\
\hline
\end{tabular}

Notes: This table establishes that country-level population density and urbanization in 1500 is adversely affected by the temperature volatility but not by the precipitation volatility. Additional geographical controls are island and landlocked dummy variables and the distance to coast or river. All independent variables have been normalized by subtracting their mean and dividing by their standard deviation. Thus, all coefficients can be compared and show the effect of a one standard deviation in the independent variable. Heteroskedasticity robust standard error estimates are reported in parentheses; *** denotes statistical significance at the $1 \%$ level, ${ }^{* *}$ at the $5 \%$ level, and * at the $10 \%$ level, all for two-sided hypothesis tests.

\section{Empirical Analysis: Second Generation Migrants}

This section analyzes the effect of intertemporal temperature volatility and temperature spatial correlation on the second-generation migrants' preferences of job security versus salary and other characteristics in Europe and the United States. In particular, it analyses the effect of temperature volatility and correlation on preferences of jobs security versus salary as reported in the European Social Survey (ESS), and on preferences of jobs security versus salary and other characteristics (short working hours, promotion opportunities and job satisfaction) as reported in the General Social Survey (GSS). The analysis of second-generation migrants accounts for time invariant unobserved heterogeneity in 
the host country (e.g., geographical and institutional characteristics). Moreover, since temperature volatility and spatial correlation in the parental country of origin are distinct from those of the country of residence, the estimated effect of temperature volatility and correlation in the country of origin captures the culturally-embodied, intergenerationally-transmitted effect, rather than the direct effect of geography. The effect of temperature volatility and correlation on preferences of job security versus salary or other characteristics is estimated via ordinary least squares (OLS) according to the following specification

$$
\begin{aligned}
j o b_{i c t}^{\text {sec }} & =\beta_{0}+\beta_{1}^{\text {vol }} \text { temp } p_{i p}^{\text {vol }}+\beta_{1}^{\text {corr }} \text { tem } p_{i p}^{\text {corr }}+\sum_{j} \gamma_{0 j} X_{i p j} \\
& +\gamma_{1} y s t_{i p}+\sum_{j} \gamma_{2 j} Z_{i j}+\sum_{c} \gamma_{c} \delta_{i c}+\sum_{t} \gamma_{t} \delta_{i t}^{\prime}+\epsilon_{i}
\end{aligned}
$$

where $j o b_{i c t}^{s e c}$ captures valuation of job security over salary or other characteristics of second-generation migrant $i$ in country $c$ measured in round/wave $t, t e m p_{i p}^{v o l}$ and $t e m p_{i p}^{\text {corr }}$ are measured in the country of origin of parent $p$ of individual $i, X_{i p j}$ is geographical characteristic $j$ of the country of origin of parent $p$ of individual $i, y_{s} t_{i p}$ are the years since the country of origin of parent $p$ of individual $i$ transitioned to agriculture, $Z_{i j}$ is characteristic $j$ of individual $i$ (age, gender, number of siblings, religion, education level, income), $\delta_{i c}$ is the country of birth fixed effect of individual $i, \delta_{i t}^{\prime}$ is the round/wave fixed effect of individual $i$, and $\epsilon_{i}$ is the error term. The theory predicts negative effect of temperature volatility and positive effect of temperature spatial correlation (i.e., $\beta_{1}^{\text {vol }}<0$ and $\beta_{1}^{\text {corr }}>0$ ).

\subsection{Determinants of Loss Aversion among Second Generation Migrants in Europe}

This subsection analyzes the effect of intertemporal temperature volatility and temperature spatial correlation on the second-generation migrants' preferences of job security versus salary in Europe, in light of the conjectured positive association between loss aversion and preference for job security over salary. The effect of temperature volatility and correlation on preferences of job security versus salary is estimated via ordinary least squares (OLS) using the empirical model (40).

Table 2 establishes the negative statistically and economically significant effect of temperature volatility and positive significant effect of temperature spatial correlation on preferences of job security versus salary as suggested by the theory. The estimated effect implies that increasing temperature 
volatility in the parental country of origin by one standard deviation decreases the difference between second-generation migrant's valuation of job security and salary between 0.16 and 0.24 units $^{11}$, while increasing temperature spatial correlation in the parental country of origin by one standard deviation increases the difference between second-generation migrant's valuation of job security and salary between 0.034 and 0.059 units.

The relationship between intertemporal temperature volatility and temperature spatial correlation and preferences of job security versus salary, accounting for country of birth fixed effects, and therefore for unobserved time-invariant omitted variables at the country of birth level, are established in column (1). The estimated effect of temperature volatility is negative and statistically significant at the $1 \%$ level, while estimated effect of temperature spatial correlation is positive and statistically significant at the $10 \%$ level, implying economically significant effects suggested by the theory.

Column (2) accounts for some of the other confounding geographical characteristics of the country of origins. In particular, absolute latitude and mean elevation. Accounting for the effects of geography and country of birth heterogeneity strengthens estimated effects of temperature volatility and spatial correlation on preferences of job security versus salary both in terms of absolute values and significances. In particular, estimated effect of temperature spatial correlation becomes statistically significant at the $5 \%$ level. Column (3) accounts for the whole set of confounding geographical characteristics of the country of origins, which, apart from absolute latitude and mean elevation, includes mean level and the gini index of land suitability, distance to coast or navigable river, landlocked dummy, percentage of land in the tropical, subtropical and temperate zones and precipitation level. Reassuringly, coefficient on temperature volatility remains statistically significant at the $1 \%$ level, while coefficient on temperature spatial correlation becomes statistically significant at the $1 \%$ level as well. The effects of other confounding geographical characteristics are less significant than the effects of temperature volatility and correlation. In particular, most geographical characteristics have no significant effect on preferences of job security versus salary.

Column (4) considers the confounding effect of the advent of sedentary agriculture, as captured by the years elapsed since the onset of the Neolithic Revolution, on the evolution of the loss aversion. The effects of temperature volatility and spatial correlation remain statistically significant at the $1 \%$ level. Additionally, the effect of the timing of transition to the Neolithic has no significant effect on

\footnotetext{
${ }^{11}$ Each characteristic is evaluated by the scale from 1 to 5 , so that their difference takes values from -4 to 4 .
} 
Table 2: Determinants of Loss Aversion: Second Generation Migrants in Europe (OLS)

\begin{tabular}{lcccccc}
\hline \hline & \multicolumn{5}{c}{ Preferred Job Characteristic: Security vs. Salary } \\
\cline { 2 - 7 } & $(1)$ & $(2)$ & $(3)$ & $(4)$ & $(5)$ & $(6)$ \\
\hline Temperature (Volatility) & $-0.157^{* * *}$ & $-0.223^{* * *}$ & $-0.228^{* * *}$ & $-0.235^{* * *}$ & $-0.241^{* * *}$ & $-0.229^{* * *}$ \\
Temperature (Spatial Correlation) & $(0.045)$ & $(0.046)$ & $(0.062)$ & $(0.062)$ & $(0.062)$ & $(0.061)$ \\
& $0.034^{*}$ & $0.052^{* *}$ & $0.059^{* * *}$ & $0.056^{* * *}$ & $0.057^{* * *}$ & $0.056^{* * *}$ \\
& $(0.020)$ & $(0.021)$ & $(0.022)$ & $(0.021)$ & $(0.021)$ & $(0.021)$ \\
Temperature (Mean) & $-0.138^{* * *}$ & $-0.095^{*}$ & -0.099 & -0.135 & -0.140 & -0.088 \\
& $(0.043)$ & $(0.050)$ & $(0.092)$ & $(0.093)$ & $(0.091)$ & $(0.092)$ \\
Absolute Latitude & & $0.093^{* * *}$ & $0.136^{* *}$ & $0.109^{*}$ & $0.113^{*}$ & $0.152^{* *}$ \\
& & $(0.032)$ & $(0.059)$ & $(0.061)$ & $(0.062)$ & $(0.062)$ \\
Elevation (Mean) & & -0.003 & 0.009 & -0.000 & 0.001 & 0.009 \\
& & $(0.017)$ & $(0.022)$ & $(0.024)$ & $(0.024)$ & $(0.024)$ \\
Land Suitability (Mean) & & & 0.030 & 0.018 & 0.016 & 0.014 \\
& & & $(0.044)$ & $(0.048)$ & $(0.048)$ & $(0.048)$ \\
Neolithic Transition Timing & & & & 0.019 & 0.020 & 0.011 \\
& & & & $(0.016)$ & $(0.016)$ & $(0.016)$ \\
\hline Country of Birth FE & Yes & Yes & Yes & Yes & Yes & Yes \\
Additional Geographical Controls & No & No & Yes & Yes & Yes & Yes \\
Round FE & No & No & No & No & Yes & Yes \\
Individual Controls & No & No & No & No & No & Yes \\
Adjusted- $R^{2}$ & 0.05 & 0.06 & 0.06 & 0.06 & 0.06 & 0.07 \\
Observations & 3907 & 3907 & 3907 & 3907 & 3907 & 3907 \\
\hline
\end{tabular}

Notes: Using OLS regressions, this table establishes that the preferred job characteristics of second generation migrants reflect loss aversion. In particular, their valuation of job security vs. salary is negatively affected by temperature volatility (idiosyncratic risk) and positively affected by temperature spatial correlation (aggregate uncertainty) in the parental country of origin. Additional geographical controls are gini index of land suitability, distance to coast or river, landlocked dummy, percentage of land in the tropical, subtropical and temperate zones and precipitation level. Individual controls include age, gender, number of siblings, religion, education level, and income. Sample excludes small island countries. All independent variables have been normalized by subtracting their mean and dividing by their standard deviation. Thus, all coefficients can be compared and show the effect of a one standard deviation in the independent variable on standard deviations in the dependent variable. Heteroskedasticity robust standard error estimates clustered at the parental country of origin level are reported in parentheses; *** denotes statistical significance at the $1 \%$ level, ${ }^{* *}$ at the $5 \%$ level, and $*$ at the $10 \%$ level, all for two-sided hypothesis tests.

preferences of job security versus salary.

Columns (5) and (6) sequentially account for the survey round fixed effects and second-generation migrant's individual characteristics (i.e., age, gender, number of siblings, religion, education level, and income). The estimated effects of temperature volatility and spatial correlation on preferences of job security versus salary continue to be statistically significant at the $1 \%$ level. It should be noted that the coefficients on temperature volatility and spatial correlation are remarkably stable in terms of absolute values across all specifications, especially in columns (2) - (6). 


\subsection{Determinants of Loss Aversion among Second Generation Migrants in the US}

This subsection examines the effect of intertemporal temperature volatility and temperature spatial correlation on the second-generation migrants' preferences of job security versus salary and other job characteristics in the US, in light of the conjectured positive association between loss aversion and preference for job security over salary and other characteristics (short working hours, promotion opportunities and job satisfaction). The effect of temperature volatility and correlation on preferences of job security versus salary and other job characteristics is estimated via ordinary least squares (OLS) using the model analogous to model (40).

Table 3 establishes a negative statistically and economically significant effect of temperature volatility and positive significant effect of temperature spatial correlation on second-generation migrants' preferences of job security versus salary and other characteristics. In particular, Columns (1) through (5) establish the effect of temperature volatility and spatial correlation on preferences for job security over all other characteristics ${ }^{12}$, sequentially accounting for the confounding effects of unobserved time-invariant omitted variables at the region of birth level, other geographical characteristics (mean temperature, absolute latitude, mean elevation, mean level and the gini index of land suitability, distance to coast or river, landlocked dummy, percentage of land in the tropical, subtropical and temperate zones and precipitation level), the advent of sedentary agriculture, as captured by the years elapsed since the onset of the Neolithic Revolution, survey wave fixed effects and individual characteristics of second generation migrant (age, gender, number of siblings, religion, education level, and income). The estimated effects imply that increasing temperature volatility in the parental country of origin by one standard deviation decreases the probability of job security having a higher ranking between 18 and 42 percentage points, while increasing temperature spatial correlation by one standard deviation increases the probability of job security having a higher ranking between 13 and 17 percentage points. It should be noted that coefficients on the temperature volatility and spatial correlation are rather stable across specifications and statistically significant at the $1 \%$ level in two final specifications.

Columns (6) and (7) replicate columns (4) and (5) with preference for job security over salary ${ }^{13}$ being the explained variable. Estimated effects of temperature volatility and spatial correlation are

\footnotetext{
${ }^{12}$ The preferences for job security versus other characteristics are measured as the rank assigned to the job security by the second-generation migrant based on the answers to the questions "... which one thing on this list (security, salary, short working hours, promotion opportunities and job satisfaction) you would most/second most/...prefer in a job?"

${ }^{13}$ Preferences of job security versus salary are measured as the difference between the rankings of the two characteristics, ranging from -4 to 4 .
} 
Table 3: Determinants of Loss Aversion: Second Generation Migrants in the US

\begin{tabular}{|c|c|c|c|c|c|c|c|}
\hline & \multicolumn{7}{|c|}{ Preferred Job Characteristic } \\
\hline & \multicolumn{5}{|c|}{ Security vs Others } & \multicolumn{2}{|c|}{ Security vs Salary } \\
\hline & (1) & $(2)$ & $(3)$ & $(4)$ & $(5)$ & (6) & (7) \\
\hline Temperature (Volatility) & $\begin{array}{c}-0.18^{*} \\
(0.09)\end{array}$ & $\begin{array}{c}-0.22^{* *} \\
(0.08)\end{array}$ & $\begin{array}{c}-0.33^{* * *} \\
(0.09)\end{array}$ & $\begin{array}{c}-0.32^{* * *} \\
(0.09)\end{array}$ & $\begin{array}{c}-0.42^{* * *} \\
(0.08)\end{array}$ & $\begin{array}{c}-0.52^{* * *} \\
(0.16)\end{array}$ & $\begin{array}{c}-0.62^{* * *} \\
(0.16)\end{array}$ \\
\hline Temperature (Spatial Correlation) & $\begin{array}{c}0.13^{* *} \\
(0.05)\end{array}$ & $\begin{array}{c}0.15^{* * *} \\
(0.05)\end{array}$ & $\begin{array}{c}0.14^{* *} \\
(0.05)\end{array}$ & $\begin{array}{c}0.17^{* * *} \\
(0.05)\end{array}$ & $\begin{array}{c}0.16^{* * *} \\
(0.04)\end{array}$ & $\begin{array}{c}0.24^{* * *} \\
(0.08)\end{array}$ & $\begin{array}{c}0.28^{* * *} \\
(0.08)\end{array}$ \\
\hline Temperature (Mean) & $\begin{array}{l}-0.05 \\
(0.08)\end{array}$ & $\begin{array}{l}-0.04 \\
(0.14)\end{array}$ & $\begin{array}{l}-0.17 \\
(0.12)\end{array}$ & $\begin{array}{c}0.00 \\
(0.17)\end{array}$ & $\begin{array}{l}-0.03 \\
(0.21)\end{array}$ & $\begin{array}{c}0.16 \\
(0.30)\end{array}$ & $\begin{array}{c}0.25 \\
(0.30)\end{array}$ \\
\hline Absolute Latitude & & $\begin{array}{c}0.02 \\
(0.12)\end{array}$ & $\begin{array}{l}-0.10 \\
(0.19)\end{array}$ & $\begin{array}{c}0.04 \\
(0.22)\end{array}$ & $\begin{array}{c}0.10 \\
(0.23)\end{array}$ & $\begin{array}{c}0.52 \\
(0.34)\end{array}$ & $\begin{array}{l}0.58^{*} \\
(0.33)\end{array}$ \\
\hline Elevation (Mean) & & $\begin{array}{l}-0.04 \\
(0.06)\end{array}$ & $\begin{array}{l}-0.06 \\
(0.07)\end{array}$ & $\begin{array}{c}0.03 \\
(0.09)\end{array}$ & $\begin{array}{c}0.00 \\
(0.11)\end{array}$ & $\begin{array}{c}0.10 \\
(0.16)\end{array}$ & $\begin{array}{c}0.07 \\
(0.15)\end{array}$ \\
\hline Land Suitability (Mean) & & & $\begin{array}{l}-0.09 \\
(0.10)\end{array}$ & $\begin{array}{l}-0.05 \\
(0.09)\end{array}$ & $\begin{array}{l}-0.12 \\
(0.08)\end{array}$ & $\begin{array}{l}-0.14 \\
(0.15)\end{array}$ & $\begin{array}{l}-0.21 \\
(0.14)\end{array}$ \\
\hline Neolithic Transition Timing & & & & $\begin{array}{l}-0.11 \\
(0.07)\end{array}$ & $\begin{array}{l}-0.10 \\
(0.08)\end{array}$ & $\begin{array}{l}-0.11 \\
(0.10)\end{array}$ & $\begin{array}{l}-0.14 \\
(0.10)\end{array}$ \\
\hline Region of Birth FE & Yes & Yes & Yes & Yes & Yes & Yes & Yes \\
\hline Additional Geographical Controls & No & No & Yes & Yes & Yes & Yes & Yes \\
\hline Wave FE & No & No & No & No & Yes & No & Yes \\
\hline Individual Controls & No & No & No & No & Yes & No & Yes \\
\hline Adjusted- $R^{2}$ & 0.02 & 0.02 & 0.01 & 0.01 & 0.08 & 0.04 & 0.07 \\
\hline Observations & 1328 & 1328 & 1328 & 1328 & 1171 & 1171 & 1171 \\
\hline
\end{tabular}

Notes: Using OLS regression, this table establishes that the preferred job characteristics of second generation migrants reflect loss aversion. In particular, their valuation of job security vs other characteristics (salary, short working hours, promotion opportunities and job satisfaction) and of job security vs. salary is negatively affected by temperature volatility (idiosyncratic risk) and positively affected by temperature spatial correlation (aggregate uncertainty) in the parental country of origin. Additional geographical controls are the gini index of land suitability, distance to coast or river, landlocked dummy, percentage of land in the tropical, subtropical and temperate zones and precipitation level. Individual controls include age, gender, number of siblings, religion, education level, and income. Sample excludes small island countries. All independent variables have been normalized by subtracting their mean and dividing by their standard deviation. Thus, all coefficients can be compared and show the effect of a one standard deviation in the independent variable on standard deviations in the dependent variable. Heteroskedasticity robust standard error estimates clustered at the parental country of origin level are reported in parentheses; *** denotes statistical significance at the $1 \%$ level, ${ }^{* *}$ at the $5 \%$ level, and ${ }^{*}$ at the $10 \%$ level, all for two-sided hypothesis tests.

statistically significant at the $1 \%$ level and imply that increasing intertemporal temperature volatility in the parental country of origin by one standard deviation decreases the difference in ranks of job security and salary between 0.52 and 0.62 units, while increasing temperature spatial correlation by one standard deviation increases the difference in ranks of job security and salary between 0.24 and 0.28 units. Reassuringly, confounding geographical characteristics of parental country of origin are less significant than the effects of temperature volatility and spatial correlation across all specifications and explained variables. In particular, most geographical characteristics have no significant effect on 
preferences of job security versus salary.

\subsection{Robustness}

\subsubsection{Alternative Estimation Method: Ordered Probit}

The results are robust to the use of an alternative estimation method, rather than OLS. In particular, using Ordered Probit, one can estimates the probability of observing each rank of preference for Job Security, conditional on intertemporal temperature volatility (idiosyncratic risk) as well as on temperature spatial correlation (aggregate uncertainty). In line with the OLS estimates, as established in Tables B.1 and B.2, and as interpreted and further discussed in Appendix A, larger temperature spatial correlation increases significantly the probability that second generation migrants in Europe, as well as in the US, will be more loss averse, whereas greater intertemporal temperature volatility decreases the probability that a second generation migrants in Europe and the US will be loss averse.

\subsubsection{Selection on Unobservables}

This subsection examines the likelihood that omitted variables could alter the qualitative findings. Table B.4 establishes that it is very improbable that omitted variables could have affected the qualitative results presented in Tables 2 and 3. In particular, as established in columns (2) and (4), (using columns (1) and (3) as the baseline specifications), the estimated value of the coefficient on intertemporal temperature volatility and temperature spatial correlation, if unobservables where as correlated as the observables (i.e., Oster's $\beta^{*}$ statistic), are very close to the estimated OLS coefficients. Furthermore, since zero does not belong to the interval created by the estimated value on and Oster's $\beta^{*}$, one can reject the hypothesis that the value of the coefficient is driven exclusively by unobservables. In addition, the indexes AET (Altonji et al., 2005; Bellows and Miguel, 2009) and $\delta$ (Oster, 2014) measure how strongly correlated unobservables would have to be in order to account for the full size of the coefficient on temperature volatility and spatial correlation ( $v$ and $c$ subscripts correspondingly), are mostly different from the critical value of 1 .

\subsubsection{Placebo Tests}

This section performs a series of placebo tests, analyzing the effect of intertemporal temperature volatility and temperature spatial correlation on the second-generation migrants' valuation of job character- 
Table 4: Determinants of Loss Aversion of Second Generation Migrants in the US and Europe: Placebo Tests

\begin{tabular}{|c|c|c|c|c|c|c|}
\hline & \multicolumn{3}{|c|}{ GSS } & \multicolumn{3}{|c|}{ ESS } \\
\hline & $(1)$ & $(2)$ & $(3)$ & $(4)$ & $(5)$ & $(6)$ \\
\hline \multirow[t]{2}{*}{ Temperature (Volatility) } & -0.081 & 0.126 & $0.177^{*}$ & -0.058 & 0.172 & 0.130 \\
\hline & $(0.123)$ & $(0.101)$ & $(0.090)$ & $(0.096)$ & $(0.115)$ & $(0.102)$ \\
\hline \multirow[t]{2}{*}{ Temperature (Spatial Correlation) } & -0.077 & -0.013 & 0.053 & 0.049 & -0.035 & 0.014 \\
\hline & $(0.089)$ & $(0.045)$ & $(0.040)$ & $(0.039)$ & $(0.035)$ & $(0.043)$ \\
\hline \multirow[t]{2}{*}{ Temperature (Mean) } & -0.219 & 0.052 & $0.477^{* * *}$ & 0.092 & 0.022 & 0.146 \\
\hline & $(0.201)$ & $(0.156)$ & $(0.130)$ & $(0.138)$ & $(0.156)$ & $(0.117)$ \\
\hline \multirow[t]{2}{*}{ Absolute Latitude } & -0.026 & -0.095 & $0.500^{* *}$ & 0.142 & -0.168 & 0.001 \\
\hline & $(0.278)$ & $(0.171)$ & $(0.184)$ & $(0.103)$ & $(0.129)$ & $(0.105)$ \\
\hline \multirow[t]{2}{*}{ Elevation (Mean) } & -0.167 & $0.206^{* *}$ & 0.022 & 0.031 & -0.024 & 0.013 \\
\hline & $(0.102)$ & $(0.077)$ & $(0.061)$ & $(0.038)$ & $(0.041)$ & $(0.035)$ \\
\hline \multirow[t]{2}{*}{ Land Suitability (Mean) } & -0.198 & -0.101 & $0.340^{* * *}$ & $0.096^{*}$ & -0.069 & 0.031 \\
\hline & $(0.137)$ & $(0.113)$ & $(0.059)$ & $(0.054)$ & $(0.080)$ & $(0.068)$ \\
\hline \multirow[t]{2}{*}{ Neolithic Transition Timing } & 0.052 & 0.052 & -0.048 & -0.012 & 0.016 & -0.001 \\
\hline & $(0.084)$ & $(0.072)$ & $(0.048)$ & $(0.031)$ & $(0.032)$ & $(0.028)$ \\
\hline Region/Country of Birth FE & Yes & Yes & Yes & Yes & Yes & Yes \\
\hline Additional Geographical Controls & Yes & Yes & Yes & Yes & Yes & Yes \\
\hline Wave/Round FE & Yes & Yes & Yes & Yes & Yes & Yes \\
\hline Individual Controls & Yes & Yes & Yes & Yes & Yes & Yes \\
\hline Adjusted- $R^{2}$ & 0.09 & 0.02 & 0.07 & 0.12 & 0.09 & 0.22 \\
\hline Observations & 1171 & 1171 & 1171 & 2397 & 2391 & 2391 \\
\hline
\end{tabular}

Notes: Using OLS regression, this table establishes that second generation migrants valuation of job characteristics that are orthogonal to loss aversion (i.e., short working hours in column 1 , job satisfaction in 2 , promotion opportunities in 3, training opportunities vs ability to use own initiative in 4, training opportunities vs salary in 5 and salary vs ability to use own initiative in 6) is neither affected by temperature volatility (idiosyncratic risk), nor by temperature spatial correlation (aggregate uncertainty) in the parental country of origin. Additional geographical controls are the gini index of land suitability, distance to coast or river, landlocked dummy, percentage of land in the tropical, subtropical and temperate zones and precipitation level. Individual controls include age, gender, number of siblings, religion, education level, and income. Sample excludes small island countries. All independent variables have been normalized by subtracting their mean and dividing by their standard deviation. Thus, all coefficients can be compared and show the effect of a one standard deviation in the independent variable on standard deviations in the dependent variable. Heteroskedasticity robust standard error estimates clustered at the parental country of origin level are reported in parentheses; *** denotes statistical significance at the $1 \%$ level, ** at the $5 \%$ level, and * at the $10 \%$ level, all for two-sided hypothesis tests.

istics that are orthogonal to the loss aversion. Table 4 establishes that preferences of second-generation migrants in the US for short working hours (Column 1), feeling of importance and accomplishment in a job (Column 2), and promotion opportunities (Column 3) are mostly unaffected by the intertemporal temperature volatility and temperature spatial correlation in the parental country of origin. ${ }^{14}$ In addition, the table indicates that the comparative valuations of second-generation migrants in Europe to training opportunities vs ability to use own initiative in a job (Column 4), training opportunities

\footnotetext{
${ }^{14}$ The marginally significant positive effect of temperature volatility on the rank of promotion opportunities in column 3 mechanically captures the negative effect on job security.
} 
vs salary (Column 5), and salary vs ability to use own initiative (Column 6) are orthogonal to the intertemporal temperature volatility and temperature spatial correlation in the parental country of origin.

\subsubsection{Orthogonality of the Climatic Variables to Other Cultural Dimensions}

This subsection establishes that the effects of intertemporal temperature volatility and temperature spatial correlation on Loss Aversion does not capture their effects on a wide range of other cultural characteristics.

Table 5: Orthogonality of other Cultural Dimensions to Idiosyncratic and Aggregate Uncertainty: Second Generation Migrants in Europe

\begin{tabular}{|c|c|c|c|c|c|c|c|}
\hline & \multicolumn{7}{|c|}{ Cultural Dimensions } \\
\hline & $(1)$ & (2) & (3) & $(4)$ & $(5)$ & $(6)$ & (7) \\
\hline & LTO & Obedience & Altruism & Equality & Gender & Strong Gov. & Tradition \\
\hline \multirow[t]{2}{*}{ Temperature (Volatility) } & 0.10 & -0.07 & -0.00 & -0.07 & -0.02 & 0.04 & -0.14 \\
\hline & $(0.32)$ & $(0.09)$ & $(0.07)$ & $(0.06)$ & $(0.10)$ & $(0.08)$ & $(0.10)$ \\
\hline \multirow[t]{2}{*}{ Temperature (Spatial Correlation) } & -0.03 & 0.05 & -0.02 & 0.04 & 0.02 & -0.01 & 0.01 \\
\hline & $(0.13)$ & $(0.03)$ & $(0.02)$ & $(0.03)$ & $(0.03)$ & $(0.03)$ & $(0.03)$ \\
\hline \multirow[t]{2}{*}{ Temperature (Mean) } & 0.25 & 0.01 & 0.11 & -0.03 & -0.18 & 0.09 & -0.10 \\
\hline & $(0.43)$ & $(0.13)$ & $(0.11)$ & $(0.09)$ & $(0.14)$ & $(0.11)$ & $(0.17)$ \\
\hline \multirow[t]{2}{*}{ Absolute Latitude } & -0.09 & -0.03 & $0.12^{* *}$ & $0.14^{* *}$ & -0.06 & $0.15^{*}$ & -0.02 \\
\hline & $(0.31)$ & $(0.09)$ & $(0.05)$ & $(0.06)$ & $(0.09)$ & $(0.08)$ & $(0.11)$ \\
\hline \multirow[t]{2}{*}{ Elevation (Mean) } & -0.04 & -0.03 & 0.03 & -0.00 & $-0.12^{* * *}$ & 0.03 & $-0.08^{* *}$ \\
\hline & $(0.15)$ & $(0.03)$ & $(0.02)$ & $(0.02)$ & $(0.04)$ & $(0.03)$ & $(0.03)$ \\
\hline \multirow[t]{2}{*}{ Land Suitability (Mean) } & -0.33 & -0.03 & 0.01 & -0.03 & -0.06 & $-0.13^{* * *}$ & 0.04 \\
\hline & $(0.24)$ & $(0.04)$ & $(0.04)$ & $(0.05)$ & $(0.05)$ & $(0.04)$ & $(0.05)$ \\
\hline \multirow[t]{2}{*}{ Neolithic Transition Timing } & 0.11 & -0.01 & -0.03 & -0.01 & 0.02 & -0.03 & $-0.09 * * *$ \\
\hline & $(0.14)$ & $(0.02)$ & $(0.02)$ & $(0.02)$ & $(0.03)$ & $(0.02)$ & $(0.03)$ \\
\hline Country of Birth FE & Yes & Yes & Yes & Yes & Yes & Yes & Yes \\
\hline Additional Geographical Controls & Yes & Yes & Yes & Yes & Yes & Yes & Yes \\
\hline Round FE & Yes & Yes & Yes & Yes & Yes & Yes & Yes \\
\hline Individual Controls & Yes & Yes & Yes & Yes & Yes & Yes & Yes \\
\hline Adjusted- $R^{2}$ & 0.07 & 0.13 & 0.07 & 0.05 & 0.15 & 0.15 & 0.19 \\
\hline Observations & 1416 & 5695 & 5718 & 5704 & 4401 & 5693 & 5712 \\
\hline
\end{tabular}

Notes: Using OLS regression, this table establishes that other cultural values of second generation migrants in Europe (i.e., long term orientation, obedience, altruism, attitude towards equality, gender roles, preference for strong government and tradition) are neither affected by temperature volatility (idiosyncratic risk) nor by temperature spatial correlation (aggregate uncertainty) in the parental country of origin. Additional geographical controls are the gini index of land suitability, distance to coast or river, landlocked dummy, percentage of land in the tropical, subtropical and temperate zones and precipitation level. Individual controls include age, gender, number of siblings, religion, education level, and income. Sample excludes small island countries. All independent variables have been normalized by subtracting their mean and dividing by their standard deviation. Thus, all coefficients can be compared and show the effect of a one standard deviation in the independent variable on standard deviations in the dependent variable. Heteroskedasticity robust standard error estimates clustered at the parental country of origin level are reported in parentheses; *** denotes statistical significance at the $1 \%$ level, ${ }^{* *}$ at the $5 \%$ level, and $*$ at the $10 \%$ level, all for two-sided hypothesis tests. 
In particular, as established in Tables 5 and 6, intertemporal temperature volatility and temperature spatial correlation in the parental country of origin do not affect long term orientation, obedience, altruism, and attitudes towards equality, gender roles, government and tradition among second-generation migrants in Europe and the US.

Table 6: Orthogonality of other Cultural Dimensions to Idiosyncratic and Aggregate Uncertainty: Second Generation Migrants in the US (OLS)

\begin{tabular}{|c|c|c|c|c|c|c|}
\hline & \multicolumn{6}{|c|}{ Cultural Dimensions } \\
\hline & $(1)$ & $(2)$ & (3) & $(4)$ & $(5)$ & $(6)$ \\
\hline & LTO & Obedience & Altruism & Equality & Gender & Government \\
\hline \multirow[t]{2}{*}{ Temperature (Volatility) } & 0.05 & 0.17 & 0.01 & 0.22 & -0.01 & -0.03 \\
\hline & $(0.03)$ & $(0.12)$ & $(0.08)$ & $(0.14)$ & $(0.02)$ & $(0.05)$ \\
\hline \multirow[t]{2}{*}{ Temperature (Spatial Correlation) } & -0.03 & -0.04 & -0.03 & -0.15 & -0.00 & 0.01 \\
\hline & $(0.02)$ & $(0.05)$ & $(0.02)$ & $(0.09)$ & $(0.01)$ & $(0.04)$ \\
\hline \multirow[t]{2}{*}{ Temperature (Mean) } & $-0.15^{*}$ & $0.47^{* * *}$ & -0.03 & -0.18 & 0.03 & -0.10 \\
\hline & $(0.07)$ & $(0.16)$ & $(0.18)$ & $(0.27)$ & $(0.04)$ & $(0.08)$ \\
\hline \multirow[t]{2}{*}{ Absolute Latitude } & -0.08 & $0.40^{* *}$ & 0.07 & -0.12 & 0.07 & -0.06 \\
\hline & $(0.07)$ & $(0.17)$ & $(0.21)$ & $(0.38)$ & $(0.05)$ & $(0.11)$ \\
\hline \multirow[t]{2}{*}{ Elevation (Mean) } & $0.07^{*}$ & $0.33^{* * *}$ & 0.03 & 0.03 & -0.01 & -0.03 \\
\hline & $(0.04)$ & $(0.10)$ & $(0.10)$ & $(0.12)$ & $(0.02)$ & $(0.03)$ \\
\hline \multirow[t]{2}{*}{ Land Suitability (Mean) } & 0.01 & -0.02 & $-0.09^{* *}$ & -0.11 & $0.10^{* * *}$ & $-0.12^{* *}$ \\
\hline & $(0.03)$ & $(0.13)$ & $(0.05)$ & $(0.17)$ & $(0.02)$ & $(0.05)$ \\
\hline \multirow[t]{2}{*}{ Neolithic Transition Timing } & 0.01 & $-0.24^{* * *}$ & 0.04 & 0.08 & $-0.04^{* * *}$ & $0.07^{* *}$ \\
\hline & $(0.03)$ & $(0.08)$ & $(0.10)$ & $(0.09)$ & $(0.01)$ & $(0.03)$ \\
\hline Region of Birth FE & Yes & Yes & Yes & Yes & Yes & Yes \\
\hline Additional Geographical Controls & Yes & Yes & Yes & Yes & Yes & Yes \\
\hline Wave FE & Yes & Yes & Yes & Yes & Yes & Yes \\
\hline Individual Controls & Yes & Yes & Yes & Yes & Yes & Yes \\
\hline Adjusted- $R^{2}$ & 0.08 & 0.15 & 0.02 & 0.06 & 0.11 & 0.04 \\
\hline Observations & 1269 & 1285 & 1287 & 1841 & 1444 & 2181 \\
\hline
\end{tabular}

Notes: Using OLS regression, this table establishes that other cultural values of second generation migrants in the US (i.e., long term orientation, obedience, altruism, attitude towards equality and gender roles, and confidence in government) are neither affected by temperature volatility (idiosyncratic risk) nor by temperature spatial correlation (aggregate uncertainty) in the parental country of origin. Additional geographical controls are the gini index of land suitability, distance to coast or river, landlocked dummy, percentage of land in the tropical, subtropical and temperate zones and precipitation level. Individual controls include age, gender, education level, religion, income and the number of siblings. Sample excludes small island countries. All independent variables have been normalized by subtracting their mean and dividing by their standard deviation. Thus, all coefficients can be compared and show the effect of a one standard deviation in the independent variable on standard deviations in the dependent variable. Heteroskedasticity robust standard error estimates clustered at the parental country of origin level are reported in parentheses; ${ }^{* * *}$ denotes statistical significance at the $1 \%$ level, ${ }^{* *}$ at the $5 \%$ level, and $*$ at the $10 \%$ level, all for two-sided hypothesis tests. 


\subsubsection{Loss Aversion vs. Risk Aversion}

This subsection establishes that intertemporal temperature volatility and temperature spatial correlation are not significantly associated with the attitude toward risk aversion rather than loss aversion. Furthermore, it demonstrates that the observed effects of climatic characteristics on loss aversion operate directly, rather than through their influence on risk aversion.

Table 7: Determinants of Risk Aversion: Second Generation Migrants in Europe

\begin{tabular}{|c|c|c|c|c|c|c|}
\hline & \multicolumn{6}{|c|}{ Importance of Adventure and Risk Seeking } \\
\hline & $(1)$ & $(2)$ & $(3)$ & $(4)$ & $(5)$ & (6) \\
\hline \multirow[t]{2}{*}{ Temperature (Volatility) } & -0.022 & -0.084 & -0.016 & -0.023 & -0.011 & -0.031 \\
\hline & $(0.103)$ & $(0.131)$ & $(0.122)$ & $(0.120)$ & $(0.119)$ & $(0.088)$ \\
\hline \multirow[t]{2}{*}{ Temperature (Spatial Correlation) } & -0.027 & -0.011 & 0.001 & -0.003 & -0.005 & -0.021 \\
\hline & $(0.042)$ & $(0.047)$ & $(0.045)$ & $(0.046)$ & $(0.046)$ & $(0.033)$ \\
\hline \multirow[t]{2}{*}{ Temperature (Mean) } & $-0.227^{* *}$ & -0.139 & -0.075 & -0.116 & -0.102 & 0.135 \\
\hline & $(0.091)$ & $(0.108)$ & $(0.147)$ & $(0.165)$ & $(0.163)$ & $(0.131)$ \\
\hline \multirow[t]{2}{*}{ Absolute Latitude } & & $0.136^{* *}$ & 0.046 & 0.015 & 0.009 & $0.170^{*}$ \\
\hline & & $(0.067)$ & $(0.120)$ & $(0.133)$ & $(0.130)$ & $(0.091)$ \\
\hline \multirow[t]{2}{*}{ Elevation (Mean) } & & 0.012 & 0.050 & 0.039 & 0.037 & $0.082^{* *}$ \\
\hline & & $(0.043)$ & $(0.048)$ & $(0.048)$ & $(0.048)$ & $(0.036)$ \\
\hline \multirow[t]{2}{*}{ Land Suitability (Mean) } & & & -0.022 & -0.036 & -0.033 & -0.034 \\
\hline & & & $(0.066)$ & $(0.070)$ & $(0.071)$ & $(0.052)$ \\
\hline \multirow[t]{2}{*}{ Neolithic Transition Timing } & & & & 0.024 & 0.022 & -0.033 \\
\hline & & & & $(0.038)$ & $(0.038)$ & $(0.028)$ \\
\hline Country of Birth FE & Yes & Yes & Yes & Yes & Yes & Yes \\
\hline Additional Geographical Controls & No & No & Yes & Yes & Yes & Yes \\
\hline Round FE & No & No & No & No & Yes & Yes \\
\hline Individual Controls & No & No & No & No & No & Yes \\
\hline Adjusted- $R^{2}$ & 0.03 & 0.04 & 0.04 & 0.04 & 0.04 & 0.15 \\
\hline Observations & 5699 & 5699 & 5699 & 5699 & 5699 & 5699 \\
\hline
\end{tabular}

Notes: Using OLS regressions, this table establishes that second generation migrants' valuation of Adventure and Risk Seeking is neither affected by temperature volatility (idiosyncratic risk), nor by temperature spatial correlation (aggregate uncertainty) in the parental country of origin. Additional geographical controls are the gini index of land suitability, distance to coast or river, landlocked dummy, percentage of land in the tropical, subtropical and temperate zones and precipitation level. Individual controls include age, gender, number of siblings, religion, education level, and income. Sample excludes small island countries. All independent variables have been normalized by subtracting their mean and dividing by their standard deviation. Thus, all coefficients can be compared and show the effect of a one standard deviation in the independent variable on standard deviations in the dependent variable. Heteroskedasticity robust standard error estimates clustered at the parental country of origin level are reported in parentheses; $* * *$ denotes statistical significance at the $1 \%$ level, ${ }^{* *}$ at the $5 \%$ level, and ${ }^{*}$ at the $10 \%$ level, all for two-sided hypothesis tests.

As established in Table 7, individuals' preference for adventure and risk seeking are not significantly associated with intertemporal temperature volatility and temperature spatial correlation. ${ }^{15}$ Moreover,

\footnotetext{
${ }^{15}$ Individuals attitude towards risk is captured by the response to the question: "Now I will briefly describe some
} 
as demonstrated in Table 8, the effect of intertemporal temperature volatility and temperature spatial correlation on the preference of second generation migrants in Europe for job security over salary, as estimated in Table 2, is unaffected by the highly significant positive association between the rates of risk aversion and the rate of loss aversion, lending credence to the hypothesis of that geographical origins of risk risk aversion are different than climatic origins of loss aversion.

Table 8: Determinants of Loss Aversion: Orthogonality of the Climatic Effects to Risk Aversion

\begin{tabular}{|c|c|c|c|c|c|c|}
\hline & \multicolumn{6}{|c|}{ Preferred Job Characteristic: Security vs. Salary } \\
\hline & $(1)$ & $(2)$ & $(3)$ & $(4)$ & $(5)$ & $(6)$ \\
\hline Temperature (Volatility) & $\begin{array}{c}-0.156^{* * *} \\
(0.049)\end{array}$ & $\begin{array}{c}-0.214^{* * *} \\
(0.051)\end{array}$ & $\begin{array}{c}-0.212^{* * *} \\
(0.067)\end{array}$ & $\begin{array}{c}-0.218^{* * *} \\
(0.068)\end{array}$ & $\begin{array}{c}-0.226^{* * *} \\
(0.067)\end{array}$ & $\begin{array}{c}-0.220 * * * \\
(0.066)\end{array}$ \\
\hline Temperature (Spatial Correlation) & $\begin{array}{c}0.038^{*} \\
(0.020)\end{array}$ & $\begin{array}{c}0.054^{* *} \\
(0.021)\end{array}$ & $\begin{array}{c}0.061^{* * *} \\
(0.022)\end{array}$ & $\begin{array}{c}0.059^{* * *} \\
(0.021)\end{array}$ & $\begin{array}{c}0.060^{* * *} \\
(0.021)\end{array}$ & $\begin{array}{c}0.060^{* * *} \\
(0.021)\end{array}$ \\
\hline Risk Aversion & $\begin{array}{c}0.058^{* * *} \\
(0.011)\end{array}$ & $\begin{array}{c}0.058 * * * \\
(0.011)\end{array}$ & $\begin{array}{c}0.057^{* * *} \\
(0.011)\end{array}$ & $\begin{array}{c}0.057^{* * *} \\
(0.011)\end{array}$ & $\begin{array}{c}0.058^{* * *} \\
(0.011)\end{array}$ & $\begin{array}{c}0.051^{* * *} \\
(0.010)\end{array}$ \\
\hline Temperature (Mean) & $\begin{array}{c}-0.126^{* * *} \\
(0.047)\end{array}$ & $\begin{array}{l}-0.086 \\
(0.053)\end{array}$ & $\begin{array}{l}-0.080 \\
(0.101)\end{array}$ & $\begin{array}{l}-0.113 \\
(0.101)\end{array}$ & $\begin{array}{l}-0.120 \\
(0.098)\end{array}$ & $\begin{array}{l}-0.082 \\
(0.098)\end{array}$ \\
\hline Absolute Latitude & & $\begin{array}{c}0.084^{* *} \\
(0.033)\end{array}$ & $\begin{array}{c}0.128 * * \\
(0.062)\end{array}$ & $\begin{array}{c}0.103 \\
(0.063)\end{array}$ & $\begin{array}{l}0.107^{*} \\
(0.063)\end{array}$ & $\begin{array}{c}0.139 * * \\
(0.065)\end{array}$ \\
\hline Elevation (Mean) & & $\begin{array}{l}-0.002 \\
(0.017)\end{array}$ & $\begin{array}{c}0.010 \\
(0.022)\end{array}$ & $\begin{array}{c}0.002 \\
(0.024)\end{array}$ & $\begin{array}{c}0.004 \\
(0.024)\end{array}$ & $\begin{array}{c}0.009 \\
(0.024)\end{array}$ \\
\hline Land Suitability (Mean) & & & $\begin{array}{c}0.032 \\
(0.044)\end{array}$ & $\begin{array}{c}0.022 \\
(0.048)\end{array}$ & $\begin{array}{c}0.020 \\
(0.048)\end{array}$ & $\begin{array}{c}0.020 \\
(0.048)\end{array}$ \\
\hline Neolithic Transition Timing & & & & $\begin{array}{c}0.018 \\
(0.017)\end{array}$ & $\begin{array}{c}0.019 \\
(0.017)\end{array}$ & $\begin{array}{c}0.011 \\
(0.017)\end{array}$ \\
\hline Country of Birth FE & Yes & Yes & Yes & Yes & Yes & Yes \\
\hline Additional Geographical Controls & No & No & Yes & Yes & Yes & Yes \\
\hline Round FE & No & No & No & No & Yes & Yes \\
\hline Individual Controls & No & No & No & No & No & Yes \\
\hline Adjusted- $R^{2}$ & 0.06 & 0.06 & 0.06 & 0.06 & 0.07 & 0.07 \\
\hline Observations & 3784 & 3784 & 3784 & 3784 & 3784 & 3784 \\
\hline
\end{tabular}

Notes: Using OLS regressions, this table establishes that second generation migrants' valuation of job security vs. salary is positively affected by the degree of risk aversion and is still negatively affected by temperature volatility (idiosyncratic risk) and positively affected by temperature spatial correlation (aggregate uncertainty) in the parental country of origin. Additional geographical controls are the gini index of land suitability, distance to coast or river, landlocked dummy, percentage of land in the tropical, subtropical and temperate zones and precipitation level. Individual controls include age, gender, number of siblings, religion, education level, and income. Sample excludes small island countries. All independent variables have been normalized by subtracting their mean and dividing by their standard deviation. Thus, all coefficients can be compared and show the effect of a one standard deviation in the independent variable on standard deviations in the dependent variable. Heteroskedasticity robust standard error estimates clustered at the parental country of origin level are reported in parentheses; *** denotes statistical significance at the $1 \%$ level, ** at the $5 \%$ level, and * at the $10 \%$ level, all for two-sided hypothesis tests.

people. Please listen to each description and tell me how much each person is or is not like you. Use this card for your answer. She/he looks for adventures and likes to take risks. She/he wants to have an exciting life." 


\subsubsection{The Insignificant Role of Preindustrial Development}

In light of the adverse effect of climatic volatility on pre-industrial development, as capture by urbanization and population density in the year 1500 (Table 1), one may be concerned about the possibility that climatic conditions affected the loss aversion via non-evolutionary channels. In particular, preindustrial development and its potential effect on contemporary economic, institutional and cultural characteristics may have directly affected the observed rate loss aversion rather than via the proposed evolutionary channel.

The chosen empirical framework, however, mitigates these concerns since the analysis is based on: (i) individual level data, accounting in particular, for income and education, and (ii) second generation migrant that are arguably operating within the same institutional and cultural environment. Moreover, as reported in columns (1)-(3) of Table B.5 for the ESS, and (4)-(6) for the GSS, the effect of the climatic variables on loss aversion is orthogonal to the potentially confounding effect of historical levels of population density in 1500 , urbanization in 1800, and GDP per capita in $1913 .{ }^{16}$

\subsubsection{Insignificant Role of Outliers}

This subsection examines the potential importance of outliers in the established relationship between intertemporal temperature volatility and temperature spatial correlation and the emergence of loss aversion. As depicted in Figure B.1 outliers do not governed the observed relationship in the ESS, whereas Figures B.2 suggests that outliers, associated with individuals from the Netherlands, may affect the observed relationship in the GSS. Nevertheless, as established in Table B.6 the results remain qualitatively intact if individuals from the Netherlands are excluded from the sample.

\section{Individuals Level Analysis (WVS)}

This section uses the World Values Survey (WVS) to analyze the effect of intertemporal temperature volatility and spatial correlation on individuals' preferences for job security over other characteristics (salary, colleagues, job satisfaction), in light of the conjectured positive association between loss aversion and preference for job security over salary and other characteristics. The effects of temperature volatility and correlation are estimated using the linear probability model via the following empirical

\footnotetext{
${ }^{16} 1913$ is the earliest date for which data on GDP per capita is available for a considerable number of countries.
} 
specification:

$$
\begin{aligned}
j o b_{i c w}^{\text {sec }} & =\beta_{0}+\beta_{1}^{\text {vol }} \text { temp }_{c}^{\text {vol }}+\beta_{1}^{c o r r} \operatorname{temp}_{c}^{c o r r}+\sum_{j} \gamma_{0 j} X_{c j} \\
& +\gamma_{1} y s t_{c}+\sum_{j} \gamma_{2 j} Z_{i c j}+\sum_{c w} \gamma_{c w} \delta_{c w}+\epsilon_{i c w}
\end{aligned}
$$

where $j o b_{i c w}^{s e c} \in\{0 ; 1\}$ is the valuation of job security over other job characteristics ${ }^{17}$ of individual $i$ in country $c$ measured in wave $w, t e m p_{c}^{v o l}$ and $t e m p_{c}^{c o r r}$ are measured in the country $c, X_{c j}$ is geographical characteristic $j$ (absolute latitude, mean elevation, mean temperature, mean level and the gini index of land suitability, distance to coast or river, landlocked dummy, percentage of land in the tropical, subtropical and temperate zones and precipitation level) of the country $c, y_{s} t_{c}$ are the years since the country $c$ transitioned to agriculture, $Z_{i c j}$ is characteristic $j$ of individual $i$ (age, gender, number of siblings, religion, education level, income) in country $c, \delta_{c w}$ is a complete set of world bank regions and wave fixed effects and $\epsilon_{i c w}$ is the error term. The theory predicts negative effect of temperature volatility and positive effect of temperature spatial correlation (i.e., $\beta_{1}^{\text {vol }}<0$ and $\beta_{1}^{\text {corr }}>0$ ).

Table 9 establishes a negative statistically and economically significant effect of temperature volatility and positive significant effect of temperature spatial correlation on individuals' preferences of job security versus other characteristics. The result is robust to the inclusion of world bank regional fixed effects (column 1), geographical controls (columns 2 and 3), wave fixed effects (column 4), the number of years since transition to agriculture (column 5) and individual characteristics (column 6). The estimated effects suggest that increasing intertemporal temperature volatility by one standard deviation decreases the probability of preferring job security to other characteristics by between 6.3 and 3.1 percentage points, while one standard-deviation increase in temperature spatial correlation increases this probability by between 1.3 and 2 percentage points.

Moreover, result remains qualitatively the same after accounting for the ancestral composition of the contemporary population (column 7 ). In particular, both effects remain significant at the $1 \%$ level and imply that one standard-deviation increase in temperature volatility decreases the probability

\footnotetext{
${ }^{17}$ The preferences of job security versus other characteristics is measured based on the answer to the question "Now I would like to ask you something about the things which would seem to you, personally, most important if you were looking for a job. Here are some of the things many people take into account in relation to their work. Regardless of whether you're actually looking for a job, which one would you, personally, place first if you were looking for a job?", the variable is coded 1 if the answer is "A safe job with no risk of closing down or unemployment" and 0 otherwise
} 
Table 9: Determinants of Loss Aversion: Individuals in the WVS

\begin{tabular}{|c|c|c|c|c|c|c|c|}
\hline & \multicolumn{7}{|c|}{ Preferred Job Characteristic: Security vs Others } \\
\hline & $(1)$ & $(2)$ & $(3)$ & $(4)$ & $(5)$ & $(6)$ & $(7)$ \\
\hline Temperature (Volatility) & $\begin{array}{c}-0.060^{* * *} \\
(0.006)\end{array}$ & $\begin{array}{c}-0.063^{* * *} \\
(0.006)\end{array}$ & $\begin{array}{c}-0.049^{* * *} \\
(0.007)\end{array}$ & $\begin{array}{c}-0.031^{* * *} \\
(0.008)\end{array}$ & $\begin{array}{c}-0.031^{* * *} \\
(0.008)\end{array}$ & $\begin{array}{c}-0.031^{* * *} \\
(0.008)\end{array}$ & \\
\hline Temperature (Spatial Correlation) & $\begin{array}{c}0.013^{* * *} \\
(0.004)\end{array}$ & $\begin{array}{c}0.014^{* * *} \\
(0.004)\end{array}$ & $\begin{array}{c}0.016^{* * *} \\
(0.004)\end{array}$ & $\begin{array}{c}0.021^{* * *} \\
(0.004)\end{array}$ & $\begin{array}{c}0.020 * * * \\
(0.004)\end{array}$ & $\begin{array}{c}0.017^{* * *} \\
(0.004)\end{array}$ & \\
\hline Temperature (Volatility, Ancestral) & & & & & & & $\begin{array}{c}-0.023^{* * *} \\
(0.007)\end{array}$ \\
\hline Temp (Spatial Correlation, Ancestral) & & & & & & & $\begin{array}{c}0.010^{* * *} \\
(0.004)\end{array}$ \\
\hline Temperature (Mean) & $\begin{array}{c}-0.016^{* * *} \\
(0.005)\end{array}$ & $\begin{array}{l}-0.010 \\
(0.007)\end{array}$ & $\begin{array}{c}0.008 \\
(0.009)\end{array}$ & $\begin{array}{c}0.043^{* * *} \\
(0.010)\end{array}$ & $\begin{array}{c}0.050^{* * *} \\
(0.010)\end{array}$ & $\begin{array}{c}0.046^{* * *} \\
(0.010)\end{array}$ & $\begin{array}{c}0.047^{* * *} \\
(0.010)\end{array}$ \\
\hline Absolute Latitude & & $\begin{array}{c}0.010 \\
(0.007)\end{array}$ & $\begin{array}{c}0.011 \\
(0.010)\end{array}$ & $\begin{array}{c}0.041^{* * *} \\
(0.011)\end{array}$ & $\begin{array}{c}0.074^{* * *} \\
(0.012)\end{array}$ & $\begin{array}{c}0.069^{* * *} \\
(0.011)\end{array}$ & $\begin{array}{c}0.059^{* * *} \\
(0.011)\end{array}$ \\
\hline Elevation (Mean) & $\begin{array}{c}-0.023^{* * *} \\
(0.003)\end{array}$ & $\begin{array}{c}-0.021^{* * *} \\
(0.003)\end{array}$ & $\begin{array}{c}0.013^{* * *} \\
(0.004)\end{array}$ & $\begin{array}{c}0.024^{* * *} \\
(0.005)\end{array}$ & $\begin{array}{c}0.014^{* * *} \\
(0.004)\end{array}$ & $\begin{array}{c}0.010^{* *} \\
(0.004)\end{array}$ & $\begin{array}{c}0.009^{*} \\
(0.005)\end{array}$ \\
\hline Land Suitability (Mean) & & & $\begin{array}{c}0.028^{* * *} \\
(0.005)\end{array}$ & $\begin{array}{c}0.042^{* * *} \\
(0.005)\end{array}$ & $\begin{array}{c}0.018^{* * *} \\
(0.005)\end{array}$ & $\begin{array}{c}0.017^{* * *} \\
(0.005)\end{array}$ & $\begin{array}{c}0.017^{* * *} \\
(0.005)\end{array}$ \\
\hline Neolithic Transition Timing & & & & & $\begin{array}{c}0.061^{* * *} \\
(0.005)\end{array}$ & $\begin{array}{c}0.058^{* * *} \\
(0.005)\end{array}$ & $\begin{array}{c}0.055^{* * *} \\
(0.005)\end{array}$ \\
\hline Region of Birth FE & Yes & Yes & Yes & Yes & Yes & Yes & Yes \\
\hline Additional Geographical Controls & No & No & Yes & Yes & Yes & Yes & Yes \\
\hline Wave FE & No & No & No & Yes & Yes & Yes & Yes \\
\hline Individual Controls & No & No & No & No & No & Yes & Yes \\
\hline Adjusted- $R^{2}$ & 0.02 & 0.02 & 0.03 & 0.03 & 0.03 & 0.04 & 0.04 \\
\hline Observations & 130933 & 130933 & 130933 & 130933 & 130933 & 130933 & 130933 \\
\hline
\end{tabular}

Notes: Using OLS regression, this table establishes that individuals' valuation of job security vs other job characteristics (i.e., salary, colleagues, job satisfaction) is negatively affected by temperature volatility (idiosyncratic risk) and positively affected by temperature spatial correlation (aggregate uncertainty) in the country of birth. Additional geographical controls are the gini index of land suitability, distance to coast or river, landlocked dummy, percentage of land in the tropical, subtropical and temperate zones and precipitation level. Individual controls include age, gender, religion, education level, and income. Sample excludes small island countries. All independent variables have been normalized by subtracting their mean and dividing by their standard deviation. Thus, all coefficients can be compared and show the effect of a one standard deviation in the independent variable on standard deviations in the dependent variable. Heteroskedasticity robust clustered standard error estimates are reported in parentheses; clustering at the region of interview and individual characteristics level; ${ }^{* * *}$ denotes statistical significance at the $1 \%$ level, ${ }^{* *}$ at the $5 \%$ level, and ${ }^{*}$ at the $10 \%$ level, all for two-sided hypothesis tests.

of job security being the most preferred job characteristic by 2.3 percentage points, while increasing temperature spatial correlation by one standard deviation increases it by 1 percentage point.

\subsection{Robustness}

\subsubsection{Alternative Estimation Method: Probit}

The results are robust to the use of an alternative estimation method, rather than OLS. In particular, using Probit, one can estimates the probability of observing preference for Job Security vs other job 
characteristics, conditional on intertemporal temperature volatility (idiosyncratic risk) as well as on temperature spatial correlation (aggregate uncertainty). In line with the OLS estimates, as established in Tables 9, larger temperature spatial correlation increases significantly the probability that second generation migrants in Europe, as well as in the US, will be more loss averse, whereas greater intertemporal temperature volatility decreases the probability that a second generation migrants in Europe and the US will be loss averse.

\subsubsection{Selection on Unobservables}

This subsection examines the likelihood that omitted variables could alter the qualitative findings. Table B.4 establishes that it is very improbable that omitted variables could have affected the qualitative results presented in Tables 2 and 3. In particular, as established in Column (6), (using Columns (5) as the baseline specifications), the estimated value of the coefficient on intertemporal temperature volatility and temperature spatial correlation, if unobservables where as correlated as the observables (i.e., Oster's $\beta^{*}$ statistic), are very close to the estimated OLS coefficients. Furthermore, since zero does not belong to the interval created by the estimated value on and Oster's $\beta^{*}$, one can reject the hypothesis that the value of the coefficient is driven exclusively by unobservables. In addition, the indexes AET (Altonji et al., 2005; Bellows and Miguel, 2009) and $\delta$ (Oster, 2014) measure how strongly correlated unobservables would have to be in order to account for the full size of the coefficient on temperature volatility and spatial correlation ( $v$ and $c$ subscripts correspondingly), are mostly different from the critical value of 1 .

\subsubsection{The Insignificant Role of Preindustrial Development}

In light of the adverse effect of climatic volatility on pre-industrial development, as capture by urbanization and population density in the year 1500 (Table 1), one may be concerned about the possibility that climatic conditions affected the loss aversion via non-evolutionary channels. In particular, preindustrial development and its potential effect on contemporary economic, institutional and cultural characteristics may have directly affected the observed rate loss aversion rather than via the proposed evolutionary channel.

The chosen empirical framework, however, mitigates these concerns since the analysis is based on individual level data, accounting in particular, for income and education. Moreover, as reported in 
columns (7)-(9) of Table B.5, the effect of the climatic variables on loss aversion is orthogonal to the potentially confounding effect of historical levels of population density in 1500, urbanization in 1800 , and GDP per capita in $1913 .^{18}$

However, the chosen empirical framework mitigates these concerns since the analysis uses individual level data, accounting in particular, for income and education, Moreover, columns (7)-(9) in Table B.X establish that the effect of the climatic variables on loss aversion is orthogonal to the potentially confounding effect of historical levels of population density, urbanization, and GDP per capita.

\section{Ethnic Group Level Analysis}

\subsection{Determinants of Loss Aversion}

This section analyzes the determinants of loss aversion across ethnic groups. Variations in the prevalence and the distribution of loss-aversion across ethnic groups are captured by a variety of newly introduced measures of the intensity of loss aversion. In particular, it analyzes the effect of intertemporal temperature volatility and temperature spatial correlation on the type of games played in the ethnic group as reported by the Ethnographic Atlas (EA), as well as on the sleeping proximity of parents to infant as reported by the (SCCS). The effect of intertemporal temperature volatility and temperature spatial correlation on loss aversion, as captured by this measures of cautiousness, is estimated via ordinary least squares (OLS) using the following specification:

$$
\begin{aligned}
L A_{e r} & =\beta_{0}+\beta_{1}^{v o l} \text { temp } p_{e}^{\text {vol }}+\beta_{1}^{\text {corr }} \text { temp } p_{e}^{\text {corr }}+\sum_{j} \gamma_{0 j} X_{e j} \\
& +\sum_{j} \gamma_{1 j} E_{e j}+\sum_{r} \gamma_{r} \delta_{r}+\epsilon_{e}
\end{aligned}
$$

where $L A_{e r}$ is the preference for loss aversion in ethnic group $e$ in region $r$, temp $p_{e}^{v o l}$ and $t e m p_{e}^{\text {corr }}$ are measured on the level of the ethnic group $e, X_{e j}$ is geographical characteristic $j$ (absolute latitude, mean elevation, mean temperature, mean land suitability and its standard deviation, distance to coast or river and precipitation level), measured on the ethnic level of group $e, E_{e j}$ is ethnographic characteristic $j$ of group $e$ (intensity of agriculture and animal husbandry, settlement structure and

\footnotetext{
${ }^{18} 1913$ is the earliest date for which data on GDP per capita is available for a considerable number of countries.
} 
plow use), $\delta_{r}$ is a set of regional fixed effects for Americas, Old World and Africa, and $\epsilon_{e}$ is the error term. The theory predicts negative effect of temperature volatility and positive effect of temperature spatial correlation (i.e., $\beta_{1}^{\text {vol }}<0$ and $\beta_{1}^{\text {corr }}>0$ ).

Table 10: Determinants of Loss Aversion across Ethnic Groups

\begin{tabular}{|c|c|c|c|c|c|c|}
\hline & \multicolumn{6}{|c|}{ Preferences for Cautiousness } \\
\hline & \multicolumn{5}{|c|}{ Ethnographic Atlas } & \multirow{2}{*}{$\frac{\text { SCCS }}{(6)}$} \\
\hline & $(1)$ & $(2)$ & $(3)$ & $(4)$ & $(5)$ & \\
\hline Temperature (Volatility) & $\begin{array}{c}-0.15^{* * *} \\
(0.02)\end{array}$ & $\begin{array}{c}-0.12^{* * *} \\
(0.02)\end{array}$ & $\begin{array}{c}-0.07^{* * *} \\
(0.02)\end{array}$ & $\begin{array}{c}-0.10^{* * *} \\
(0.03)\end{array}$ & $\begin{array}{c}-0.08^{* * *} \\
(0.03)\end{array}$ & $\begin{array}{c}-0.76^{* * *} \\
(0.26)\end{array}$ \\
\hline Temperature (Spatial Correlation) & $\begin{array}{c}0.07^{* * *} \\
(0.03)\end{array}$ & $\begin{array}{c}0.07 * * * \\
(0.02)\end{array}$ & $\begin{array}{c}0.07 * * * \\
(0.02)\end{array}$ & $\begin{array}{c}0.07^{* * *} \\
(0.02)\end{array}$ & $\begin{array}{c}0.05^{* *} \\
(0.02)\end{array}$ & $\begin{array}{c}0.65^{* * *} \\
(0.24)\end{array}$ \\
\hline Temperature (Mean) & $\begin{array}{c}0.01 \\
(0.02)\end{array}$ & $\begin{array}{l}-0.00 \\
(0.02)\end{array}$ & $\begin{array}{c}-0.07^{* * *} \\
(0.03)\end{array}$ & $\begin{array}{c}-0.05^{*} \\
(0.03)\end{array}$ & $\begin{array}{l}-0.02 \\
(0.02)\end{array}$ & $\begin{array}{l}-0.08 \\
(0.25)\end{array}$ \\
\hline Absolute Latitude & & & $\begin{array}{c}-0.12^{* * *} \\
(0.03)\end{array}$ & $\begin{array}{c}-0.07^{* *} \\
(0.04)\end{array}$ & $\begin{array}{l}-0.03 \\
(0.04)\end{array}$ & $\begin{array}{c}0.52 \\
(0.34)\end{array}$ \\
\hline Elevation (Mean) & & & $\begin{array}{c}-0.04^{* *} \\
(0.02)\end{array}$ & $\begin{array}{c}-0.01 \\
(0.03)\end{array}$ & $\begin{array}{l}-0.00 \\
(0.03)\end{array}$ & $\begin{array}{c}-0.63^{* *} \\
(0.27)\end{array}$ \\
\hline Land Suitability (Mean) & & & & $\begin{array}{c}-0.04^{*} \\
(0.02)\end{array}$ & $\begin{array}{l}-0.02 \\
(0.02)\end{array}$ & $\begin{array}{c}0.26 \\
(0.20)\end{array}$ \\
\hline Ethnographic Controls & No & Yes & Yes & Yes & Yes & Yes \\
\hline Additional Geographical Controls & No & No & No & Yes & Yes & Yes \\
\hline Region FE & No & No & No & No & Yes & Yes \\
\hline Adjusted- $R^{2}$ & 0.28 & 0.40 & 0.41 & 0.42 & 0.47 & 0.14 \\
\hline Observations & 471 & 471 & 471 & 471 & 471 & 123 \\
\hline
\end{tabular}

Using OLS regression, this table establishes based on the Ethnographic Atlas and the SCCS that preferences for loss aversion is negatively affected by temperature volatility (idiosyncratic risk) and positively affected by temperature spatial correlation (aggregate uncertainty) in the region. Column 1-5 focus on preference for strategy over luck in games based on v35 in the Ethnographic Atlas, and column 6 on preference for Sleeping Proximity of Parents to Infant (v23) in the SSCS. Additional geographical controls are standard deviation of land suitability, distance to coast or river, and the level of precipitation. Ethnographic controls include intensity of agriculture and animal husbandry, settlement structure, and plow use. Region fixed effects include dummy variables for Americas, Old World and Africa that may govern the characteristics of ethnic groups. All independent variables have been normalized by subtracting their mean and dividing by their standard deviation. Thus, all coefficients can be compared and show the effect of a one standard deviation in the independent variable on standard deviations in the dependent variable. Heteroskedasticity robust standard error estimates clustered at the parental country of origin level are reported in parentheses; *** denotes statistical significance at the $1 \%$ level, ${ }^{* *}$ at the $5 \%$ level, and * at the $10 \%$ level, all for two-sided hypothesis tests.

Table 10 establishes a negative statistically and economically significant effect of temperature volatility and positive significant effect of temperature spatial correlation on preference for cautiousness at the ethnic group level. The result, based on the EA, is robust for the inclusion of ethnographic controls (Column 2), additional geographical controls (Columns 3 and 4) and region fixed effects (Column 5). These results are remarkably stable and remain significant on the 1\%- and 5\%-level across specifications. 
In addition, results based on the SCCS data are qualitatively the same. In particular, Column 6 replicates specification of Column 5 for SCCS data and establishes negative significant effect of temperature volatility and positive significant effect of temperature spatial correlation on preference for cautiousness, as captured by the sleeping proximity of parents to infant reported in SCCS.

\subsection{Robustness}

\subsubsection{Selection on Unobservables}

This subsection examines the likelihood that omitted variables could alter the qualitative findings. Table B.4 establishes that it is very improbable that omitted variables could have affected the qualitative results presented in Tables 2 and 3. In particular, as established in column (8), (using columns (7) as the baseline specifications), the estimated value of the coefficient on intertemporal temperature volatility and temperature spatial correlation, if unobservables where as correlated as the observables (i.e., Oster's $\beta^{*}$ statistic), are very close to the estimated OLS coefficients. Furthermore, since zero does not belong to the interval created by the estimated value on and Oster's $\beta^{*}$, one can reject the hypothesis that the value of the coefficient is driven exclusively by unobservables. In addition, the indexes AET (Altonji et al., 2005; Bellows and Miguel, 2009) and $\delta$ (Oster, 2014) measure how strongly correlated unobservables would have to be in order to account for the full size of the coefficient on temperature volatility and spatial correlation ( $v$ and $c$ subscripts correspondingly), are different from the critical value of 1 .

\subsubsection{Placebo Tests}

This section establishes that the relationship between intertemporal temperature volatility and spatial correlation in temperature and the proposed proxies of loss aversion are unique to ethnographic characteristics that reflect cautiousness about losses, rather than a broader spectrum of ethnographic traits. A wide spectrum of placebo tests demonstrates that indeed intertemporal temperature volatility and spatial correlation in temperature do not affect other cultural characteristics at the ethnic group level.

In particular, as established in Table 11, ethnographic characteristics such as sex taboos, group's political integration, inheritance property rights, gender roles in agriculture, attitude towards premarital sex, and belief in the evil eye are affected neither by intertemporal temperature volatility nor by the temperature spatial correlation, lending further credence to the proposed hypothesis. 
Table 11: Determinants of Loss Aversion across Ethnic Groups: Placebo Tests

\begin{tabular}{lcccccc}
\hline \hline & $(1)$ & $(2)$ & $(3)$ & $(4)$ & $(5)$ & $(6)$ \\
& Sex & Political & Property & Gender & Premarital & Evil Eye \\
& Taboos & Integration & Rights & Roles & Sex & Belief \\
\hline Temperature (Volatility) & 0.12 & 0.07 & 0.01 & -0.05 & 0.21 & -0.00 \\
& $(0.15)$ & $(0.13)$ & $(0.02)$ & $(0.04)$ & $(0.15)$ & $(0.06)$ \\
Temperature (Spatial Correlation) & 0.04 & -0.12 & -0.01 & 0.02 & -0.15 & -0.01 \\
& $(0.12)$ & $(0.13)$ & $(0.02)$ & $(0.04)$ & $(0.14)$ & $(0.05)$ \\
Temperature (Mean) & 0.06 & $0.21^{* *}$ & 0.01 & $-0.08^{* *}$ & $-0.30^{* *}$ & $0.07^{*}$ \\
& $(0.19)$ & $(0.09)$ & $(0.03)$ & $(0.03)$ & $(0.14)$ & $(0.04)$ \\
Absolute Latitude & -0.05 & $0.41^{* *}$ & 0.03 & 0.02 & $-0.37^{* *}$ & 0.11 \\
Elevation (Mean) & $(0.23)$ & $(0.17)$ & $(0.03)$ & $(0.05)$ & $(0.18)$ & $(0.08)$ \\
& 0.13 & $-0.37^{* * *}$ & $0.06^{* *}$ & -0.05 & -0.14 & $0.13^{* *}$ \\
Land Suitability (Mean) & $(0.15)$ & $(0.13)$ & $(0.02)$ & $(0.03)$ & $(0.12)$ & $(0.06)$ \\
& 0.04 & 0.12 & -0.01 & -0.01 & -0.08 & 0.06 \\
& $(0.10)$ & $(0.10)$ & $(0.02)$ & $(0.03)$ & $(0.10)$ & $(0.04)$ \\
\hline Ethnographic Controls & Yes & Yes & Yes & Yes & Yes & Yes \\
Additional Geographical Controls & Yes & Yes & Yes & Yes & Yes & Yes \\
Region FE & Yes & Yes & Yes & Yes & Yes & Yes \\
Adjusted- $R^{2}$ & 0.19 & 0.41 & 0.60 & 0.04 & 0.07 & 0.23 \\
\hline
\end{tabular}

Notes: Using OLS regression, this table establishes that behavioral characteristics that are orthogonal to loss aversion (i.e., severity of post-partum sex taboos, level of political integration, presence of property rights, presence of distinct gender roles in agriculture, norms of premarital sexual behavior and presence of evil eye belief) are neither affected by temperature volatility (idiosyncratic risk), nor by temperature spatial correlation (aggregate uncertainty) in the parental country of origin. Additional geographical controls are land suitability standard deviation, distance to coast or river and precipitation level. Ethnographic controls include intensity of agriculture and animal husbandry, settlement structure and plow use. Region fixed effects include dummy variables for Americas, Old World and Africa that may govern the characteristics of ethnic groups. All independent variables have been normalized by subtracting their mean and dividing by their standard deviation. Thus, all coefficients can be compared and show the effect of a one standard deviation in the independent variable on standard deviations in the dependent variable. Heteroskedasticity robust standard error estimates clustered at the parental country of origin level are reported in parentheses; *** denotes statistical significance at the $1 \%$ level, ${ }^{* *}$ at the $5 \%$ level, and ${ }^{*}$ at the $10 \%$ level, all for two-sided hypothesis tests.

\section{Concluding Remarks}

This research explores the origins of loss aversion and the variation in the prevalence of this important traits across regions, nations, and ethnic groups. It advances the hypothesis and establishes empirically that the evolution of loss aversion in the course of human history can be traced to the adaptation of individuals to the asymmetric effects of climatic shocks on reproductive success during the Malthusian epoch; an era in which adverse climatic conditions could have brought individuals to extinction.

The study develops an evolutionary theory that captures the fundamental asymmetry that the Malthusian environment has generated with respect to the attitude of individuals towards gains and loses in productivity, and thus with respect to the evolution of loss aversion. 
Exploiting variations in the degree of loss aversion among second generation migrants in Europe and the US, as well as across precolonial ethnic groups, the research establishes that consistent with the predictions of the theory, individuals and ethnic groups that are originated in regions in which climatic conditions tended to be spatially correlated, and thus shocks were aggregate in nature, are characterized by greater intensity of loss aversion, while descendants of regions marked by climatic volatility have greater propensity towards loss-neutrality. 


\section{Appendix (Supplementary Online Material)}

\section{A Climatic Stability Over the Period 700-2000}

\section{A.1 Temperature Volatility: 1900-2000 Relative to Earlier Centuries}

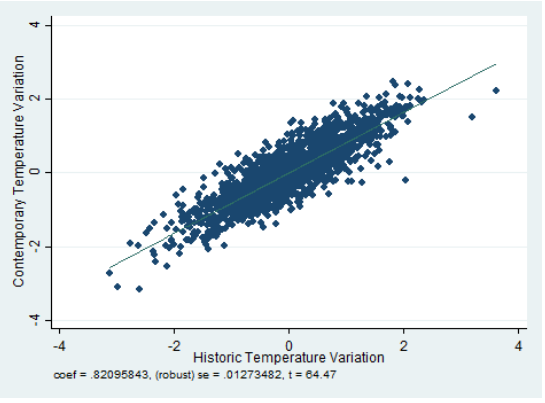

(a) $1900-2000$ vs $1800-1900$

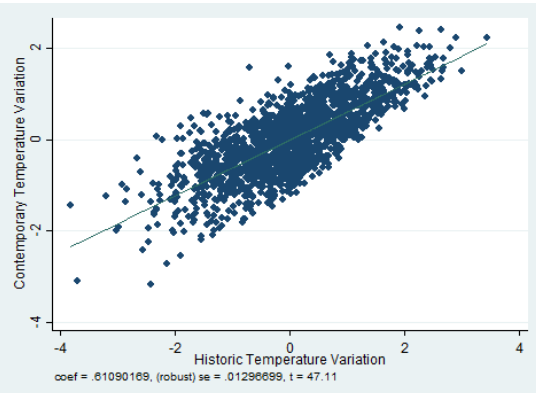

(d) $1900-2000$ vs $1500-1600$

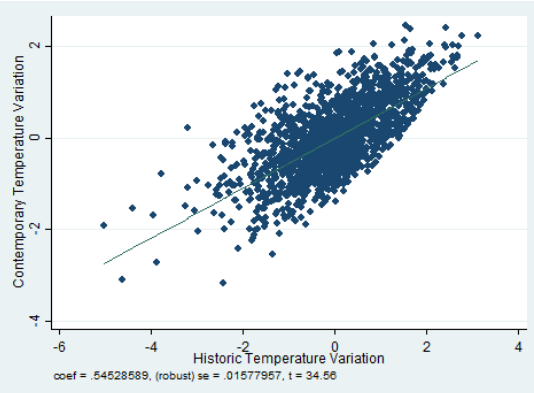

(g) $1900-2000$ vs $1200-1300$

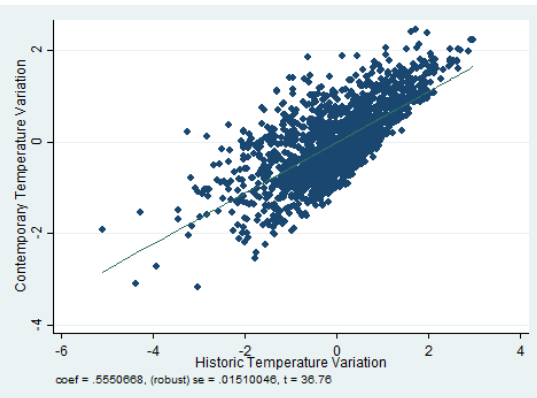

(j) 1900-2000 vs 900-1000

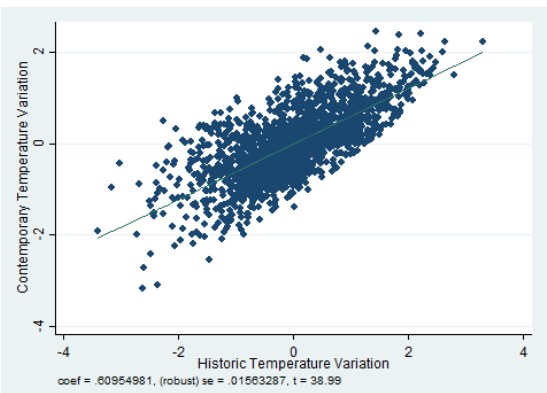

(b) $1900-2000$ vs $1700-1800$

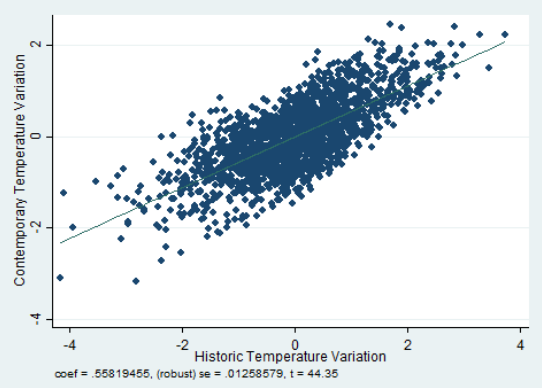

(e) $1900-2000$ vs $1400-1500$

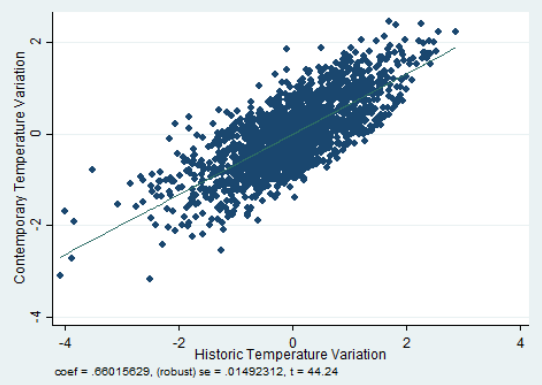

(h) $1900-2000$ vs $1100-1200$

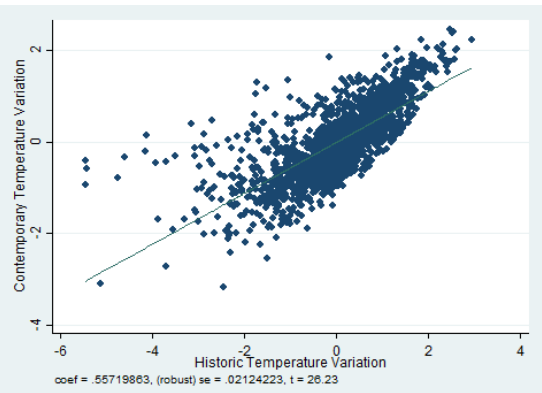

(k) 1900-2000 vs $800-900$

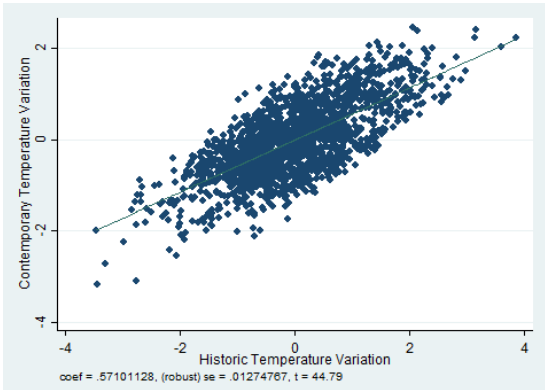

(c) $1900-2000$ vs $1600-1700$

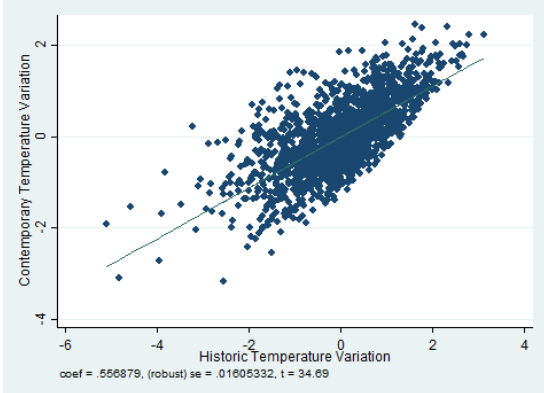

(f) $1900-2000$ vs $1300-1400$

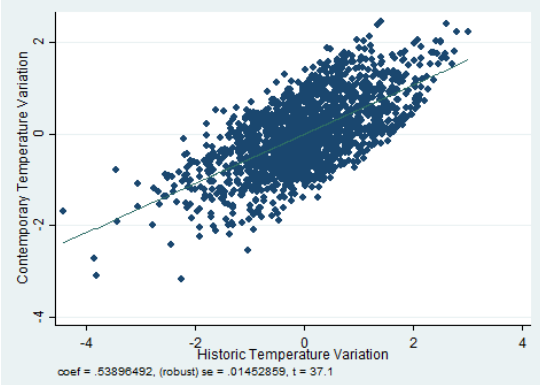

(i) $1900-2000$ vs $1000-1100$

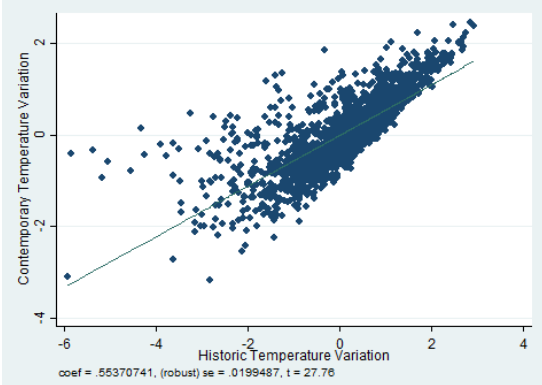

(l) $1900-2000$ vs $700-800$

Figure A.1: Contemporary vs. Historical Intertemporal Temperature Volatility 


\section{A.2 Mean Temperature: 1900-2000 Relative to Earlier Centuries}

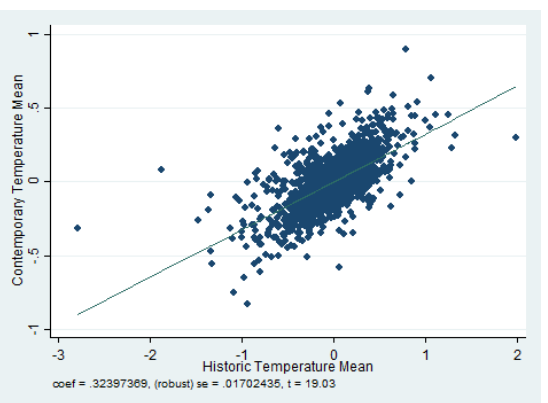

(a) $1900-2000$ vs $1800-1900$

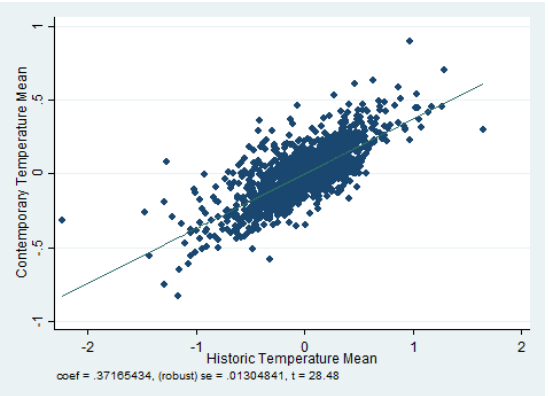

(d) $1900-2000$ vs $1500-1600$

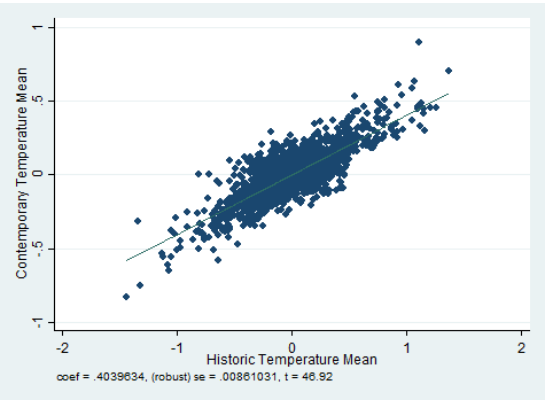

(g) $1900-2000$ vs $1200-1300$

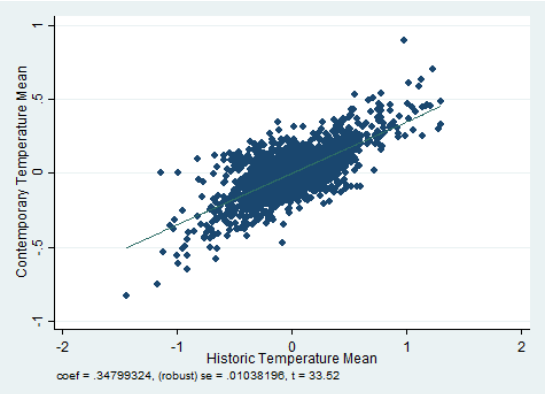

(j) 1900-2000 vs 900-1000

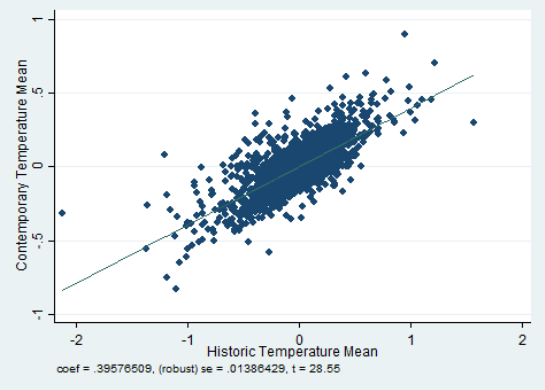

(b) $1900-2000$ vs $1700-1800$

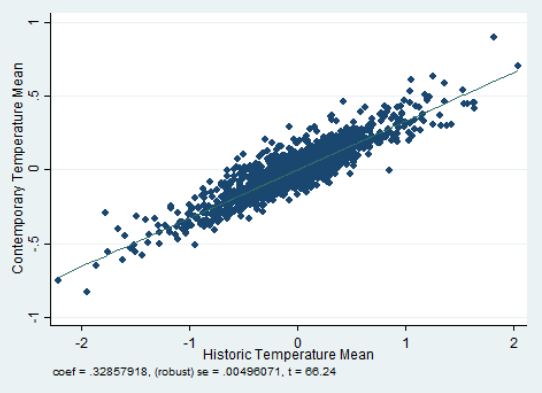

(e) $1900-2000$ vs $1400-1500$

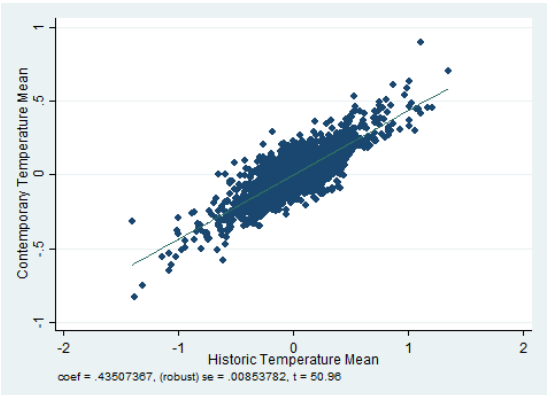

(h) $1900-2000$ vs $1100-1200$

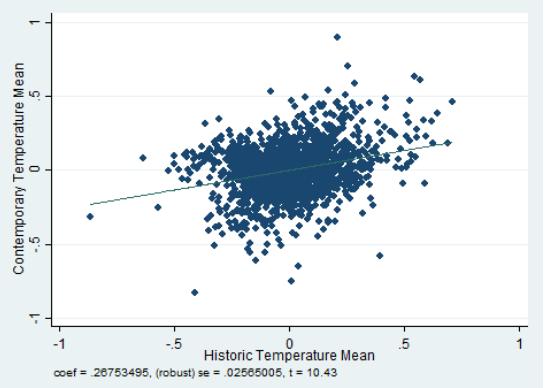

(k) 1900-2000 vs 800-900

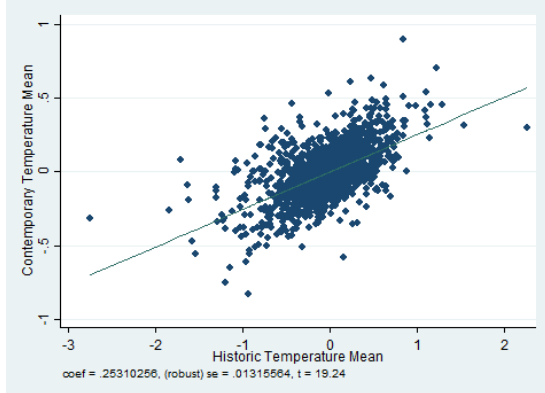

(c) $1900-2000$ vs $1600-1700$

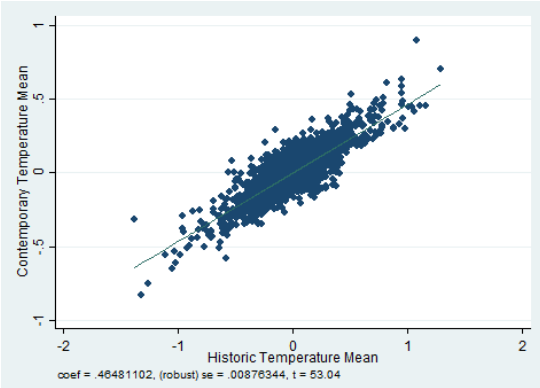

(f) $1900-2000$ vs $1300-1400$

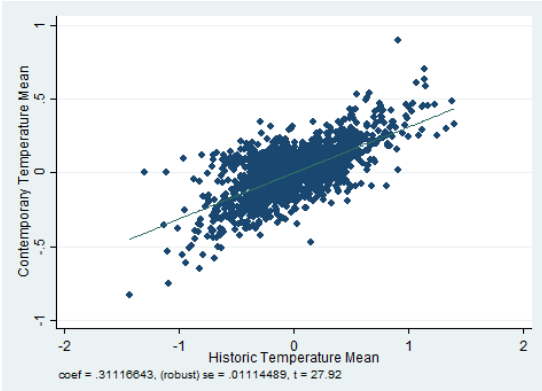

(i) $1900-2000$ vs $1000-1100$

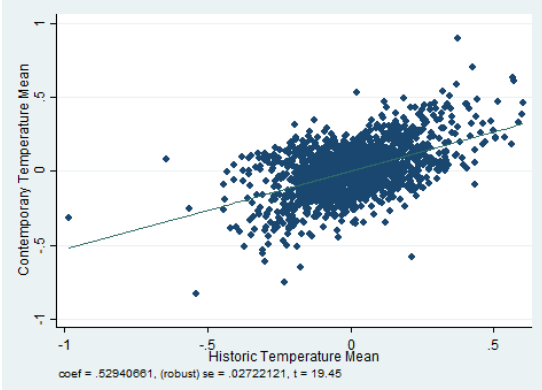

(l) $1900-2000$ vs $700-800$

Figure A.2: Contemporary vs. Historical Mean Temperature 


\section{B Robustness Checks}

\section{B.1 Alternative Estimation Method: Probit and Ordered Probit}

This subsection establishes that the results obtained in sections 4 and 5 are robust to the use of an alternative estimation method, rather than OLS. In particular, using Ordered Probit for the ESS and GSS and Probit for the WVS, one can estimates the probability of observing the ranked preference (in the ESS and GSS) or the preference for Job Security (in the WVS), conditional on intertemporal temperature volatility (idiosyncratic risk) as well as on temperature spatial correlation (aggregate uncertainty).

Table B.1: Determinants of Loss Aversion: Second Generation Migrants in Europe (Ordered Probit)

\begin{tabular}{lcccccc}
\hline \hline & \multicolumn{5}{c}{ Preferred job Characteristic: Security vs. Salary } \\
\cline { 2 - 7 } & $(1)$ & $(2)$ & $(3)$ & $(4)$ & $(5)$ & $(6)$ \\
\hline Temperature (Volatility) & $-0.194^{* * *}$ & $-0.279^{* * *}$ & $-0.284^{* * *}$ & $-0.292^{* * *}$ & $-0.298^{* * *}$ & $-0.286^{* * *}$ \\
& $(0.060)$ & $(0.062)$ & $(0.083)$ & $(0.083)$ & $(0.083)$ & $(0.083)$ \\
Temperature (Spatial Correlation) & $0.043^{*}$ & $0.068^{* *}$ & $0.077^{* * *}$ & $0.074^{* * *}$ & $0.075^{* * *}$ & $0.075^{* * *}$ \\
& $(0.025)$ & $(0.027)$ & $(0.028)$ & $(0.027)$ & $(0.027)$ & $(0.027)$ \\
Temperature (Mean) & $-0.172^{* * *}$ & $-0.125^{*}$ & -0.116 & -0.160 & -0.165 & -0.095 \\
& $(0.055)$ & $(0.066)$ & $(0.122)$ & $(0.125)$ & $(0.122)$ & $(0.125)$ \\
Absolute Latitude & & $0.111^{* * *}$ & $0.166^{* *}$ & $0.134^{*}$ & $0.138^{*}$ & $0.195^{* *}$ \\
& & $(0.041)$ & $(0.074)$ & $(0.078)$ & $(0.078)$ & $(0.079)$ \\
Elevation (Mean) & & -0.008 & 0.008 & -0.003 & -0.002 & 0.009 \\
& & $(0.021)$ & $(0.028)$ & $(0.031)$ & $(0.031)$ & $(0.031)$ \\
Land Suitability (Mean) & & & 0.031 & 0.017 & 0.015 & 0.013 \\
& & & $(0.055)$ & $(0.060)$ & $(0.061)$ & $(0.060)$ \\
Neolithic Transition Timing & & & & 0.023 & 0.024 & 0.012 \\
& & & & $(0.021)$ & $(0.021)$ & $(0.021)$ \\
\hline Country of Birth FE & Yes & Yes & Yes & Yes & Yes & Yes \\
Additional Geographical Controls & No & No & Yes & Yes & Yes & Yes \\
Round FE & No & No & No & No & Yes & Yes \\
Individual Controls & No & No & No & No & No & Yes \\
Pseudo- $R^{2}$ & 0.03 & 0.03 & 0.03 & 0.03 & 0.03 & 0.04 \\
Observations & 3907 & 3907 & 3907 & 3907 & 3907 & 3907 \\
\hline
\end{tabular}

Notes: Using Ordered Probit regressions, this table establishes that the preferred job characteristics of second generation migrants reflect loss aversion. In particular, their valuation of job security vs. salary is negatively affected by temperature volatility (idiosyncratic risk) and positively affected by temperature spatial correlation (aggregate uncertainty) in the parental country of origin. Additional geographical controls are land suitability gini, distance to coast or river, landlocked dummy, percentage of land in the tropical, subtropical and temperate zones and precipitation level. Individual controls include age, gender, number of siblings, religion, education level, and income. Sample excludes small island countries. All independent variables have been normalized by subtracting their mean and dividing by their standard deviation. Thus, all coefficients can be compared and show the effect of a one standard deviation in the independent variable on standard deviations in the dependent variable. Heteroskedasticity robust standard error estimates clustered at the parental country of origin level are reported in parentheses; ${ }^{* * *}$ denotes statistical significance at the $1 \%$ level, ${ }^{* *}$ at the $5 \%$ level, and ${ }^{*}$ at the $10 \%$ level, all for two-sided hypothesis tests. 
Table B.2: Determinants of Loss Aversion: Second Generation Migrants in the US (Ordered Probit)

\begin{tabular}{|c|c|c|c|c|c|c|c|}
\hline & \multicolumn{7}{|c|}{ Preferred Job Characteristic } \\
\hline & \multicolumn{5}{|c|}{ Security vs Others } & \multicolumn{2}{|c|}{ Security vs Salary } \\
\hline & (1) & $(2)$ & $(3)$ & $(4)$ & $(5)$ & $(6)$ & $(7)$ \\
\hline Temperature (Volatility) & $\begin{array}{c}-0.15^{*} \\
(0.09)\end{array}$ & $\begin{array}{c}-0.19^{* *} \\
(0.08)\end{array}$ & $\begin{array}{c}-0.30 * * * \\
(0.08)\end{array}$ & $\begin{array}{c}-0.28^{* * *} \\
(0.08)\end{array}$ & $\begin{array}{c}-0.41^{* * * *} \\
(0.08)\end{array}$ & $\begin{array}{c}-0.29^{* * *} \\
(0.09)\end{array}$ & $\begin{array}{c}-0.36^{* * *} \\
(0.10)\end{array}$ \\
\hline Temperature (Spatial Correlation) & $\begin{array}{c}0.11^{* *} \\
(0.05)\end{array}$ & $\begin{array}{c}0.13^{* * *} \\
(0.05)\end{array}$ & $\begin{array}{c}0.11^{* *} \\
(0.05)\end{array}$ & $\begin{array}{c}0.14^{* * *} \\
(0.05)\end{array}$ & $\begin{array}{c}0.14^{* * *} \\
(0.04)\end{array}$ & $\begin{array}{c}0.13^{* * *} \\
(0.04)\end{array}$ & $\begin{array}{c}0.16^{* * *} \\
(0.04)\end{array}$ \\
\hline Temperature (Mean) & $\begin{array}{l}-0.04 \\
(0.07)\end{array}$ & $\begin{array}{l}-0.01 \\
(0.14)\end{array}$ & $\begin{array}{l}-0.15 \\
(0.10)\end{array}$ & $\begin{array}{c}0.03 \\
(0.15)\end{array}$ & $\begin{array}{l}-0.02 \\
(0.19)\end{array}$ & $\begin{array}{c}0.08 \\
(0.17)\end{array}$ & $\begin{array}{c}0.13 \\
(0.18)\end{array}$ \\
\hline Absolute Latitude & & $\begin{array}{c}0.04 \\
(0.12)\end{array}$ & $\begin{array}{l}-0.06 \\
(0.17)\end{array}$ & $\begin{array}{c}0.08 \\
(0.19)\end{array}$ & $\begin{array}{c}0.13 \\
(0.23)\end{array}$ & $\begin{array}{c}0.27 \\
(0.19)\end{array}$ & $\begin{array}{c}0.30 \\
(0.20)\end{array}$ \\
\hline Elevation (Mean) & & $\begin{array}{l}-0.04 \\
(0.06)\end{array}$ & $\begin{array}{l}-0.07 \\
(0.06)\end{array}$ & $\begin{array}{c}0.02 \\
(0.07)\end{array}$ & $\begin{array}{l}-0.01 \\
(0.10)\end{array}$ & $\begin{array}{c}0.06 \\
(0.09)\end{array}$ & $\begin{array}{c}0.02 \\
(0.09)\end{array}$ \\
\hline Land Suitability (Mean) & & & $\begin{array}{l}-0.09 \\
(0.08)\end{array}$ & $\begin{array}{l}-0.05 \\
(0.08)\end{array}$ & $\begin{array}{l}-0.11 \\
(0.07)\end{array}$ & $\begin{array}{l}-0.10 \\
(0.10)\end{array}$ & $\begin{array}{l}-0.14 \\
(0.09)\end{array}$ \\
\hline Neolithic Transition Timing & & & & $\begin{array}{c}-0.11^{*} \\
(0.06)\end{array}$ & $\begin{array}{l}-0.10 \\
(0.07)\end{array}$ & $\begin{array}{l}-0.08 \\
(0.06)\end{array}$ & $\begin{array}{l}-0.08 \\
(0.06)\end{array}$ \\
\hline Region of Birth FE & Yes & Yes & Yes & Yes & Yes & Yes & Yes \\
\hline Additional Geographical Controls & No & No & Yes & Yes & Yes & Yes & Yes \\
\hline Wave FE & No & No & No & No & Yes & No & Yes \\
\hline Individual Controls & No & No & No & No & Yes & No & Yes \\
\hline Pseudo- $R^{2}$ & 0.01 & 0.01 & 0.01 & 0.01 & 0.05 & 0.02 & 0.03 \\
\hline Observations & 1328 & 1328 & 1328 & 1328 & 1171 & 1181 & 1171 \\
\hline
\end{tabular}

Using Ordered Probit regression, this table establishes that the preferred job characteristics of second generation migrants reflect loss aversion. In particular, their valuation of job security vs other characteristics (salary, short working hours, promotion opportunities and job satisfaction) and of job security vs. salary is negatively affected by temperature volatility (idiosyncratic risk) and positively affected by temperature spatial correlation (aggregate uncertainty) in the parental country of origin. Additional geographical controls are land suitability gini, distance to coast or river, landlocked dummy, percentage of land in the tropical, subtropical and temperate zones and precipitation level. Individual controls include age, gender, number of siblings, religion, education level, and income. Sample excludes small island countries. All independent variables have been normalized by subtracting their mean and dividing by their standard deviation. Thus, all coefficients can be compared and show the effect of a one standard deviation in the independent variable on standard deviations in the dependent variable. Heteroskedasticity robust standard error estimates clustered at the parental country of origin level are reported in parentheses; *** denotes statistical significance at the $1 \%$ level, ${ }^{* *}$ at the $5 \%$ level, and ${ }^{*}$ at the $10 \%$ level, all for two-sided hypothesis tests.

In line with the predictions of the theory, as well as with the OLS estimates, as established in Tables B.1, B.2, and 9 larger temperature spatial correlation increases significantly the probability that: (i) second generation migrants in Europe, (ii) second generation migrants in the US, and (iii) individuals in the WVS, will be more loss averse, whereas greater intertemporal temperature volatility decreases the probability that individuals in these distinct samples will be loss averse. 
Table B.3: Determinants of Loss Aversion: Individuals in the WVS (Probit)

\begin{tabular}{|c|c|c|c|c|c|c|c|}
\hline & \multicolumn{7}{|c|}{ Preferred Job Characteristic: Security vs Others } \\
\hline & (1) & $(2)$ & $(3)$ & $(4)$ & $(5)$ & $(6)$ & (7) \\
\hline Temperature (Volatility) & $\begin{array}{c}-0.062^{* * *} \\
(0.006)\end{array}$ & $\begin{array}{c}-0.066^{* * *} \\
(0.006)\end{array}$ & $\begin{array}{c}-0.047^{* * *} \\
(0.008)\end{array}$ & $\begin{array}{c}-0.030 * * * \\
(0.008)\end{array}$ & $\begin{array}{c}-0.030 * * * \\
(0.008)\end{array}$ & $\begin{array}{c}-0.030 * * * \\
(0.008)\end{array}$ & \\
\hline Temperature (Spatial Correlation) & $\begin{array}{c}0.013^{* * *} \\
(0.004)\end{array}$ & $\begin{array}{c}0.014^{* * *} \\
(0.004)\end{array}$ & $\begin{array}{c}0.016^{* * *} \\
(0.004)\end{array}$ & $\begin{array}{c}0.021^{* * *} \\
(0.004)\end{array}$ & $\begin{array}{c}0.019 * * * \\
(0.004)\end{array}$ & $\begin{array}{c}0.016^{* * *} \\
(0.004)\end{array}$ & \\
\hline Temperature (Volatility, Ancestral) & & & & & & & $\begin{array}{c}-0.023 * * * \\
(0.007)\end{array}$ \\
\hline Temp (Spatial Correlation, Ancestral) & & & & & & & $\begin{array}{c}0.010^{* *} \\
(0.004)\end{array}$ \\
\hline Temperature (Mean) & $\begin{array}{c}-0.017^{* * *} \\
(0.005)\end{array}$ & $\begin{array}{l}-0.008 \\
(0.007)\end{array}$ & $\begin{array}{c}0.009 \\
(0.009)\end{array}$ & $\begin{array}{c}0.044^{* * *} \\
(0.010)\end{array}$ & $\begin{array}{c}0.050^{* * *} \\
(0.010)\end{array}$ & $\begin{array}{c}0.047^{* * *} \\
(0.009)\end{array}$ & $\begin{array}{c}0.046^{* * *} \\
(0.010)\end{array}$ \\
\hline Absolute Latitude & & $\begin{array}{c}0.014^{* *} \\
(0.007)\end{array}$ & $\begin{array}{c}0.009 \\
(0.010)\end{array}$ & $\begin{array}{c}0.040 * * * \\
(0.011)\end{array}$ & $\begin{array}{c}0.072^{* * *} \\
(0.011)\end{array}$ & $\begin{array}{c}0.065^{* * *} \\
(0.011)\end{array}$ & $\begin{array}{c}0.056^{* * *} \\
(0.011)\end{array}$ \\
\hline Elevation (Mean) & $\begin{array}{c}-0.023^{* * *} \\
(0.003)\end{array}$ & $\begin{array}{c}-0.021^{* * *} \\
(0.003)\end{array}$ & $\begin{array}{c}0.014^{* * *} \\
(0.004)\end{array}$ & $\begin{array}{c}0.025^{* * *} \\
(0.005)\end{array}$ & $\begin{array}{c}0.014^{* * *} \\
(0.005)\end{array}$ & $\begin{array}{c}0.010 * * \\
(0.005)\end{array}$ & $\begin{array}{l}0.008^{*} \\
(0.005)\end{array}$ \\
\hline Land Suitability (Mean) & & & $\begin{array}{c}0.026^{* * *} \\
(0.005)\end{array}$ & $\begin{array}{c}0.039 * * * \\
(0.005)\end{array}$ & $\begin{array}{c}0.015^{* * *} \\
(0.005)\end{array}$ & $\begin{array}{c}0.015^{* * *} \\
(0.005)\end{array}$ & $\begin{array}{c}0.014^{* * *} \\
(0.005)\end{array}$ \\
\hline Neolithic Transition Timing & & & & & $\begin{array}{c}0.062^{* * *} \\
(0.005)\end{array}$ & $\begin{array}{c}0.059^{* * *} \\
(0.005)\end{array}$ & $\begin{array}{c}0.056^{* * *} \\
(0.005)\end{array}$ \\
\hline Region of Birth FE & Yes & Yes & Yes & Yes & Yes & Yes & Yes \\
\hline Additional Geographical Controls & No & No & Yes & Yes & Yes & Yes & Yes \\
\hline Year FE & No & No & No & Yes & Yes & Yes & Yes \\
\hline Individual Controls & No & No & No & No & No & Yes & Yes \\
\hline Pseudo- $R^{2}$ & 0.01 & 0.01 & 0.02 & 0.03 & 0.03 & 0.03 & 0.03 \\
\hline Observations & 130933 & 130933 & 130933 & 130933 & 130933 & 130933 & 130933 \\
\hline
\end{tabular}

Notes: Using Probit regression, this table establishes that individuals' valuation of job security vs other job characteristics (i.e., salary, colleagues, job satisfaction) is negatively affected by temperature volatility (idiosyncratic risk) and positively affected by temperature spatial correlation (aggregate uncertainty) in the country of birth. Additional geographical controls are land suitability gini, distance to coast or river, landlocked dummy, percentage of land in the tropical, subtropical and temperate zones and precipitation level. Individual controls include age, gender, religion, education level, and income. Sample excludes small island countries. All independent variables have been normalized by subtracting their mean and dividing by their standard deviation. All coefficients represent average marginal effects, and since all independent variables have been normalized by subtracting their mean and dividing by their standard deviation, all coefficients are comparable. Heteroskedasticity robust clustered standard error estimates are reported in parentheses; clustering at the region of interview and individual characteristics level; ${ }^{* * *}$ denotes statistical significance at the $1 \%$ level, ${ }^{* *}$ at the $5 \%$ level, and ${ }^{*}$ at the $10 \%$ level, all for two-sided hypothesis tests.

\section{B.2 Selection by Unobservables}

This subsection examines the likelihood that omitted variables could alter the qualitative findings.

Table B.4 establishes that it is very improbable that omitted variables could have affected the qualitative results presented in Tables 2 and 3. In particular, as established in Column (2) and (4), (using Columns (1) and (3) as the baseline specifications), the estimated value of the coefficient on intertemporal temperature volatility and temperature spatial correlation, if unobservables where as correlated as the observables (i.e., Oster's $\beta^{*}$ statistic), are very close to the estimated OLS coefficients. Fur- 
thermore, since zero does not belong to the interval created by the estimated value on and Oster's $\beta^{*}$, one can reject the hypothesis that the value of the coefficient is driven exclusively by unobservables. In addition, the indexes AET (Altonji et al., 2005; Bellows and Miguel, 2009) and $\delta$ (Oster, 2014) measure how strongly correlated unobservables would have to be in order to account for the full size of the coefficient on temperature volatility and spatial correlation ( $v$ and $c$ subscripts correspondingly), are mostly different from the critical value of 1.

Table B.4: Determinants of Loss Aversion: Robustness to Selection on Unobservables

\begin{tabular}{|c|c|c|c|c|c|c|c|c|}
\hline & \multicolumn{8}{|c|}{ Loss Aversion } \\
\hline & (1) & $(2)$ & $(3)$ & $(4)$ & $(5)$ & $(6)$ & $(7)$ & $(8)$ \\
\hline & ESS & ESS & GSS & GSS & WVS & WVS & EA & EA \\
\hline \multirow[t]{2}{*}{ Temperature (Volatility) } & $-0.22^{* * *}$ & $-0.23^{* * *}$ & $-0.20^{*}$ & $-0.42^{* * *}$ & $-0.06 * * *$ & $-0.03^{* * *}$ & $-0.15^{* * *}$ & $-0.08^{* * *}$ \\
\hline & $(0.05)$ & $(0.06)$ & $(0.10)$ & $(0.08)$ & $(0.01)$ & $(0.01)$ & $(0.02)$ & $(0.03)$ \\
\hline \multirow[t]{2}{*}{ Temperature (Spatial Correlation) } & $0.05^{* *}$ & $0.06^{* * *}$ & $0.15^{* *}$ & $0.16^{* * *}$ & $0.01^{* * *}$ & $0.02^{* * *}$ & $0.07^{* * *}$ & $0.05^{* *}$ \\
\hline & $(0.02)$ & $(0.02)$ & $(0.06)$ & $(0.04)$ & $(0.00)$ & $(0.00)$ & $(0.03)$ & $(0.02)$ \\
\hline \multirow[t]{2}{*}{ Temperature (Mean) } & $-0.09 *$ & -0.09 & 0.02 & -0.03 & -0.01 & $0.05^{* * *}$ & 0.01 & -0.02 \\
\hline & $(0.05)$ & $(0.09)$ & $(0.17)$ & $(0.21)$ & $(0.01)$ & $(0.01)$ & $(0.02)$ & $(0.02)$ \\
\hline Country/Region of Birth FE & Yes & Yes & Yes & Yes & Yes & Yes & $\mathrm{N} / \mathrm{A}$ & $\mathrm{N} / \mathrm{A}$ \\
\hline Additional Geographical Controls & No & Yes & No & Yes & No & Yes & No & Yes \\
\hline Wave/Round FE & No & Yes & No & Yes & No & Yes & $\mathrm{N} / \mathrm{A}$ & $\mathrm{N} / \mathrm{A}$ \\
\hline Individual/Ethnographic Controls & No & Yes & No & Yes & No & Yes & No & Yes \\
\hline$A E T_{v}$ & & -34.61 & & -1.90 & & 0.98 & & 1.13 \\
\hline$\delta_{v}$ & & -5.18 & & -0.75 & & 1.60 & & 1.36 \\
\hline$\beta_{v}^{*}$ & & -0.24 & & -0.52 & & -0.01 & & -0.02 \\
\hline$A E T_{c}$ & & -15.36 & & -16.72 & & -5.04 & & 2.32 \\
\hline$\delta_{c}$ & & -8.27 & & -27.29 & & -8.14 & & 2.78 \\
\hline$\beta_{c}^{*}$ & & 0.06 & & 0.16 & & 0.02 & & 0.03 \\
\hline$R^{2}$ & 0.06 & 0.08 & 0.03 & 0.13 & 0.02 & 0.04 & 0.28 & 0.49 \\
\hline Adjusted- $R^{2}$ & 0.06 & 0.07 & 0.02 & 0.08 & 0.02 & 0.04 & 0.28 & 0.47 \\
\hline Observations & 3907 & 3907 & 1171 & 1171 & 130933 & 130933 & 471 & 471 \\
\hline
\end{tabular}

Notes: This table shows the robustness of the results to selection by unobservables. It presents the Altonji et al. (2005) AET ratio as extended by Bellows and Miguel (2009). Additionally, it presents the $\delta$ and $\beta^{*}\left(1, R_{\max }^{2}\right)$ statistics suggested by Oster (2014), where $R_{\max }^{2}$ is 1.33 of $R^{2}$ in the full specification. All statistics suggest that the results are not driven by unobservables. Heteroskedasticity robust standard errors in round parenthesis. $* * *$ denotes statistical significance at the $1 \%$ level, $* *$ at the $5 \%$ level, and * at the $10 \%$ level, all for two-sided hypothesis tests.

\section{B.3 The Insignificant Role of Preindustrial Development}

This subsection establishes that the effect of the climatic variables on loss aversion is orthogonal to the potentially confounding effect of historical levels of population density, urbanization and income per capita density. In particular, Table B.X demonstrates that, accounting for population density in 1500, 
urbanization in 1800, and GDP per capita in 1913, the effects of intertemporal climatic volatility and temperature spatial correlation on loss aversion in the ESS (columns (1)-(3)), GSS (columns (4)-(6)), and WVS (columns(7)-(9)) remain stable and mostly highly significant and qualitatively similar.

Table B.5: Temperature Volatility, Spatial Correlation and Loss Aversion: Accounting for the Persistence of Preindustrial Development

\begin{tabular}{|c|c|c|c|c|c|c|c|c|c|}
\hline & \multicolumn{9}{|c|}{ Temperature Volatility, Spatial Correlation and Loss Aversion } \\
\hline & \multicolumn{3}{|c|}{ ESS } & \multicolumn{3}{|c|}{ GSS } & \multicolumn{3}{|c|}{ WVS } \\
\hline & $(1)$ & $(2)$ & $(3)$ & $(4)$ & $(5)$ & $(6)$ & $(7)$ & $(8)$ & $(9)$ \\
\hline Temperature (Volatility) & $\begin{array}{c}-0.21^{* * *} \\
(0.06)\end{array}$ & $\begin{array}{c}-0.23^{* * *} \\
(0.06)\end{array}$ & $\begin{array}{c}-0.23^{* *} \\
(0.09)\end{array}$ & $\begin{array}{c}-0.82^{* * *} \\
(0.21)\end{array}$ & $\begin{array}{c}-0.80^{* * *} \\
(0.20)\end{array}$ & $\begin{array}{c}-0.60 * * * \\
(0.18)\end{array}$ & $\begin{array}{c}-0.03^{* * *} \\
(0.01)\end{array}$ & $\begin{array}{c}-0.04^{* * *} \\
(0.01)\end{array}$ & $\begin{array}{c}-0.03^{* * *} \\
(0.01)\end{array}$ \\
\hline Temperature (Spatial Correlation) & $\begin{array}{c}0.05^{* *} \\
(0.02)\end{array}$ & $\begin{array}{c}0.06^{* *} \\
(0.02)\end{array}$ & $\begin{array}{c}0.08 * * * \\
(0.02)\end{array}$ & $\begin{array}{c}0.36^{* * *} \\
(0.13)\end{array}$ & $\begin{array}{c}0.39^{* *} \\
(0.15)\end{array}$ & $\begin{array}{c}0.34^{* * *} \\
(0.10)\end{array}$ & $\begin{array}{c}0.02^{* * *} \\
(0.00)\end{array}$ & $\begin{array}{c}0.02^{* * *} \\
(0.00)\end{array}$ & $\begin{array}{c}0.02^{* * *} \\
(0.01)\end{array}$ \\
\hline Population Density (1500) & $\begin{array}{c}0.00 \\
(0.00)\end{array}$ & & & $\begin{array}{l}-0.00 \\
(0.01)\end{array}$ & & & $\begin{array}{c}0.00 \\
(0.00)\end{array}$ & & \\
\hline Urbanization Rate (1800) & & $\begin{array}{c}0.15 \\
(0.17)\end{array}$ & & & $\begin{array}{c}0.48 \\
(0.93)\end{array}$ & & & $\begin{array}{c}-0.09 * * \\
(0.04)\end{array}$ & \\
\hline Income percapita (1913) & & & $\begin{array}{c}0.03 \\
(0.04) \\
\end{array}$ & & & $\begin{array}{c}0.21 \\
(0.14) \\
\end{array}$ & & & $\begin{array}{c}-0.03^{* * *} \\
(0.01) \\
\end{array}$ \\
\hline Country/Region of Birth FE & Yes & Yes & Yes & Yes & Yes & Yes & Yes & Yes & Yes \\
\hline Additional Geographical Controls & Yes & Yes & Yes & Yes & No & Yes & Yes & Yes & Yes \\
\hline Wave/Round FE & Yes & Yes & Yes & Yes & Yes & Yes & Yes & Yes & Yes \\
\hline Individual Controls & Yes & Yes & Yes & Yes & Yes & Yes & Yes & Yes & Yes \\
\hline$R^{2}$ & 0.08 & 0.08 & 0.08 & 0.12 & 0.12 & 0.12 & 0.04 & 0.04 & 0.05 \\
\hline Adjusted- $R^{2}$ & 0.07 & 0.07 & 0.06 & 0.07 & 0.07 & 0.07 & 0.04 & 0.04 & 0.05 \\
\hline Observations & 3907 & 3864 & 3061 & 1171 & 1171 & 1117 & 130933 & 125078 & 83350 \\
\hline
\end{tabular}

Notes: This table shows the robustness of the results to the level of historical development as captured by the population density in year $1500 \mathrm{CE}$, urbanization rate in $1800 \mathrm{CE}$ and GDP per capita in $1913 \mathrm{CE}$. Heteroskedasticity robust standard errors in round parenthesis. ${ }^{* * *}$ denotes statistical significance at the $1 \%$ level, ${ }^{* *}$ at the $5 \%$ level, and ${ }^{*}$ at the $10 \%$ level, all for two-sided hypothesis tests. 


\section{B.4 Insignificant outliers}

This subsection examines the potential importance of outliers in the established relationship between intertemporal temperature volatility and temperature spatial correlation and the emergence of loss aversion. As observed depicted in Figure B.1 outliers do not governed the observed relationship in the ESS, whereas, Figures B.2 suggests that outliers, associated with individuals from the Netherlands, may affect the observed relationship. Nevertheless, as established in Table B.6 the results remain qualitatively intact if individuals from the Netherlands are excluded from the sample.

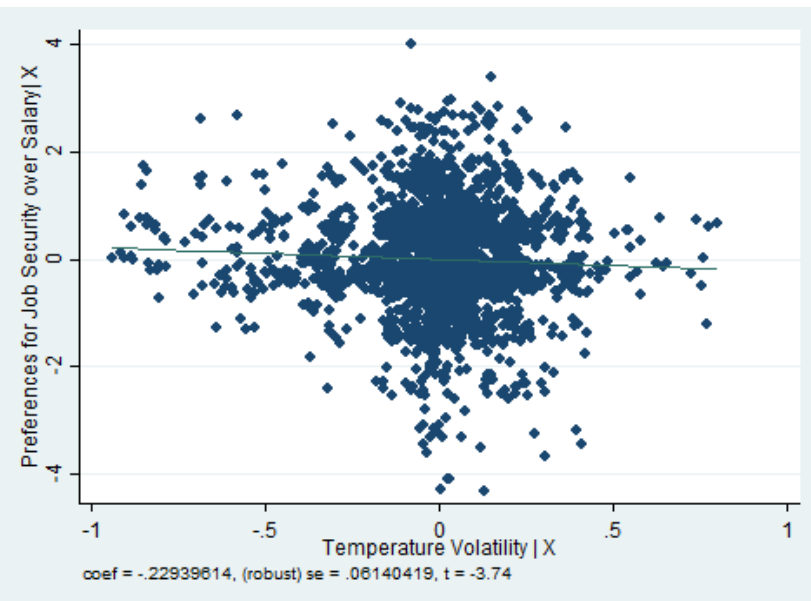

(a) Effect of Temperature Volatility

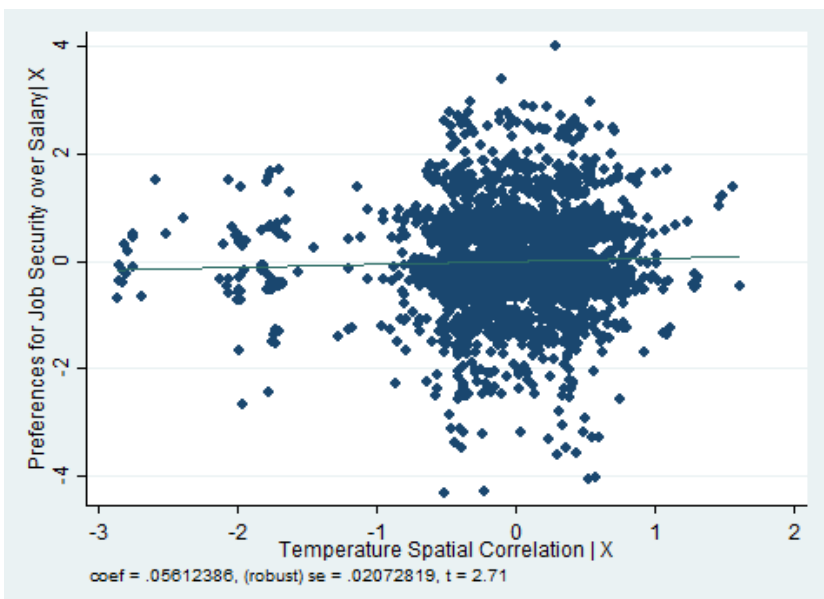

(b) Effect of Temperature Spatial Correlation

Figure B.1: Temperature Shocks Characteristics and Preferences for Job Security in Europe

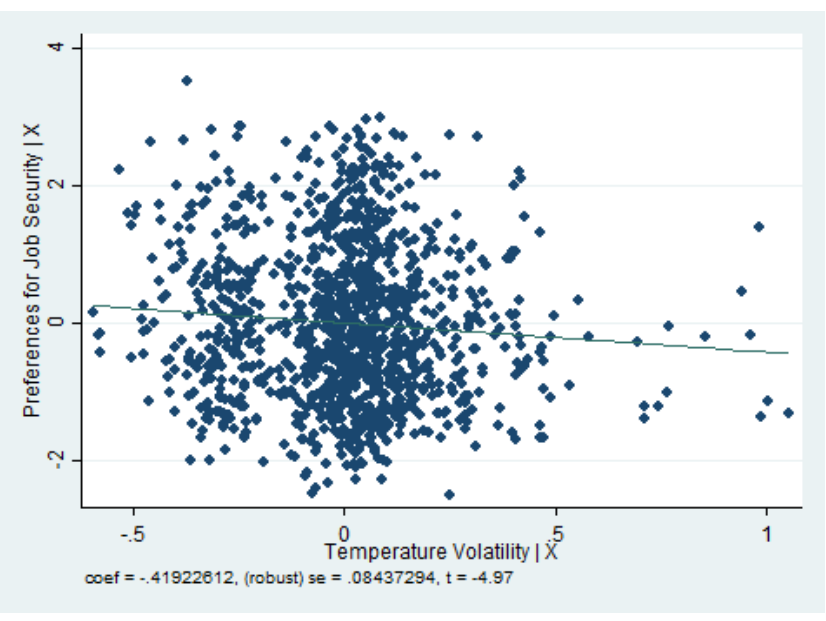

(a) Effect of Temperature Volatility

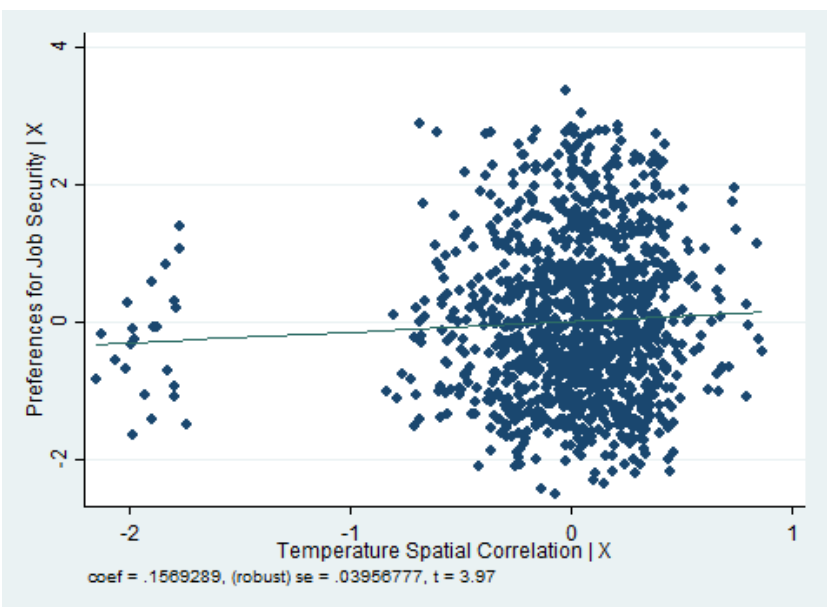

(b) Effect of Temperature Spatial Correlation

Figure B.2: Temperature Shocks Characteristics and Preferences for Job Security in the US 
Table B.6: Determinants of Loss Aversion: Second Generation Migrants in the US: Excluding Potential Outliers - the Netherlands

\begin{tabular}{|c|c|c|c|c|c|c|}
\hline & \multicolumn{6}{|c|}{ Preferred Job Characteristic } \\
\hline & \multicolumn{3}{|c|}{ Security vs Others } & \multicolumn{3}{|c|}{ Security vs Salary } \\
\hline & (1) & $(2)$ & $(3)$ & $(4)$ & $(5)$ & (6) \\
\hline Temperature (Volatility) & $\begin{array}{c}-0.34^{* * *} \\
(0.08)\end{array}$ & $\begin{array}{c}-0.35 * * * \\
(0.08)\end{array}$ & $\begin{array}{c}-0.36^{* * *} \\
(0.11)\end{array}$ & $\begin{array}{c}-0.56^{* * *} \\
(0.17)\end{array}$ & $\begin{array}{c}-0.57^{* * *} \\
(0.17)\end{array}$ & $\begin{array}{c}-0.67^{* * *} \\
(0.17)\end{array}$ \\
\hline Temperature (Spatial Correlation) & $\begin{array}{c}0.31^{* * *} \\
(0.07)\end{array}$ & $\begin{array}{c}0.31^{* * * *} \\
(0.06)\end{array}$ & $\begin{array}{l}0.21^{*} \\
(0.11)\end{array}$ & $\begin{array}{c}0.47 * * * \\
(0.13)\end{array}$ & $\begin{array}{c}0.47 * * * \\
(0.13)\end{array}$ & $\begin{array}{c}0.40^{* *} \\
(0.17)\end{array}$ \\
\hline Temperature (Mean) & $\begin{array}{c}0.13 \\
(0.16)\end{array}$ & $\begin{array}{c}0.15 \\
(0.16)\end{array}$ & $\begin{array}{c}0.06 \\
(0.23)\end{array}$ & $\begin{array}{c}0.38 \\
(0.31)\end{array}$ & $\begin{array}{c}0.42 \\
(0.31)\end{array}$ & $\begin{array}{c}0.40 \\
(0.33)\end{array}$ \\
\hline Absolute Latitude & $\begin{array}{c}0.19 \\
(0.19)\end{array}$ & $\begin{array}{c}0.24 \\
(0.19)\end{array}$ & $\begin{array}{c}0.19 \\
(0.26)\end{array}$ & $\begin{array}{l}0.71^{*} \\
(0.35)\end{array}$ & $\begin{array}{c}0.77^{* *} \\
(0.33)\end{array}$ & $\begin{array}{c}0.77^{* *} \\
(0.35)\end{array}$ \\
\hline Elevation (Mean) & $\begin{array}{c}0.11 \\
(0.09)\end{array}$ & $\begin{array}{c}0.13 \\
(0.09)\end{array}$ & $\begin{array}{c}0.08 \\
(0.12)\end{array}$ & $\begin{array}{l}0.28^{*} \\
(0.16)\end{array}$ & $\begin{array}{l}0.29 * \\
(0.16)\end{array}$ & $\begin{array}{c}0.15 \\
(0.18)\end{array}$ \\
\hline Land Suitability (Mean) & $\begin{array}{l}0.14^{*} \\
(0.07)\end{array}$ & $\begin{array}{c}0.13 \\
(0.08)\end{array}$ & $\begin{array}{c}0.03 \\
(0.11)\end{array}$ & $\begin{array}{c}0.12 \\
(0.20)\end{array}$ & $\begin{array}{c}0.11 \\
(0.20)\end{array}$ & $\begin{array}{l}-0.08 \\
(0.20)\end{array}$ \\
\hline Neolithic Transition Timing & $\begin{array}{c}-0.19^{* * *} \\
(0.07)\end{array}$ & $\begin{array}{c}-0.20^{* *} \\
(0.07)\end{array}$ & $\begin{array}{l}-0.16 \\
(0.09)\end{array}$ & $\begin{array}{c}-0.30^{* *} \\
(0.11)\end{array}$ & $\begin{array}{c}-0.30^{* *} \\
(0.11)\end{array}$ & $\begin{array}{l}-0.21 \\
(0.13)\end{array}$ \\
\hline Region of Birth FE & Yes & Yes & Yes & Yes & Yes & Yes \\
\hline Additional Geographical Controls & Yes & Yes & Yes & Yes & Yes & Yes \\
\hline Wave FE & No & Yes & Yes & No & Yes & Yes \\
\hline Individual Controls & No & No & Yes & No & No & Yes \\
\hline Adjusted- $R^{2}$ & 0.01 & 0.01 & 0.09 & 0.01 & 0.01 & 0.07 \\
\hline Observations & 1373 & 1373 & 1217 & 1300 & 1300 & 1148 \\
\hline \multicolumn{7}{|c|}{$\begin{array}{l}\text { Notes: Using OLS regression, this table establishes that the preferred job characteristics of second generation migrants } \\
\text { reflect loss aversion. In particular, their valuation of job security vs all other characteristics (salary, short working } \\
\text { hours, promotion opportunities and job satisfaction) and of job security vs. salary is negatively affected by temperature } \\
\text { volatility (idiosyncratic risk) and positively affected by temperature spatial correlation (aggregate uncertainty) in the } \\
\text { parental country of origin. Additional geographical controls are land suitability gini, distance to coast or river, land- } \\
\text { locked dummy, percentage of land in the tropical, subtropical and temperate zones and precipitation level. Individual } \\
\text { controls include age, gender, number of siblings, religion, education level, and income. Sample does not include the } \\
\text { Netherlands in all columns, in columns }(4)-(6) \text { small island countries are also excluded. All independent variables } \\
\text { have been normalized by subtracting their mean and dividing by their standard deviation. Thus, all coefficients can } \\
\text { be compared and show the effect of a one standard deviation in the independent variable on standard deviations in } \\
\text { the dependent variable. Heteroskedasticity robust standard error estimates clustered at the parental country of origin } \\
\text { level are reported in parentheses; } * * * \text { denotes statistical significance at the } 1 \% \text { level, } * * \text { at the } 5 \% \text { level, and } * \text { at the } \\
10 \% \text { level, all for two-sided hypothesis tests. }\end{array}$} \\
\hline
\end{tabular}




\section{Variable Definitions}

\section{C.1 Outcome Variables}

\section{C.1.1 Measures of Loss Aversion}

- Preferred Job Characteristic: Security vs Others (Second-generation analysis: GSS): Based on the answer to the question "Would you please look at this card and tell me which one thing on this list you would most prefer in a job" taken from the core module of the General Social Survey. Coded 5 if "No danger of being fired" is the most preferred characteristic, 4 if it is the second most preferred, 3 - third most preferred, 2 - fourth most preferred, 1 - least preferred.

- Preferred Job Characteristic: Security vs Salary (Second-generation analysis: GSS): Based on the answers to the question "Would you please look at this card and tell me which one thing on this list you would most prefer in a job?" taken from the core module of the General Social Survey. Computed as the difference between the ranks of characteristics "High Income" and "No danger of being fired", normalizing the lowest value to 1 (i.e., JOBINC - JOBSEC + $5)$.

- Preferred Job Characteristic: Security vs Salary (Second-generation analysis: ESS): Based on the answers to the question "For you personally, how important do you think each of the following would be if you were choosing a job? A secure job?/ A high income?" taken from the "Family work and well-being" module in the second and fifth rounds of the European Social Survey. Computed as the difference between the importance of characteristics "Secure job" and "High Income", normalizing the lowest value to 1 (i.e., ipjbscr - ipjbhin + 5).

- Preferred Job Characteristic: Security vs Other (Individual-level analysis: WVS): Based on the answers to the question "Now I would like to ask you something about the things which would seem to you, personally, most important if you were looking for a job. Here are some of the things many people take into account in relation to their work. Regardless of whether you're actually looking for a job, which one would you, personally, place first if you were looking for a job?" taken from the core module of the World Values Survey. Coded as 1 if "A safe job with no risk of closing down or unemployment" was an answer and coded 0 otherwise. 
- Preferences for Cautiousness (Ethnic group-level: Ethnographic Atlas): Based on "Games" from Ethnographic Atlas (i.e., v35_1, v35_2, v35_3). Coded 2 if strategy element is present in the games, while the chance element is not (i.e., v35_3=2 and v35_2=1), coded 1 if both the strategy and chance elements are present or absent (i.e., v35_3=v35_2) and coded 0.5 if only chance component is present (i.e., v35_3=1 and v35_2=2).

- Preferences for Cautiousness (Ethnic group-level: SCCS): Based on "Sleeping proximity of parents to infant" from SCCS (v23).

\section{C.1.2 Placebo Measures}

- Preferred Job Characteristic: Satisfaction vs Others (Second-generation analysis: GSS): Based on the answer to the question "Would you please look at this card and tell me which one thing on this list you would most prefer in a job?" taken from the core module of the General Social Survey. Coded 5 if "Work important and gives a feeling of accomplishment" is the most preferred characteristic, 4 if it is the second most preferred, 3 - third most important, 2 - fourth most important, 1 - least important.

- Preferred Job Characteristic: Hours vs Others (Second-generation analysis: GSS): Based on the answer to the question "Would you please look at this card and tell me which one thing on this list you would most prefer in a job?" taken from the core module of the General Social Survey. Coded 5 if "Workings hours are short, lots of free time" is the most preferred characteristic, 4 if it is the second most preferred, 3 - third most important, 2 - fourth most important, 1 - least important.

- Preferred Job Characteristic: Promotion opportunities vs Others (Second-generation analysis: GSS): Based on the answer to the question "Would you please look at this card and tell me which one thing on this list you would most prefer in a job?" taken from the core module of the General Social Survey. Coded 5 if "Chances for advancement" is the most preferred characteristic, 4 if it is the second most preferred, 3 - third most important, 2 - fourth most important, 1 - least important.

- Preferred Job Characteristic: Training opportunities vs Ability to use own initiative (Second-generation analysis: ESS): Based on the answers to the question "For you person- 
ally, how important do you think each of the following would be if you were choosing a job? Job offered good training opportunities?/ Job enabled you to use own initiative?" taken from the "Family work and well-being" module in the second and fifth rounds of the European Social Survey. Computed as the difference between the importance of characteristics "Job offered good training opportunities" and "Job enabled you to use own initiative" (i.e., ipjbtro - ipjbini).

- Preferred Job Characteristic: Salary vs Training opportunities (Second-generation analysis: ESS): Based on the answers to the question "For you personally, how important do you think each of the following would be if you were choosing a job? A high income?/ Job offered good training opportunities?" taken from the "Family work and well-being" module in the second and fifth rounds of the European Social Survey. Computed as the difference between the importance of characteristics "A high income?" and "Job offered good training opportunities" (i.e., ipjbhin - ipjbtro).

- Preferred Job Characteristic: Salary vs Ability to use own initiative (Secondgeneration analysis: ESS): Based on the answers to the question "For you personally, how important do you think each of the following would be if you were choosing a job? A high income?/ Job enabled you to use own initiative?" taken from the "Family work and well-being" module in the second and fifth rounds of the European Social Survey. Computed as the difference between the importance of characteristics "A high income?" and "Job enabled you to use own initiative" (i.e., ipjbhin - ipjbini).

- Sex Taboos (Ethnic group-level: Ethnographic Atlas): Taken from Ethnographic Atlas "Post-partum Sex Taboos" (v36)

- Political Integration (Ethnic group-level: Ethnographic Atlas): Taken from Ethnographic Atlas "Political Integration" (v90)

- Property Rights (Ethnic group-level: Ethnographic Atlas): Based on the "Inheritance Rule for Real Property (Land)" from Ethnographic Atlas (v74). Coded 0 if land property rights do not exist (i.e., v74=1), coded 1 otherwise.

- Gender Roles (Ethnic group-level: Ethnographic Atlas): Based on the "Sex Differences: Agriculture " from Ethnographic Atlas (v54). Coded 1 if gender roles in agriculture exist (i.e., 
$\mathrm{v} 54=5$ or 6 or 7 or 8 ), coded 0 if gender roles do not exists (i.e., v54=1 or 2 or 3 or 4 ).

- Political Integration (Ethnic group-level: Ethnographic Atlas): Taken from Ethnographic Atlas "Norms of Premarital Sexual Behavior of Girls" (v78)

- Evil Eye Belief (Ethnic group-level: SCCS): Taken from SCCS "Evil Eye Belief" (v1189)

\section{C.1.3 Measures of Cultural Values}

- LTO (Second-generation analysis: GSS): Based on the answer to the question "Do you smoke?" taken from the core module of the General Social Survey.

- Obedience (Second-generation analysis: GSS): Based on the answer to the question "If you had to choose, which thing on this list would you pick as the most important for a child to learn to prepare him or her for life?" taken from the core module of the General Social Survey. Coded 5 if "To Obey" is the most preferred characteristic, 4 if it is the second most preferred, 3 - third most important, 2 - fourth most important, 1 - least important.

- Altruism (Second-generation analysis: GSS): Based on the answer to the question "If you had to choose, which thing on this list would you pick as the most important for a child to learn to prepare him or her for life?" taken from the core module of the General Social Survey. Coded 5 if "To help others when they need help" is the most preferred characteristic, 4 if it is the second most preferred, 3 - third most important, 2 - fourth most important, 1 - least important.

- Equality (Second-generation analysis: GSS): Based on the answer to the question "It is the responsibility of the government to reduce the differences in income between people with high incomes and those with low incomes. Do you agree or disagree?" taken from the "ISSP Social Inequality" module of the General Social Survey.

- Gender (Second-generation analysis: GSS): Based on the answer to the question "Do you approve or disapprove of a married woman earning money in business or industry if she has a husband capable of supporting her?" taken from the core module of the General Social Survey.

- Government (Second-generation analysis: GSS): Based on the answer to the question "As far as the people running these institutions are concerned, would you say you have a great 
deal of confidence, only some confidence, or hardly any confidence at all in them? Executive branch of the federal government" taken from the core module of the General Social Survey.

- LTO (Second-generation analysis: ESS): Based on the answers to the question "Do you generally plan for your future or do you just take each day as it comes? Please express your opinion on a scale of 0 to 10 , where 0 means 'I plan for my future as much as possible' and 10 means 'I just take each day as it comes' " taken from the "Timing of life" module in the third round of the European Social Survey.

- Obedience (Second-generation analysis: ESS): Based on the answers to the question "Now I will briefly describe some people. Please listen to each description and tell me how much each person is or is not like you. Use this card for your answer. She/he believes that people should do what they're told. She/he thinks people should follow rules at all times, even when no-one is watching" taken from the "Human Values" module of the European Social Survey.

- Altruism (Second-generation analysis: ESS): Based on the answers to the question "Now I will briefly describe some people. Please listen to each description and tell me how much each person is or is not like you. Use this card for your answer. It's very important to her/him to help the people around her/him. She/he wants to care for their well-being" taken from the "Human Values" module of the European Social Survey.

- Equality (Second-generation analysis: ESS): Based on the answers to the question "Now I will briefly describe some people. Please listen to each description and tell me how much each person is or is not like you. Use this card for your answer. She/he thinks it is important that every person in the world should be treated equally. She/he believes everyone should have equal opportunities in life" taken from the "Human Values" module of the European Social Survey.

- Gender (Second-generation analysis: ESS): Based on the answers to the question "Using this card, please say how much you agree or disagree with each of the following statements. A woman should be prepared to cut down on her paid work for the sake of her family" taken from the "Welfare Attitudes" module in the fourth round of the European Social Survey.

- Strong Government (Second-generation analysis: ESS): Based on the answers to the question "Now I will briefly describe some people. Please listen to each description and tell me 
how much each person is or is not like you. Use this card for your answer. It is important to her/him that the government ensures her/his safety against all threats. She/he wants the state to be strong so it can defend its citizens" taken from the "Human Values" module of the European Social Survey.

- Tradition (Second-generation analysis: ESS): Based on the answers to the question "Now I will briefly describe some people. Please listen to each description and tell me how much each person is or is not like you. Use this card for your answer. Tradition is important to her/him. She/he tries to follow the customs handed down by her/his religion or her/his family" taken from the "Human Values" module of the European Social Survey.

\section{C.2 Main Independent Variables: Temperature Temporal Volatility and Spatial Correlation}

- Temperature Volatility: Volatility of temperature constructed using v3.2 of the Climatic Research Unit (CRU) database following the method of Durante (2009). Computed for each month as the temperature volatility over all years, and averaged across months. Measure is calculated at the grid cell level and then aggregated at the regional level.

- Temperature Spatial Correlation: Spatial Correlation of temperature shocks constructed using v3.2 of the Climatic Research Unit (CRU) database following the method of Durante (2009). Computed as the correlation between monthly deviations of temperature in a given cell and its neighbors over all months and years, averaged over the neighbors. Measure is calculated at the grid cell level and then aggregated at the regional level.

\section{C.3 Controls}

\section{C.3.1 Geographical Controls}

- Absolute latitude: The absolute value of the latitude of a country's approximate geodesic centroid, as reported by the CIA's World Factbook.

- Mean Elevation: The mean elevation of a country in $\mathrm{km}$ above sea level, calculated using geospatial elevation data reported by the G-ECON project (Nordhaus, 2006) at a 1-degree resolution. The interested reader is referred to the G-ECON project web site for additional details. 
- Mean distance to nearest waterway: The distance, in thousands of $\mathrm{km}$, from a GIS grid cell to the nearest ice-free coastline or sea-navigable river, averaged across the grid cells of a country. This variable was originally constructed by Gallup et al. (1999) and is part of Harvard University's CID Research Datasets on General Measures of Geography.

- Percentage of population living in tropical, subtropical and temperate zones: The percentage of a country's population in 1995 that resided in areas classified as tropical by the Köppen-Geiger climate classification system. This variable was originally constructed by Gallup et al. (1999) and is part of Harvard University's CID Research Datasets on General Measures of Geography.

- Land Suitability: Average probability within a region that a particular grid cell will be cultivated as computed by Ramankutty et al. (2002).

- Land Suitability (Range): Range of probabilities within a region that a particular grid cell will be cultivated as computed by Ramankutty et al. (2002).

- Land Suitability (Gini): Gini of probabilities within a region that a particular grid cell will be cultivated as computed by Ramankutty et al. (2002).

- Land Suitability (Std.): Standard deviation of probabilities within a region that a particular grid cell will be cultivated as computed by Ramankutty et al. (2002).

- Island nation dummy: An indicator for whether or not a country shares a land border with any other country, as reported by the CIA's World Factbook online.

- Landlocked dummy: An indicator for whether or not a country is landlocked, as reported by the CIA's World Factbook online.

- Neolithic Transition Timing: The number of thousand years elapsed (as of the year 2000) since the majority of the population residing within a country's modern national borders began practicing sedentary agriculture as the primary mode of subsistence (Putterman, 2008). See the Agricultural Transition Data Set website http://www.econ.brown.edu/fac/louis_putterman/agricultural $\% 20$ data $\% 20$ page.htm for additional details on primary data sources and methodological assumptions. 
- Total land area: The total land area of a country, in millions of square kilometers, as reported for the year 2000 by the World Bank's World Development Indicators online.

\section{C.3.2 Ethnographic Controls}

- Intensity of Agriculture: Taken from Ethnographic Atlas "Intensity of Agriculture" (v28)

- Intensity of Animal Husbandry: Taken from Ethnographic Atlas "Animal Husbandry" (v4)

- Settlement Patterns: Taken from Ethnographic Atlas "Settlement Patterns" (v30)

- Plow Use: Taken from Ethnographic Atlas "Animals and Plow Cultivation" (v39). Coded as a separate dummy variable for each category.

\section{C.3.3 Individual Controls}

- Individual level controls (Second-generation analysis: GSS): Age, Gender, Education level (highest year of school completed), Religion in which raised (coded as a separate dummy variable for each denomination), Income (coded as a separate dummy variable for each income bracket) for each individual in the GSS data sets.

- Individual level controls (Second-generation analysis: ESS): Age, Gender, Education level (classified according to ICSDE, coded as a separate dummy variable for each category), Religiosity (based on the question "How often pray apart from at religious services"), Income (coded as a separate dummy variable for each income bracket) for each individual in the ESS data sets.

- Individual level controls (Individual-level analysis: WVS): Age, Gender, Education level (Highest educational level attained, coded as a separate dummy variable for each category), Religiosity (based on the question "How often do you attend religious services"), Income (coded as a separate dummy variable for each income bracket) for each individual in the WVS data sets.

\section{C.3.4 Other Controls}

- Terrain roughness: The degree of terrain roughness of a country, calculated using geospatial surface undulation data reported by the G-ECON project (Nordhaus, 2006) at a 1-degree 
resolution. The interested reader is referred to the G-ECON project web site for additional details.

- Population Density in 1500CE: Population density (in persons per square $\mathrm{km}$ ) in 1500C E as reported by McEvedy et al. (1978), divided by total land area, as reported by the World Bank's World Development Indicators.

- Urbanization Rate in 1500CE and 1800CE: Share of population living in cities as reported in Acemoglu et al. (2005).

- GDP per capita in 1870CE, 1913CE: Income per capita as reported by Maddison (2003) . The data is available at http://www.ggdc.net/maddison/Historical_Statistics/horizontal-file_02-2010.xls.

- Major religion shares: Share of major religion in each country as reported in La Porta et al. (1999).

- Legal Origins: Dummy variables for origin of legal system as identified in La Porta et al. (1999).

- GDP per capita: GDP per capita is gross domestic product divided by midyear population. GDP is the sum of gross value added by all resident producers in the economy plus any product taxes and minus any subsidies not included in the value of the products. It is calculated without making deductions for depreciation of fabricated assets or for depletion and degradation of natural resources. Data are in constant 2005 U.S. dollars for the year 2005 from the World Bank's World Development Indicators and for 2005 from Penn World Table v8 Feenstra et al. (2015).

- Institutions: Democracy index from Polity IV project.

- Trust: Share of population that have generalized trust. Based on the following question taken from the integrated file for waves 1-5 of the WVS: "Generally speaking, would you say that most people can be trusted or that you need to be very careful in dealing with people?". An individual has trust if she answered "Most people can be trusted". 
- Power Distance: Dimension of national culture identified by Hofstede (2001), which measures the degree to which there exists a preference for hierarchical power structures or inequality in economic, political or other societal dimensions. Scale between 0 (Horizontal) to 100 (Vertical). ${ }^{19}$

- Individualism: Dimension of national culture identified by Hofstede (2001), which measures the degree to which a society is individualistic as opposed to collectivistic. Scale between 0 (Collectivistic) to 100 (Individualistic). ${ }^{20}$

- Cooperation: Dimension of national culture identified by Hofstede (2001), which measures the degree to which a society is cooperative. Scale between 0 (Non-cooperative) to 100 (Cooperative). ${ }^{21}$

- Uncertainty Avoidance: Dimension of national culture identified by Hofstede (2001), which measures the degree to which a society is tolerant of the ambiguous and the unpredictable. Scale between 0 (Intolerant) to 100 (Tolerant). ${ }^{22}$

- Ancestry Adjustment: Original data is adjusted by ancestry using the method and data from Putterman and Weil (2010).

- Regional Data: For regions within a country, data is computed using GIS software to compute the area of each region's polygon in the corresponding shape file of the Seamless Digital Chart of the World. Whenever possible, the same primary data sources as the ones used in the sources for the country level data is used. E.g. regional agricultural suitability is constructed using the data from Ramankutty et al. (2002).

\footnotetext{
${ }^{19}$ Hofstede and Hofstede (n.d., p.61) defines it as "Power distance can therefore be defined as the extent to which the less powerful members of institutions and organizations within a country expect and accept that power is distributed unequally. Institutions are the basic elements of society, such as the family, the school, and the community; organizations are the places where people work."

${ }^{20}$ Hofstede and Hofstede (n.d., p.92) defines it as follows: "Individualism pertains to societies in which the ties between individuals are loose: everyone is expected to look after him- or herself and his or her immediate family. Collectivism as its opposite pertains to societies in which people from birth onward are integrated into strong, cohesive in-groups, which throughout people's lifetime continue to protect them in exchange for unquestioning loyalty."

${ }^{21}$ Hofstede and Hofstede (n.d., p.140) defines this dimension as Masculinity vs Femininity, since he found gender based differences in the answers to the questions that defined this value.

${ }^{22}$ According to Hofstede and Hofstede (n.d., p.191) "Uncertainty avoidance can therefore be defined as the extent to which the members of a culture feel threatened by ambiguous or unknown situations."
} 


\section{References}

Acemoglu, D., Johnson, S. and Robinson, J. A. (2005). Institutions as a fundamental cause of long-run growth, Handbook of economic growth 1: 385-472.

Alesina, A., Giuliano, P. and Nunn, N. (2013). On the origins of gender roles: Women and the plough, The Quarterly Journal of Economics 128(2): 469-530.

Altonji, J. G., Elder, T. E. and Taber, C. R. (2005). Selection on observed and unobserved variables: Assessing the effectiveness of catholic schools, Journal of political economy 113(1): 151-184.

Ashraf, Q. and Galor, O. (2011). Dynamics and stagnation in the malthusian epoch, The American Economic Review 101(5): 2003-2041.

Ashraf, Q. and Galor, O. (2013). The "out of africa" hypothesis, human genetic diversity, and comparative economic development, The American Economic Review 103(1): 1-46.

Barberis, N. and Huang, M. (2001). Mental accounting, loss aversion, and individual stock returns, The Journal of Finance 56(4): 1247-1292.

Bellows, J. and Miguel, E. (2009). War and local collective action in sierra leone, Journal of Public Economics 93(11): 1144-1157.

Benartzi, S. and Thaler, R. H. (1995). Myopic loss aversion and the equity premium puzzle, The quarterly journal of Economics 110(1): 73-92.

Bisin, A. and Verdier, T. (2001). The economics of cultural transmission and the dynamics of preferences, Journal of Economic theory 97(2): 298-319.

Dalgaard, C.-J. and Strulik, H. (2015). The physiological foundations of the wealth of nations, Journal of Economic Growth 20(1): 37-73.

Diamond, J. (1997). Guns, Germs and Steel: The Fates of Human Societies, Vintage.

Durante, R. (2009). Risk, cooperation and the economic origins of social trust: an empirical investigation.

Feenstra, R. C., Inklaar, R. and Timmer, M. P. (2015). The next generation of the penn world table, The American Economic Review 105(10): 3150-3182. 
Fisher, P. J. and Montalto, C. P. (2011). Loss aversion and saving behavior: Evidence from the 2007 us survey of consumer finances, Journal of Family and Economic Issues 32(1): 4-14.

Gallup, J. L., Sachs, J. D. and Mellinger, A. D. (1999). Geography and economic development, International regional science review 22(2): 179-232.

Galor, O. and Moav, O. (2002). Natural selection and the origin of economic growth, The Quarterly Journal of Economics 117(4): 1133-1191.

Galor, O. and Özak, Ö. (2016). The agricultural origins of time preference, The American Economic Review 106(10): 3064-3103.

Genesove, D. and Mayer, C. (2001). Loss aversion and seller behavior: Evidence from the housing market, The Quarterly Journal of Economics 116(4): 1233-1260.

Giuliano, P. and Nunn, N. (2017). Understanding cultural persistence and change, Technical report, National Bureau of Economic Research.

Hofstede, G. (2001). Culture's consequences: Comparing values, behaviors, institutions, and organizations across cultures.

Hofstede, G. H. and Hofstede, G. (n.d.). Gj and minkov, m.(2010) cultures and organisations: software of the mind.

Jervis, R. (1992). Political implications of loss aversion, Political psychology pp. 187-204.

Kahneman, D., Knetsch, J. L. and Thaler, R. H. (1991). Anomalies: The endowment effect, loss aversion, and status quo bias, The journal of economic perspectives 5(1): 193-206.

La Porta, R., Lopez-de Silanes, F., Shleifer, A. and Vishny, R. (1999). The quality of government, The Journal of Law, Economics, and Organization 15(1): 222-279.

Levy, J. S. (1996). Loss aversion, framing, and bargaining: The implications of prospect theory for international conflict, International Political Science Review 17(2): 179-195.

Maddison, A. (2003). Historical statistics, OECD.

Mayshar, J., Moav, O., Neeman, Z. and Pascali, L. (2016). Cereals, appropriability and hierarchy. 
McEvedy, C., Jones, R. et al. (1978). Atlas of world population history., Penguin Books Ltd, Harmondsworth, Middlesex, England.

Nordhaus, W. D. (2006). Geography and macroeconomics: New data and new findings, Proceedings of the National Academy of Sciences of the United States of America 103(10): 3510-3517.

Oster, E. (2014). Unobservable selection and coefficient stability: Theory and evidence, Journal of Business $8 \mathcal{G}$ Economic Statistics .

Putterman, L. (2008). Agriculture, diffusion and development: Ripple effects of the neolithic revolution, Economica 75(300): 729-748.

Putterman, L. and Weil, D. N. (2010). Post-1500 population flows and the long-run determinants of economic growth and inequality, The Quarterly journal of economics 125(4): 1627-1682.

Ramankutty, N., Foley, J. A., Norman, J. and McSweeney, K. (2002). The global distribution of cultivable lands: current patterns and sensitivity to possible climate change, Global Ecology and biogeography 11(5): 377-392.

Shalev, J. (2002). Loss aversion and bargaining, Theory and decision 52(3): 201-232.

Spolaore, E. and Wacziarg, R. (2013). How deep are the roots of economic development?, Journal of Economic Literature 51(2): 325-369.

Tversky, A. and Kahneman, D. (1991). Loss aversion in riskless choice: A reference-dependent model, The quarterly journal of economics 106(4): 1039-1061.

Vollrath, D. (2011). The agricultural basis of comparative development, Journal of Economic Growth 16(4): $343-370$. 